\title{
EVALUATION OF HIGH PERFORMANCE FIBER-REINFORCED CONCRETE FOR BRIDGE DECK CLOSURE POURS
}

\author{
A Thesis \\ Presented to \\ The faculty of the School of Engineering and Applied Science \\ University of Virginia \\ in partial fulfillment \\ of the requirements for the degree \\ Master of Science \\ by \\ Levon Carey Hoomes
}

August

2013 


\section{APPROVAL SHEET}

\section{The thesis}

is submitted in partial fulfillment of the requirements

for the degree of

Master of Science

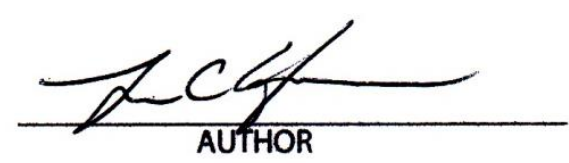

The thesis has been read and approved by the examining committee:

\begin{tabular}{c} 
Dr. Michael C. Brown \\
\hline Advisor \\
\hline Dr. Steven B. Chase \\
\hline
\end{tabular}

Accepted for the School of Engineering and Applied Science:

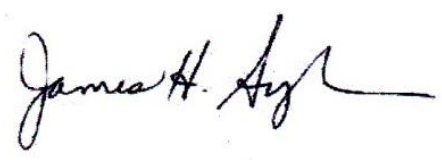

Dean, School of Engineering and Applied Science

August

2013 


\begin{abstract}
Connections and closure pours in bridges are often a source of irreversible damage to bridges due to the penetration of harmful agents into cracks that can lead to costly repairs. These cracks are caused by shrinkage, the application of service loads after the concrete has hardened, and poor bonding of these poured sections to bridge deck sections at the bond interface, where wide cracks allow the ingress of water and other compounds. This causes damage to the bridge deck sections as well as the bridge substructure, where the penetration of harmful solutions causes the corrosion of reinforcing steel, as well as alkali-silica reactions, sulfate attack, and freeze-thaw damage in concrete. Problems such as these can also occur in situations where joints are to be eliminated to create joint-less bridge structures, and subsequent shrinkage and flexure of these connections can cause wide cracks in the concrete. In these situations, bridge joints are removed and sections of the deck are cut away. The moving joint systems are then replaced with a link slab that rigidly connects adjacent deck sections. When normal concrete is used, cracks that allow corrosive compounds to damage the underlying beams and piers may occur in the link slab. Two major issues with closure pours and connections are cracking in the sections and separation at the bond surfaces. When fibers are added to a conventional concrete matrix, cracking may be minimized, but the sizes of these cracks still permit the intrusion of harmful solutions. When using high performance fiber-reinforced concrete (HPFRC), multiple very tight cracks ( $<0.1 \mathrm{~mm}$ wide) may occur when the material is placed in flexure instead of one larger localized crack. Tight cracks do not allow ingress of water and other harmful solutions as larger cracks do. Thus HPFRC offers a potential solution to damage of bridge connections.

In this project, four different high-performance fiber-reinforced systems were tested for properties that relate to their ability to produce tight cracks in flexure and bond to typical bridge deck concrete. These systems include of High-Performance Fiber-Reinforced Concrete (HPFRC), which encompasses Hybrid Fiber-Reinforced Concrete (HyFRC), and HighPerformance Fiber-Reinforced Cementitious Composite (HPFRCC) mixtures, which include Engineered Cementitious Composites (ECC). Of these systems, ECC displayed the highest deflection hardening capacity, while UHPC exhibited the most desirable results in flexural toughness and bond strength tests. The overall material properties of ECC and UHPC were the most desirable, but a cost benefit analysis was completed to determine which mix is the most cost-effective option for closure pours and joints. It was concluded from this study that HyFRC
\end{abstract}


using only synthetic discontinuous fibers provides the most cost efficient option for a material that will not only deflection harden, but will also provide adequate bond strength to typical A4 bridge deck concrete. 


\section{ACKNOWLEDGEMENTS}

I would like to thank everyone who supported me throughout my research, specifically Dr. Celik Ozyildirim of the Virginia Center for Transportation Innovation and Research for sharing his enthusiasm and love for research and for providing me with sound advice and guidance along the way. I would also like to thank my advisor, Dr. Michael Brown for always keeping my academic goals in mind and for his guidance with academic course decisions and the completion of my thesis paper. Last but not least, I would like to thank Michael Burton, Lewis Lloyd, and Bill Ordel of the Virginia Center for Transportation Innovation and Research for preparation and testing of specimens for my research. 


\section{TABLE OF CONTENTS}

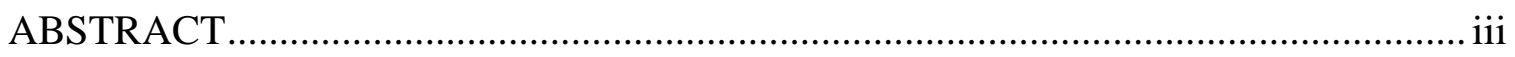

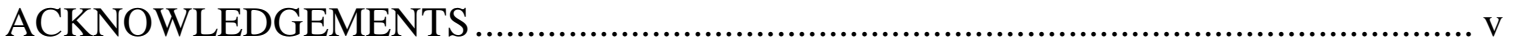

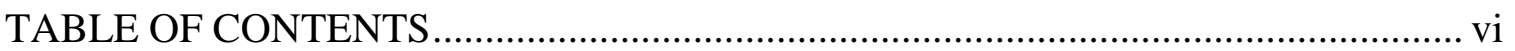

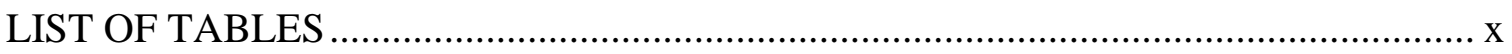

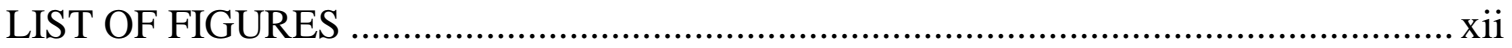

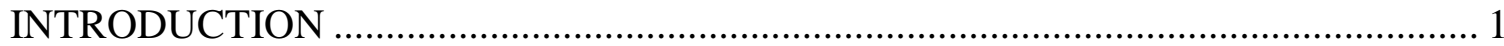

REVIEW OF THE LITERATURE ....................................................................... 2

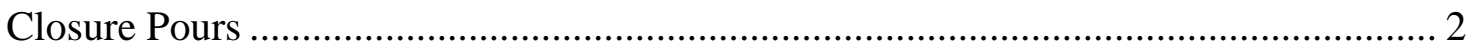

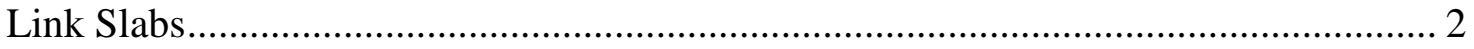

Loads on Closure Pour Sections...................................................................... 3

Required Material Properties for Closure Pours and Link Slabs ................................ 4

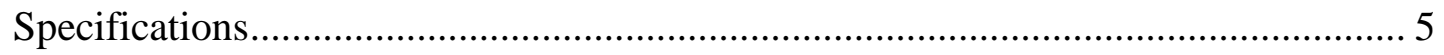

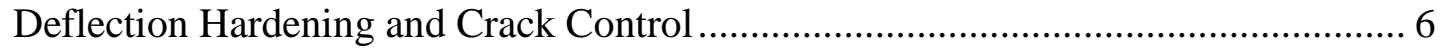

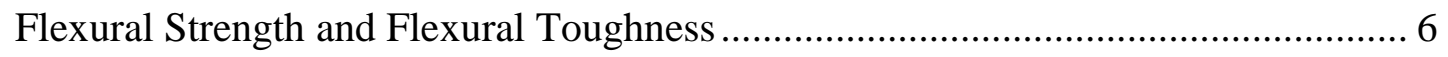

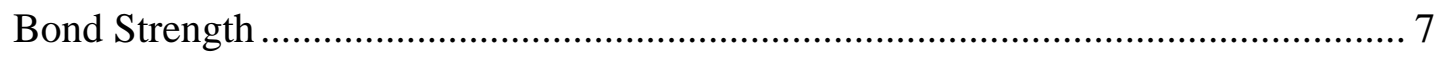

Problems with Conventional Concrete ......................................................... 9

Benefits and Drawbacks of Fibers in Conventional Concrete ................................... 9

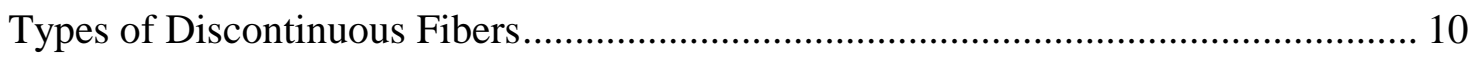

High Performance Fiber-Reinforced Concrete .................................................... 13

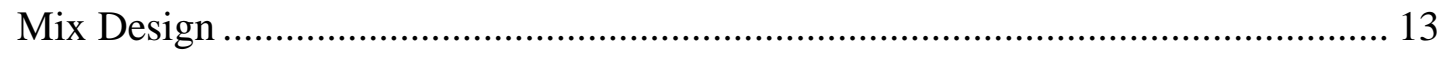

Types of High-Performance Fiber-Reinforced Concrete .................................... 13

Synthetic and Steel Fiber Combinations .................................................... 13

Synthetic Fiber Combinations.................................................................... 14

High-Performance Fiber-Reinforced Cementitious Composite .................................. 14

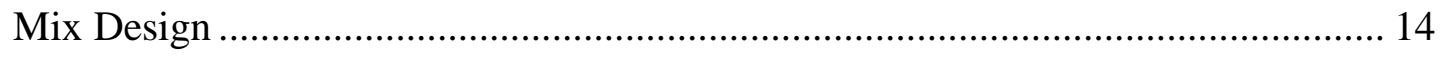

Engineered Cementitious Composite …........................................................... 15

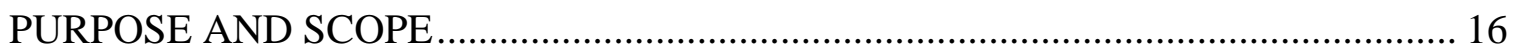

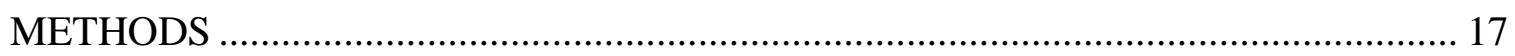




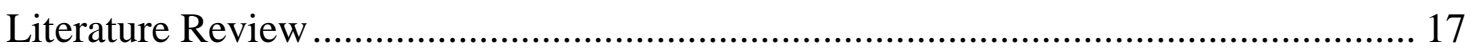

Determining Potential Mixes ............................................................................. 17

Engineered Cementitious Composite ………………………………………….... 17

Hybrid Fiber-Reinforced Concrete (Steel and Synthetic Fibers) .............................. 18

Hybrid Fiber-Reinforced Concrete (Synthetic Fibers) .............................................. 18

Ductal JS1000 ${ }^{\mathrm{TM}}$ Joint Fill .................................................................................. 18

Evaluating Preliminary Laboratory Batches …………............................................ 19

Engineered Cementitious Composite ………………………………………….... 19

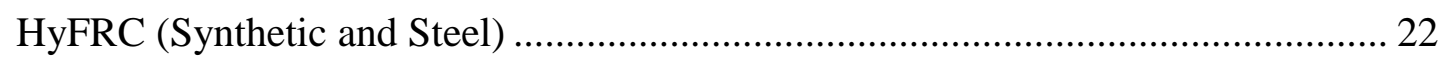

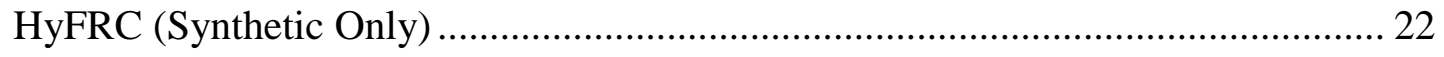

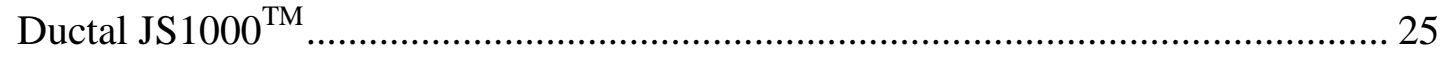

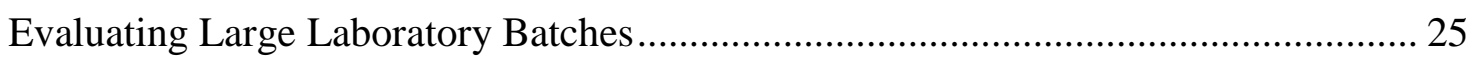

Fresh and Hardened Concrete Tests ........................................................................ 26

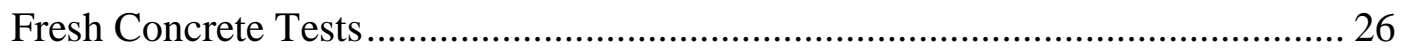

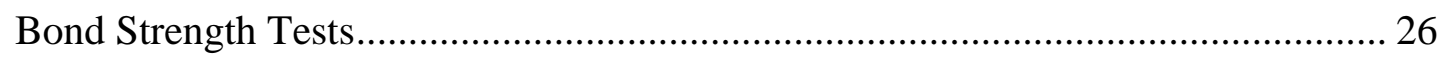

ASTM C1404: Direct-Tension Bond Test............................................................ 27

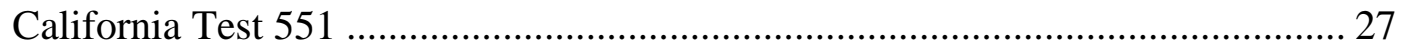

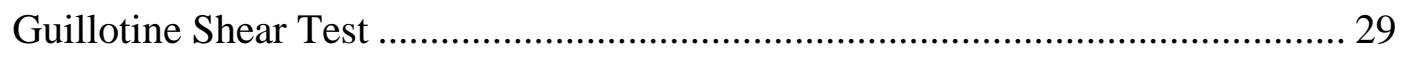

Splitting Prism Test.......................................................................................... 31

Base Concrete Preparation for Bond Strength Specimens .......................................... 33

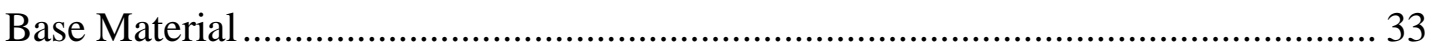

Engineered Cementitious Composite ………………………………………….... 34

HyFRC (Synthetic and Steel): HyFRC-A ……………….................................... 35

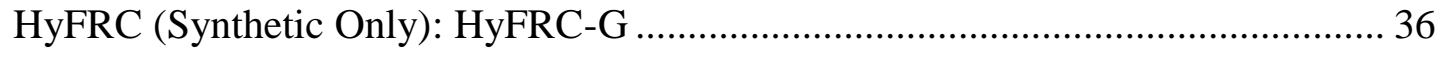

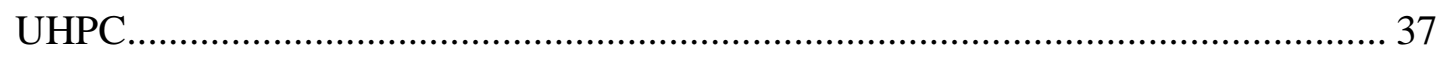

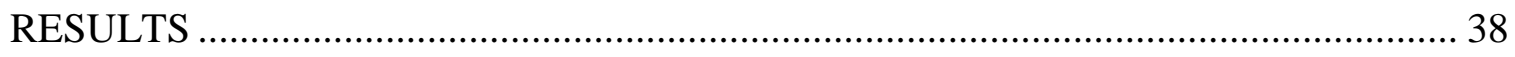

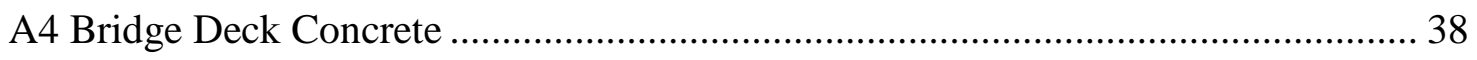

Preliminary Laboratory Batches............................................................................... 38 
Strength and Strain Hardening ......................................................................... 38

Engineered Cementitious Composite ……………………………………………..... 39

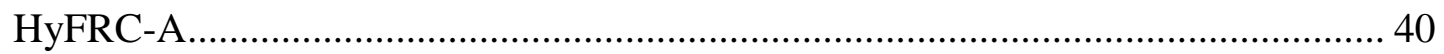

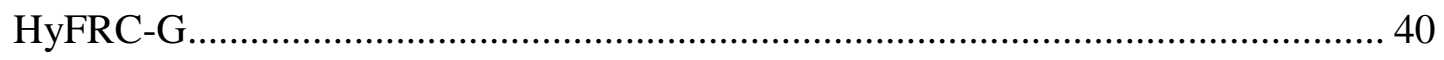

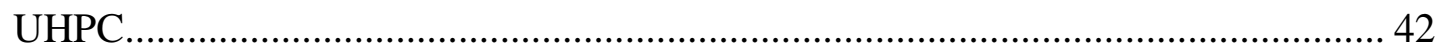

Large Laboratory Batches ……………………….............................................. 42

Engineered Cementitious Composite ……………………….................................. 42

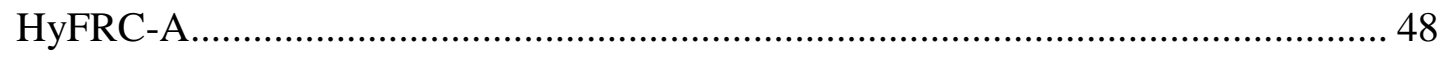

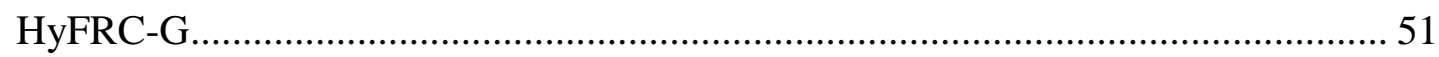

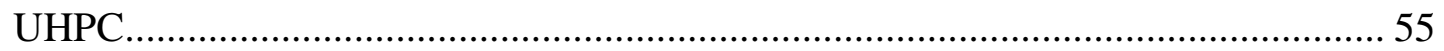

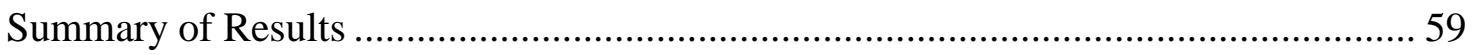

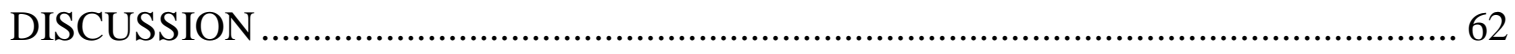

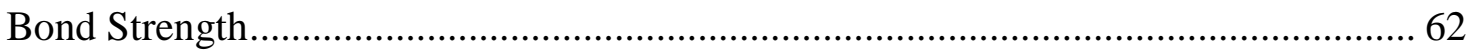

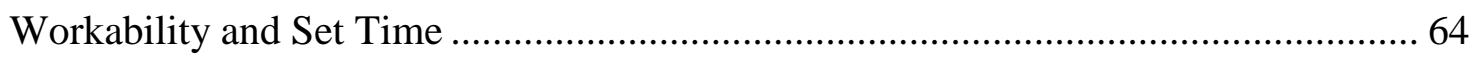

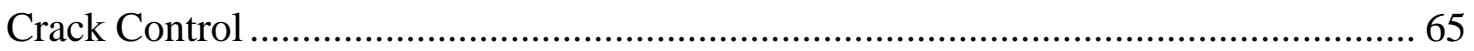

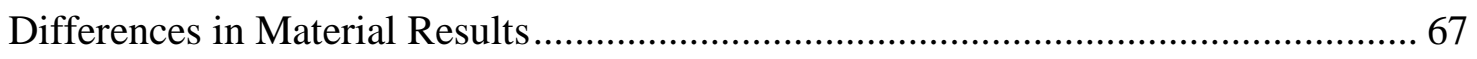

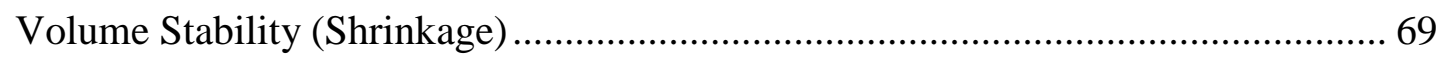

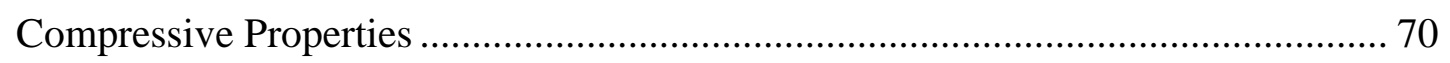

COSTS AND BENEFITS ASSESSMENT …………………………................... 71

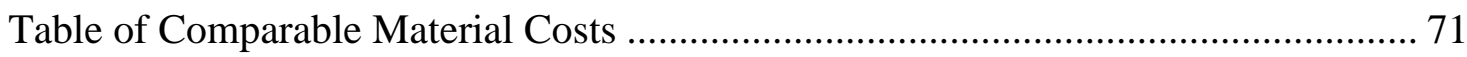

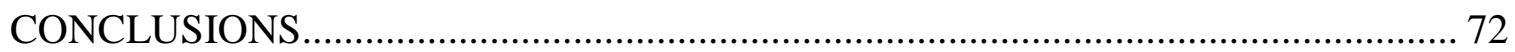

Evaluation of Materials for Use in Closure Pours ……………………………........ 72

Evaluation of Reliability of Bond Strength Tests ........................................................ 72

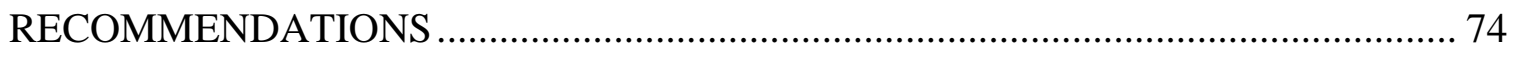

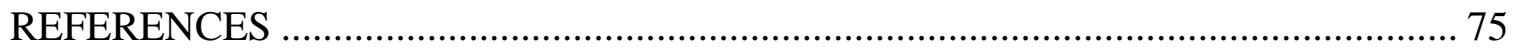

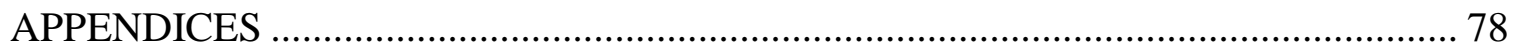

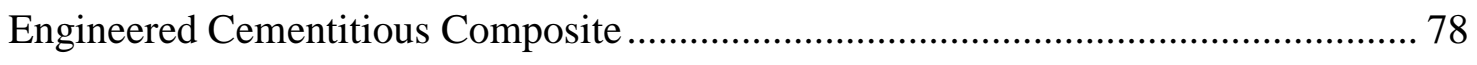

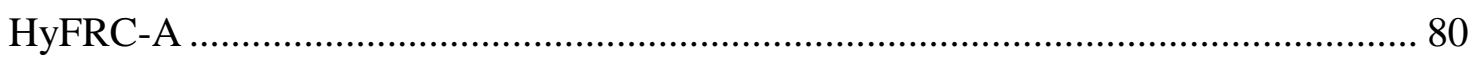




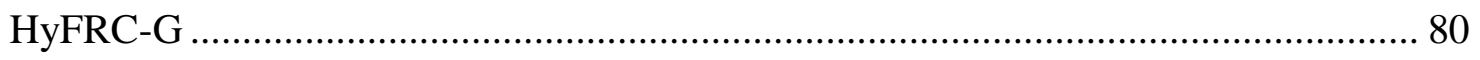

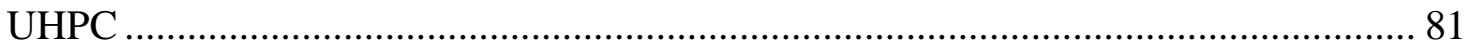

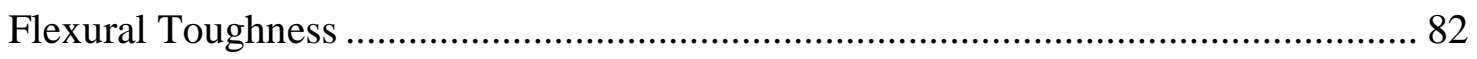

Elastic Modulus Test Results ........................................................................... 83 


\section{LIST OF TABLES}

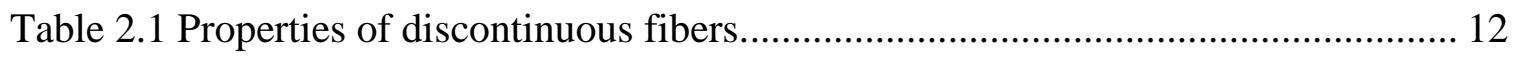

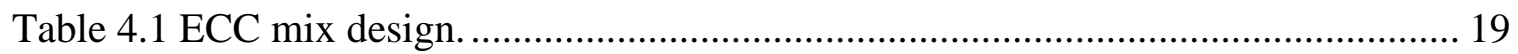

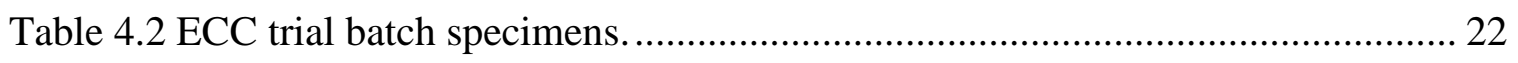

Table 4.3 Mix designs for HyFRC containing only synthetic fibers. .............................. 24

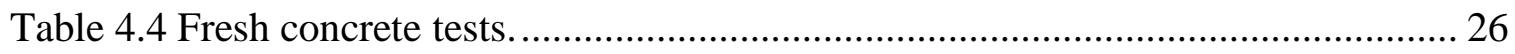

Table 4.5 Hardened concrete tests. .......................................................................... 26

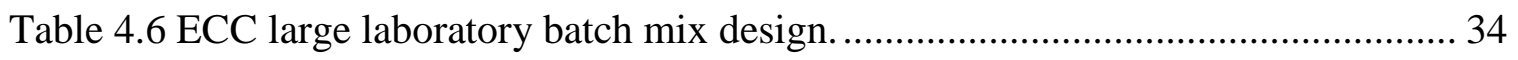

Table 4.7 HyFRC-A large laboratory batch mix design........................................... 35

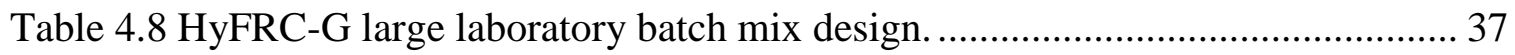

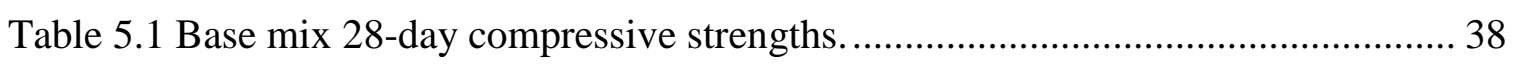

Table 5.2 Compressive and flexural strength of ECC preliminary batches..................... 40

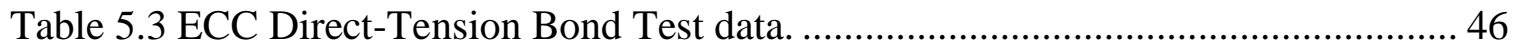

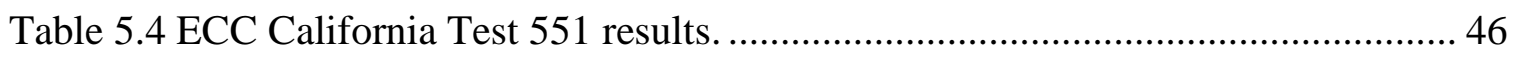

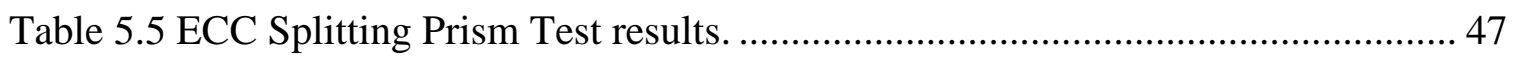

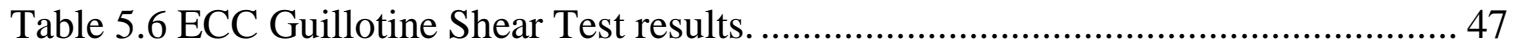

Table 5.7 HyFRC-A Direct-Tension Bond Test data. ................................................... 49

Table 5.8 HyFRC-A California Test 551 results. ......................................................... 50

Table 5.9 HyFRC-A Splitting Prism Test results. ......................................................... 50

Table 5.10 HyFRC-A Guillotine Shear Test results................................................ 51

Table 5.11 HyFRC-G Direct-Tension Bond Test data. ............................................... 53

Table 5.12 HyFRC-G California Test 551 results. ......................................................... 53

Table 5.13 HyFRC-G Splitting Prism Test results. .................................................... 54

Table 5.14 HyFRC-G Guillotine Shear Test results. .................................................. 55

Table 5.15 UHPC Direct-Tension Bond Test data. ................................................... 57

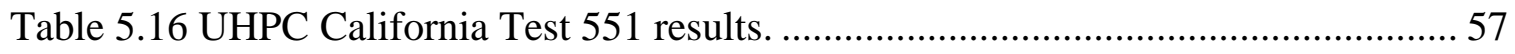

Table 5.17 UHPC Splitting Prism Test results. ......................................................... 58

Table 5.18 UHPC Guillotine Shear Test results. ................................................... 58

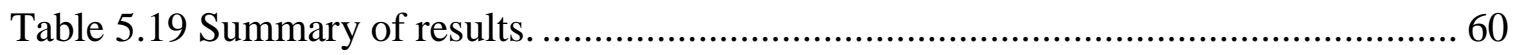

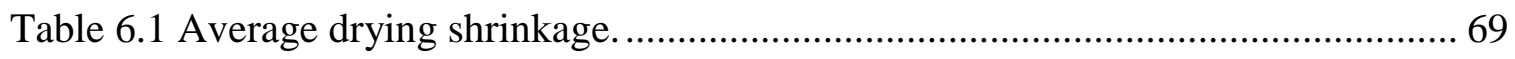

Table 6.2 Average elastic modulus and Poisson's ratio............................................. 70 


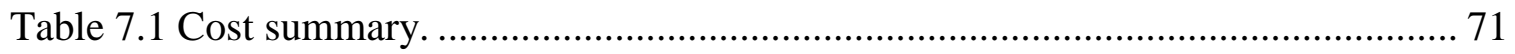

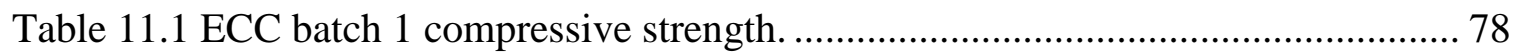

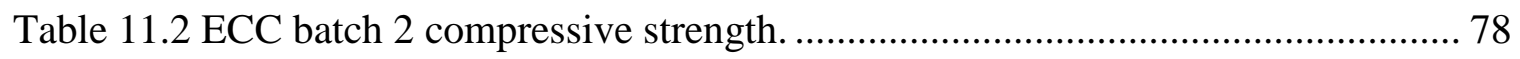

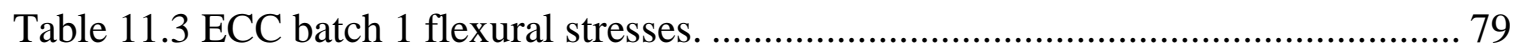

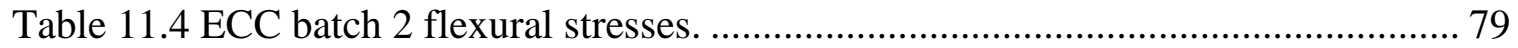

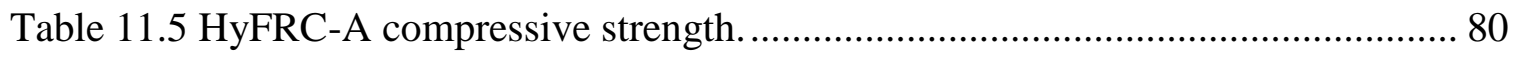

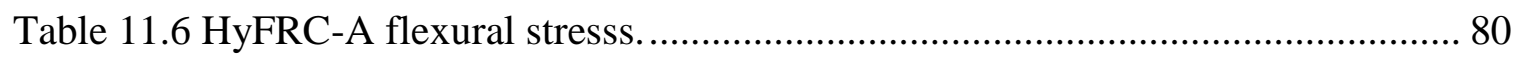

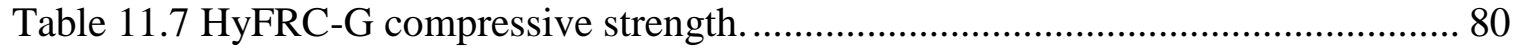

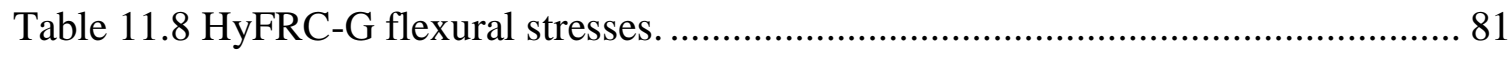

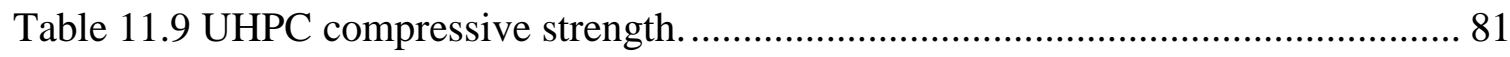

Table 11.10 UHPC flexural stresses. ................................................................ 81

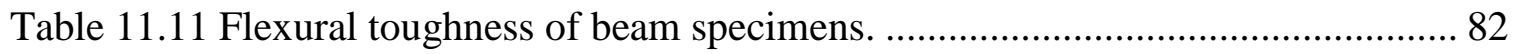

Table 11.12 Elastic modulus and Poisson's ratio..................................................... 83 


\section{LIST OF FIGURES}

Figure 2.1: Typical link slab system. (adapted from Li and Lepech, 2009.) .................... 3

Figure 2.2 Guillotine Shear Test load distribution............................................................ 9

Figure 2.3 RECS15 (left) and RSC15 (right) PVA microfibers. ................................... 11

Figure 2.4 RF4000 PVA macrofibers and BT50 polypropylene macrofibers................. 11

Figure 2.5 Hooked-end type steel macrofibers and brass-coated steel microfibers. ....... 12

Figure 4.1 Third-point loading for thin ECC beams....................................................... 20

Figure 4.2 Deflection and tight cracking during third-point loading of ECC beams. ...... 21

Figure 4.3 Tight cracking during third-point loading of ECC beam. ........................... 21

Figure 4.4 ASTM C1404: Direct-Tension Bond Test. ................................................. 27

Figure 4.5 CA 551: California Bond Test...................................................................... 28

Figure 4.6 Guillotine Shear Test specimen............................................................. 29

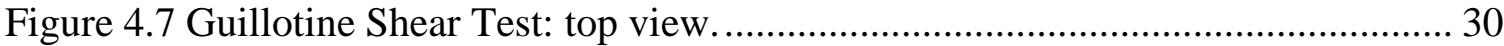

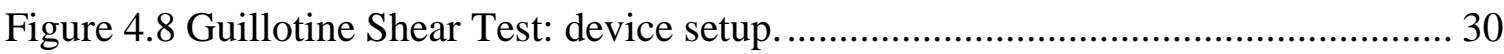

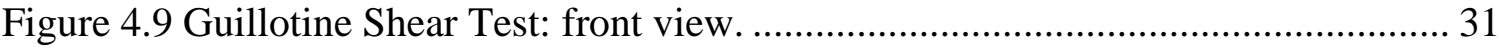

Figure 4.10 Splitting Prism Test: device setup....................................................... 31

Figure 4.11 Splitting Prism Test: front view. ............................................................ 32

Figure 4.12 Splitting Prism Test: failed specimen................................................ 33

Figure 5.1 Typical deflection hardening and softening behavior. ................................. 39

Figure 5.2 HyFRC-G preliminary batch 7-day flexure results. ................................... 41

Figure 5.3 HyFRC-G preliminary batch 28-day flexure results. ................................. 41

Figure 5.4 Dutal preliminary batch 7-day flexure results. ........................................ 42

Figure 5.5 ECC batch 1 7-day flexural performance.................................................. 43

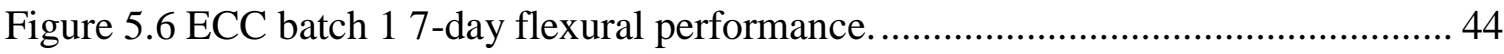

Figure 5.7 ECC batch 128 -day flexural performance................................................ 44

Figure 5.8 ECC batch 2 28-day flexural performance................................................ 45

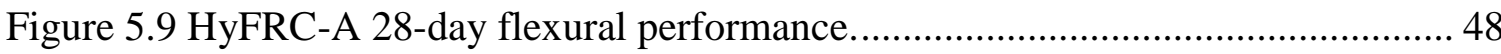

Figure 5.10 HyFRC-G 28-day flexural performance............................................... 52

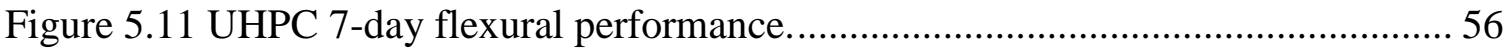

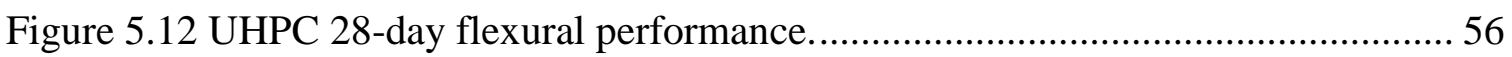

Figure 5.13 Stress vs. deflection for beam specimens at 28 days................................ 61 


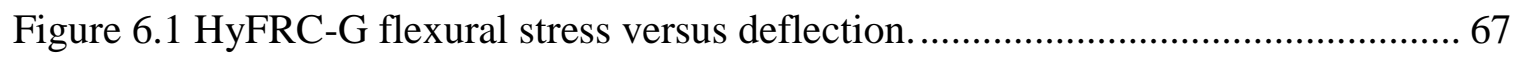

Figure 6.2 UHPC beam cross-section exhibits uneven fiber distribution........................ 69 


\section{INTRODUCTION}

Cracking of concrete in bridge closure pours and joints is often the source of permanent damage to bridges, which can lead to costly repairs. To alleviate these problems and extend the length of service of closure pours and connections, High-Performance Fiber-Reinforced Concrete (HPFRC), which includes Hybrid Fiber-Reinforced Concrete (HyFRC), and HighPerformance Fiber-Reinforced Cementitious Composite (HPFRCC) mixtures, which include Engineered Cementitious Composites (ECC), were investigated to determine which systems provide high bond strength and control cracking to produce tight cracks ( $<0.1 \mathrm{~mm}$ in width). Cracks of this size do not readily allow water and other chemical agents to penetrate the concrete surface. One way to ensure that a fiber-reinforced concrete or cementitious composite will provide tight cracks is the occurrence of strain hardening. Bond strength of the connection material to deck concrete is also critical to the prevention of the ingress of harmful solutions into the bridge connection. This project presents several potential candidates for a closure pour material that will function properly while providing tight cracks and adequate bond strength to the deck sections and seeks to determine the most cost efficient of these materials. 


\section{REVIEW OF THE LITERATURE}

\section{Closure Pours}

Cast in place concrete closure pours are used to connect bridge girders and deck sections of adjacent bridge spans where these sections meet on top of a pier. While closure pours can be used to join studded steel girder systems as well as concrete girder systems, only concrete girder and deck closure pours will be discussed in this paper. Closure pours are cast after deck sections have been constructed and are generally used when other joint options, such as a sleeved joint, are not feasible because of spacing tolerances between the two bridge sections. Closure pours are the most commonly used connection type for joining two cast-in-place deck sections (Prefabricated Bridge Elements and Systems 2012).

In a closure pour, the gap between deck sections generally contains simple reinforcement lap splices. Cast-in-place concrete is cast between the two sections after the vertical bond surfaces have been sandblasted and moistened. The lap splices in this type of connection cause a very specific loading to the closure pour as the deck sections are subjected to service loads. Service loads cause negative moments above and directly adjacent to bridge supports, where closure pours are typically located, thus inducing tensile stresses at the top of the vertical bond interfaces. Tensile stresses may also develop as the closure pour material undergoes shrinkage after placement. These tensile stresses promote separation at the bond interface. For this reason, bond strength of closure pour materials is critical to prevent separation. While typical steel reinforcing bars assist in carrying this negative moment, cracking may still occur at the top surface of the closure pour section as loads are applied and as the section experiences shrinkage. The addition of discontinuous fibers in closure pour materials further assists with crack control in these regions.

\section{Link Slabs}

A common type of closure pour for joining two deck sections is a link slab. Link slabs are used primarily in joint-less bridge structures to provide a continuous riding surface over the supports and eliminate the need for expansion joint materials that may be easily damaged. To eliminate joints in a bridge, link slabs are cast in-plane with the riding surface of the deck sections, spanning the gaps between bridge deck segments. The dynamic loading of traffic on these bridges results in both axial and flexural strains in the link slab in addition to vertical shear 
under wheel loads. Link slabs function compositely with the deck sections, where horizontal shear connectors also allow for composite action with the girders. To allow the link slab to function efficiently as a hinge between the two bridge deck sections as they deflect, a debond zone is used to transition the link slab section from complete composite action with the bridge girders to separate flexural behavior in the center of the link slab (Li and Lepech 2009). Shear connectors are removed in this debond zone, as shown in Figure 2.1.

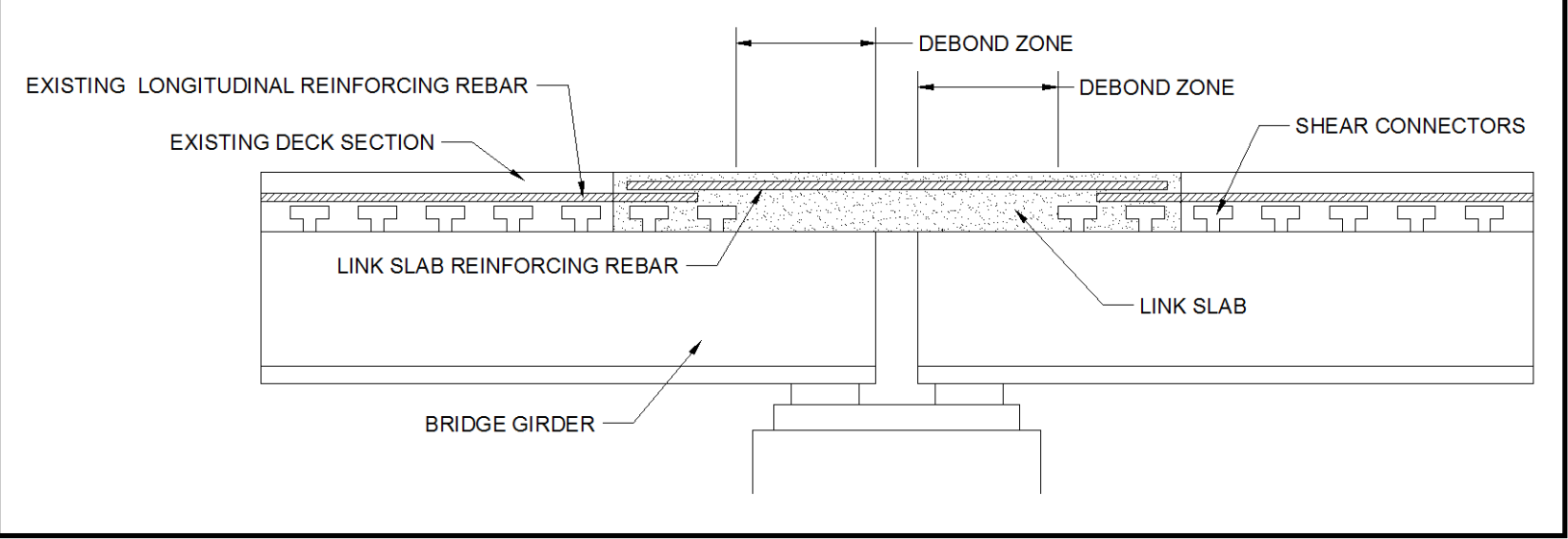

Figure 2.1: Typical link slab system. (adapted from Li and Lepech, 2009.)

Link slabs are generally more heavily reinforced than the adjacent bridge deck sections to control cracking when conventional concrete is used for link slabs. For this reason, link slab sections tend to have a much higher stiffness than desired for ideal link slab behavior (Li and Lepech 2009). This causes stress concentrations at the ends of the link slab, which can lead to severe cracking. A typical link slab system is shown in Figure 2.1. Fiber-reinforced materials that develop tight cracks when placed in flexure eliminate the need for extra longitudinal reinforcement for crack control in link slabs. This reduction of conventional reinforcement in the link slab increases the functionality of the link slab as a flexible connection between deck sections, as the deck sections deflect independently of each other.

\section{Loads on Closure Pour Sections}

A general approach to designing bridges is to consider simple spans for dead load and continuous spans for live load (Prefabricated Bridge Elements and Systems 2012). This loading creates a negative bending moment in the connections over the piers, as well as shear forces along the bond interface, as vehicles travel over the connection. Shrinkage of closure pour 
material creates a perpendicular tensile force at the bond interface between the closure pour material and substrate bridge components, as well as internal stress in the closure pour material that can lead to cracking within the closure pour section. The live loads created by vehicular traffic on the bridge deck occur with varying frequency and magnitude on the closure pour and joint sections in a bridge. Laboratory tests conducted in Ontario applied a mid-span point load in a cyclic pattern and found that the first cracking in the subject closure pour specimens occurred at the bond interface between the deck concrete and the closure pour section (Au, Lam and Tharmabala 2011). In these tests, small slabs were cast using conventional concrete for the closure pour segments in these slabs. While the maximum moment was located at the center of the slab specimen in the center of the closure pour, the stress levels were found to be significantly higher at the bond interface, and no further cracking occurred within the closure pour.

\section{Required Material Properties for Closure Pours and Link Slabs}

When cracks exceed $0.1 \mathrm{~mm}$ wide, water and other harmful agents penetrate to react with reinforcing steel, causing corrosion and compromising the structural integrity of the connection (Ozyildirim 2011). Conventional steel reinforcement provides the majority of the tensile resistance across joints, but only provides the core flexural tensile resistance at these connections and does not prevent separation of the joint material from the bridge deck due to shrinkage of the connection material. Therefore, the bond strength between the deck and the connection material is critical to preventing the formation of cracks at the bond interface. Traditional steel reinforcing bars provide limited crack control at the surface of the concrete.

Resistance to shrinkage is another vital component of bridge joints. Shrinkage can occur in both the fresh and hardened states of the concrete system. When the material is still in the plastic state, plastic shrinkage cracking can occur. Such cracks may allow chlorides to penetrate the closure pour and eventually cause damage to the reinforcing steel within the closure pour section. Plastic shrinkage cracking occurs when the rate of evaporation is greater than the rate of bleeding in freshly placed concrete (Kosmatka and Wilson 2011). This causes internal stresses in the closure pour material when it dries and begins to shrink. While measures can be taken to reduce the evaporation rate, cracks may still form on the surface, and shrinkage may still occur after the concrete has hardened. Autogenous shrinkage of concrete is also of concern in young concrete. This type of shrinkage occurs when water in the cement paste matrix is used up rapidly 
in the hydration process and the demand for more water creates capillaries in the matrix. The surface tension within these capillaries causes shrinkage to occur. This may lead to the development of cracks throughout the concrete matrix. Proper wet curing techniques can eliminate the affects of autogenous shrinkage (The Concrete Society n.d.). After the curing process is complete, drying shrinkage is a major concern. The excess water not consumed by the hydration process begins to leave the system and the concrete begins to shrink. Shrinkage of the closure pour section causes higher stresses to develop along the bond interface between the closure pour and the bridge deck, furthering the issue of separation at these locations. (Tarr and Farny 2008) Volumetric changes in concrete due to drying shrinkage are assumed to be negligible after 30 years, and the rate of shrinkage decreases over that time period. Volumetric shrinkage values for conventional concrete range from $0.01 \%$ and $0.08 \%$. (Kosmatka and Wilson 2011) Because of the concern for vertical bond interface separation, lower shrinkage values are ideal for closure pour materials. However, high bond strength paired with internal crack control of a closure pour system may counter the effects of volumetric shrinkage of the system.

In summary, materials being used for closure pours must exhibit adequate bond strength and crack control.

\section{$\underline{\text { Specifications }}$}

Materials being used for closure pours must meet standards set forth to evaluate the material properties of typical concrete in the fresh and hardened states. VDOT standards require compressive strengths that meet or exceed 4,000 psi at 28 days for typical A4 bridge deck concrete mixes, and this minimum would apply to closure pours for decks as well. (Virginia Department of Transportation 2007) Elastic modulus for A4 concrete is generally between 2,000 ksi and 6,000 ksi (Kosmatka and Wilson 2011). Typically, flexural strength is expected to be approximately $10-15 \%$ of the compressive strength of a concrete material, and is not directly specified by VDOT. VDOT special provision for bond strength of overlays establishes the minimum acceptable bond strength of $150 \mathrm{psi}$, and this provides a convenient reference for closure pours, since no specified bond value exists for closures. (Virginia Department of Transportation 2002) 


\section{Deflection Hardening and Crack Control}

Strain hardening is a property by which the tensile or flexural strength capacity of the composite material increases as strain is increased beyond the tensile capacity of the concrete and yield point of the reinforcing material. Strain hardening is exhibited when the material is placed in tension. This characteristic is also displayed by deflection hardening, which occurs when specimens undergo physical deformations (bending) in flexure and increased residual strength in the tension region leads to extended flexural strength and deflection control exceeding that of conventional mixtures. Generally strain hardening is only exhibited in ductile materials such as steel. However, with the introduction of steel and synthetic fibers into the concrete matrix, the concrete composite is able to achieve ductile properties as cracks are formed in the cement paste and the load is transferred to the fibers across the cracks. The forces are then transferred into the concrete anchoring the fiber ends. This causes more small cracks to form in the concrete rather than the single crack opening, which transfers the load to adjacent fibers. This behavior allows many tight cracks to form instead of a few localized cracks (Fantilli, Mihashi and Vallini 2009). As previously mentioned, tight cracks do not readily allow harmful solutions to enter the concrete and damage reinforcement as larger cracks would.

\section{$\underline{\text { Flexural Strength and Flexural Toughness }}$}

Flexural strength and toughness are two different properties that determine the behavior of a material in flexure. Flexural strength can be measured by placing a beam specimen under center-point loading or third-point loading and recording the maximum load applied to the specimen before failure. In this study, third-point loading was used per ASTM C78. For this loading, the maximum load is used to determine the flexural strength as a function of the specimen moment of inertia using the following equation:

$$
f=\frac{P L}{b d^{2}}
$$

where: $\mathrm{f}=$ the strength, psi

$\mathrm{P}=$ the load, lbf

$\mathrm{L}=$ the span length, in.

$\mathrm{b}=$ the average width of the specimen at the fracture, as oriented for testing, in. $\mathrm{d}=$ the average depth of the specimen at the fracture, as oriented for testing, in. 
Flexural toughness determines the post-crack flexural behavior of fiber-reinforced concrete or mortar mixtures. Flexural toughness is calculated by first plotting the load vs. deflection curve for a beam specimen. The area under the curve between the point of first cracking and the point where the deflection of the specimen reaches 0.08 in is then calculated. This area is a means by which post-cracking flexural toughness can be measured. Specimens with greater deflection hardening capacity will have higher flexural toughness.

ASTM C1609 presents a method for calculating the flexural toughness of FRC specimens placed in flexure under a third-point load. As directed by this procedure, the first-peak (hereafter "first crack") is located by the first point on the load-deflection curve where the slope equals zero. This method is viable for materials experiencing deflection softening after reaching first crack, but it does not apply to systems which immediately strain harden. In this study, first crack for systems that do not exhibit deflection softening immediately after first crack will be located where the load-deflection curve begins to exhibit non-linear behavior. The method outlined by ASTM C1609 uses Equation 1 to calculate the strength of the specimen at first crack, L/600, and $\mathrm{L} / 150$. The flexural toughness of the specimen is defined by the area under the load-deflection curve between first crack and L/150 for the beam specimen. Several of the beam specimens in this study did not reach the required deflection for calculation of flexural toughness due to constraints set by the testing apparatus. Thus the deflection limit for calculating flexural toughness was lowered from L/150 to L/220 for this study to enable comparison of the flexural toughness of each system.

\section{Bond Strength}

Bond strength of closure pour material to bridge deck material is a characteristic attributed primarily to the paste of the closure pour material system. Several test procedures have been developed for determining bond strength. While these tests are generally used for obtaining the bond strength of overlays, the procedures can be used to determine the bond strength of other materials that can be cast against a standard concrete specimen. In this case, the various mixes being evaluated were cast against a standard VDOT A4 Post and Rail concrete mix. (Virginia Department of Transportation 2007)

In the particular case of a link slab, shrinkage of the closure pour material may affect the tensile stresses perpendicular to the vertical bond interface between the closure pour and deck section. However, the tensile stresses at the vertical bond interface are not a function only of 
shrinkage of the closure pour material, as reinforcing bars provide resistance to these tensile stresses at the bond interface.

There are several methods for determining bond strength of two materials. Four tests used in this study are ASTM C1404 (Direct-Tension Bond Test), California Test 551, the Splitting Prism Test (modified from ASTM C496), and the Guillotine Shear Test.

ASTM C1404 was withdrawn in 2010 because of limited use by the industry. This test requires a composite cylindrical specimen consisting of a base material and an overlay material. The bond is located in the middle of the specimen lengthwise, as shown in the METHODS section. Steel caps with threaded holes in the center are attached to the ends of the specimen with epoxy and the specimen is subjected to a tensile load. If the load distribution caps are not exactly centered on the specimen, eccentricity can cause scatter in the results.

California Test 551 evaluates bond strength by subjecting a composite beam specimen to midpoint loading. Under this load scenario, assuming perfect geometry and specimen placement, the maximum positive moment occurs at the center of the span where the vertical bond is located. This causes tensile stresses to occur in the lower half of the beam specimen and compressive stresses to occur in the top half of the specimen. If the load is placed off-center or the bond is not placed directly in the center of the span, the cross-sectional area that experiences tensile stresses may increase or decrease, causing abnormal variance of results.

The Splitting Prism Test is a modification of ASTM C496 splitting tensile test wherein the bond interface is located along the vertical plane at which the highest tensile stress concentration occurs. Either a composite rectangular prism specimen or composite cylindrical specimen is used for this test. Tensile stresses occur along the vertical bond due to the Poisson effect as a compressive load is applied to the top and bottom of the specimen along the bond interface.

The Guillotine Shear Test subjects the specimen to direct shear at the bond interface. A vertical load is applied to a head which distributes the vertical load across the top half of the cylindrical specimen as shown in Figure 2.2. A bending moment is induced in the specimen because of the geometry of the test apparatus along with the desired direct shear stresses at the bond interface. Friction between the base and closure pour material at the bond is also characteristic of this test. One drawback of this test is that failure is forced to occur at the bond. 


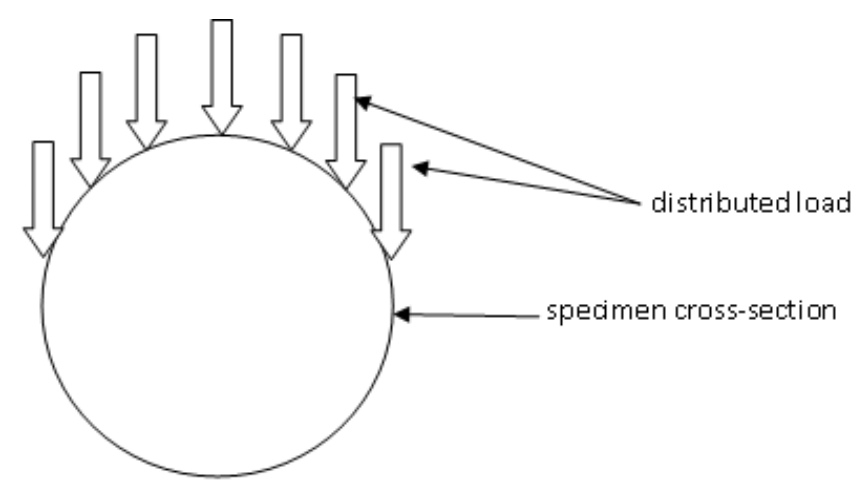

Figure 2.2 Guillotine Shear Test load distribution.

\section{Problems with Conventional Concrete}

The specific behavior and loadings on closure pours and joints pose several issues when using conventional concrete. Concrete is a brittle material and fails suddenly when loaded beyond its elastic state. At this point, cracks form, resulting in permanent deformation and loss of strength. When placed in tension, conventional concrete has limited strength (approximately $10 \%$ of compressive strength). When conventional reinforcement is added to concrete and placed in flexure, large cracks form in the tension face of the concrete. These cracks may allow harmful solutions to penetrate the concrete matrix and cause irreversible damage to steel reinforcement. Concrete is also subject to shrinkage cracking as previously mentioned.

\section{Benefits and Drawbacks of Fibers in Conventional Concrete}

Various types of fibers have been used in concrete to resolve some of the issues found in conventional concrete for use in closure pours and joints. Major advantages to adding fibers to a concrete mix are crack control and increased durability. When shrinkage occurs in the plastic state, internal tensile forces cause micro-cracks to form in the concrete. In conventional concrete mixes, these micro-cracks propagate and coalesce to form macro-cracks, allowing for the intrusion of harmful solutions. When fibers are present in the mix, they transfer these tensile forces across fractured regions. The fiber-to-concrete bond distributes these forces throughout the concrete matrix and delays the growth of micro-cracks. Fibers can also control cracking when concrete is placed in flexure by effectively bridging cracks to distribute stresses in the concrete matrix. Adding high dosages ( $1.5-2 \%$ by volume) of fibers to the concrete mix enhances 
ductility and flexural toughness. Fibers also minimize the effects of plastic shrinkage by engaging water in the mix, thus reducing bleeding and segregation of the mix (N. Banthia 2008).

The use of fibers in concrete has many benefits, but also has some drawbacks. Reduced workability is a common issue with fiber-reinforced concrete mixes and can cause issues with mixing, placement, and finishing. Workability can be increased in some mixes by adjusting the length of fibers. Typically mixes containing short fibers ( $<1$ inch) of small diameter (e.g., $<0.75$ mil) are more workable than mixes employing the use of long fibers (1-2 inches). Another issue with the use of fibers is that metal fibers may corrode and cause discoloration of the hardened concrete surface after weathering has occurred. This problem does not have an effect on the structural capacity of the material and can be avoided by using galvanized or brass-coated steel or synthetic fibers (Rossi 2011). Change in water demand of concrete mixes is yet another issue caused by some types of synthetic fibers. This typically occurs when hydrophilic microfibers are used in the mix. The fibers attract water, causing difficulty with mixing and potentially delaying hydration of the cement. Some mix designs account for this absorption by adjusting the water content as needed.

The advantages can far outweigh the disadvantages if the proper amounts of reinforcing fibers are used and the concrete matrix is optimized to accommodate these fibers and provide a good bond to the fibers.

\section{Types of Discontinuous Fibers}

There are many types of fibers that can be used to enhance mechanical properties in concrete. Fibers are defined by size and type. There are two basic size ranges for discontinuous fibers: macrofibers and microfibers. Macro- and microfibers are defined by their diameter, where fibers with a diameter greater than or equal to 0.012 in are classified as macrofibers and fibers with diameter less than 0.012 in are called microfibers (American Concrete Institute 2013). The main classes of fibers are steel, synthetic, and organic. Several types of steel and synthetic fibers are used in this study. One type of fiber is RECS15, which is a polyvinyl alcohol (PVA) microfiber. This fiber is primarily used to control microcracks and improve the durability of the concrete. RSC15 has the same geometry as RECS15 and is also a PVA microfiber but it provides slightly lower tensile strengths. Both of these fibers are hydrophilic and tend to absorb water during mixing. These fibers are shown in Figure 2.3. 

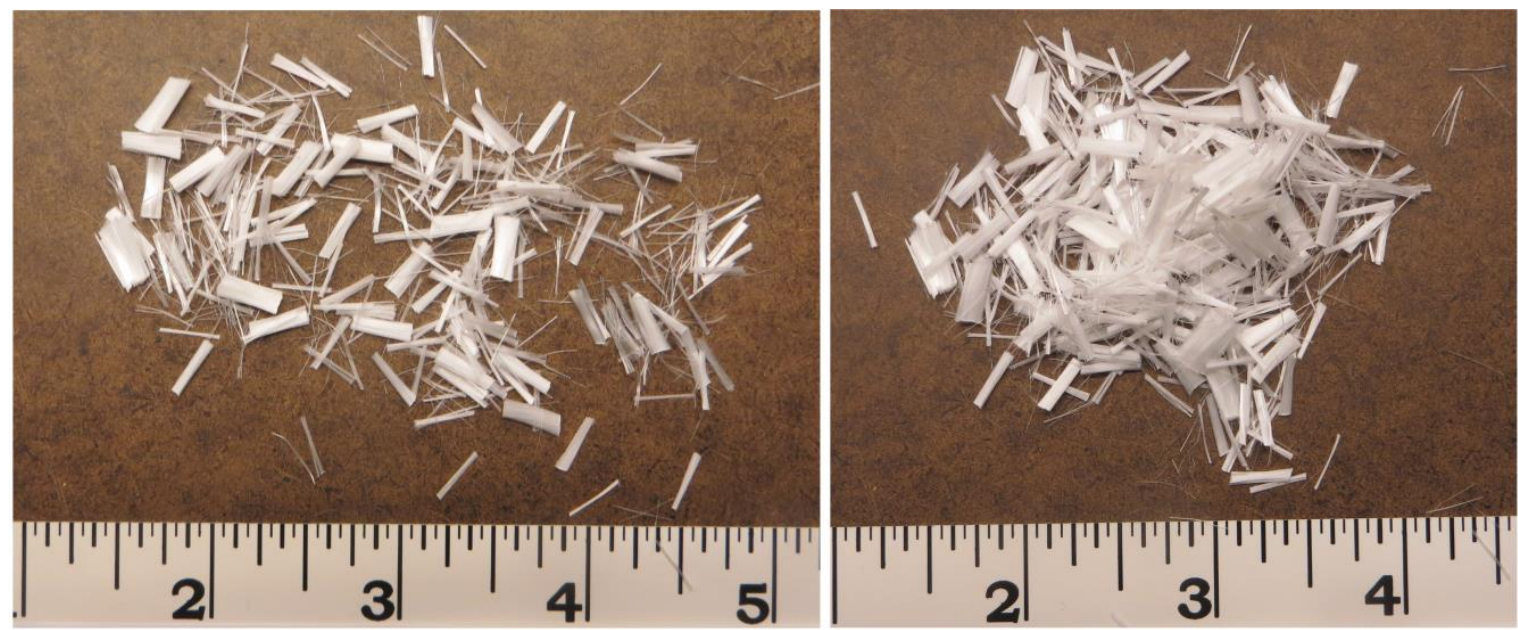

Figure 2.3 RECS15 (left) and RSC15 (right) PVA microfibers.

RF4000 is a PVA macrofiber which measures just over 1 in long and serves to prevent the coalescence of micro-cracks and subsequent formation of macro-cracks. BT50 is a polypropylene macrofiber which functions primarily to inhibit the widening of macro-cracks. These fibers have small deformations along the length (see Figure 2.4) to improve bond to the concrete matrix and decrease development length.
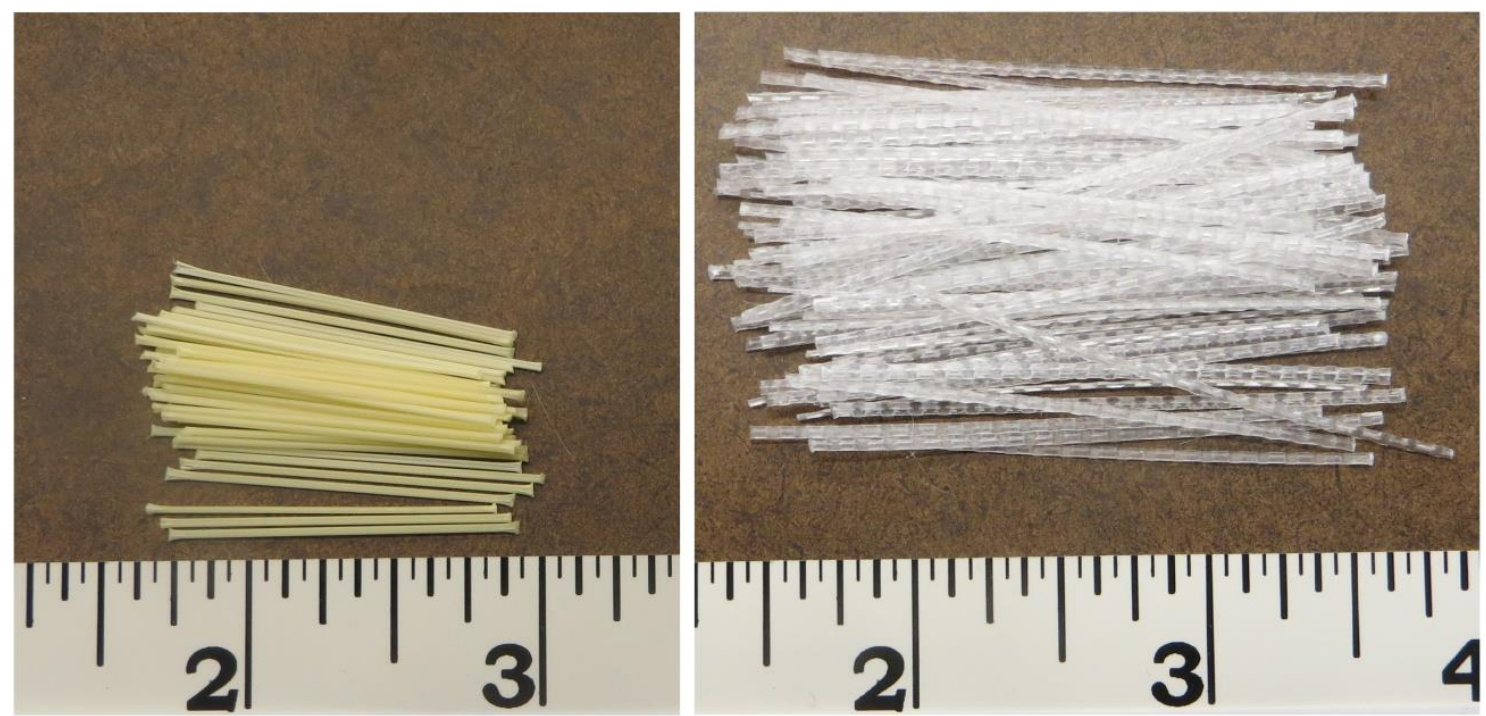

Figure 2.4 RF4000 PVA macrofibers (left) and BT50 polypropylene macrofibers (right).

Steel fibers provide higher ductility to cracked concrete specimens than synthetic fibers. Three different types of steel fibers were used in this study. ZP 305 is a hooked-end type steel macrofiber (seen in Figure 2.5) measuring just over 1 in long. These fibers include end 
deformations to decrease development length and improve effectiveness of the fibers when concrete cracks. RC80/60BN fibers are steel fibers that resemble ZP 305 in geometry but measure 2.4 in long. Steel fibers used in Ductal $\mathrm{JS} 1000^{\mathrm{TM}}$ measure $14 \mathrm{~mm}$ long and are brasscoated to prevent corrosion.

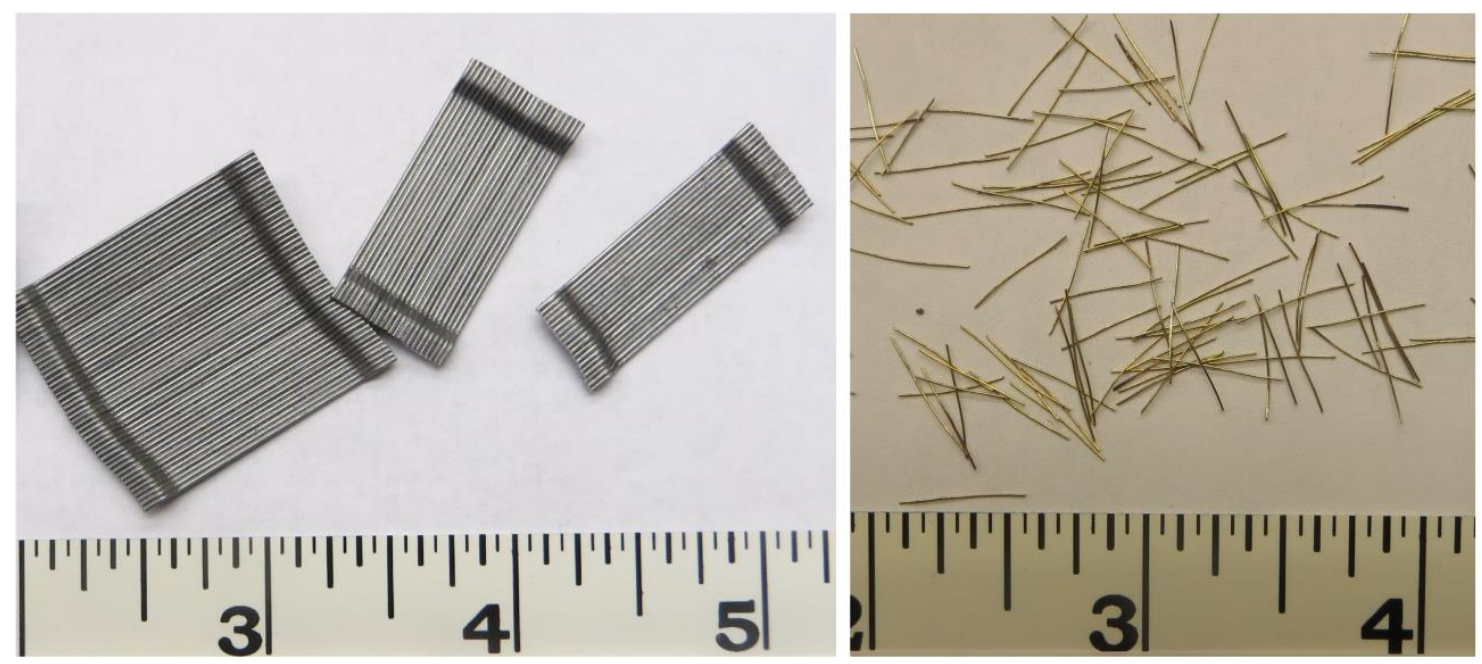

Figure 2.5 Hooked-end type steel macrofibers (left) and brass-coated steel microfibers (right).

Table 2.1 shows some material and geometric properties of the fibers used in this study including fiber material, size class based on diameter, and basic dimensions.

Table 2.1 Properties of discontinuous fibers.

\begin{tabular}{|l|c|c|c|c|c|c|c|}
\hline Property & RSC15 & RECS15 & RF4000 & BT50 & ZP 305 & RC80/60BN & $\begin{array}{c}\text { UHPC } \\
\text { Fibers }\end{array}$ \\
\hline Material & PVA & PVA & PVA & $\begin{array}{c}\text { Polypro- } \\
\text { pylene }\end{array}$ & steel & steel & $\begin{array}{c}\text { brass- } \\
\text { coated } \\
\text { steel }\end{array}$ \\
\hline $\begin{array}{l}\text { Size } \\
\text { Class }\end{array}$ & micro & micro & macro & macro & macro & macro & micro \\
\hline $\begin{array}{l}\text { Diameter } \\
\text { (in) }\end{array}$ & 0.002 & 0.002 & 0.026 & 0.026 & 0.022 & 0.030 & 0.008 \\
\hline $\begin{array}{l}\text { Length } \\
\text { (in) }\end{array}$ & 0.32 & 0.32 & 1.2 & 2.0 & 1.2 & 2.4 & 0.56 \\
\hline $\begin{array}{l}\text { Specific } \\
\text { Gravity }\end{array}$ & 1.3 & 1.3 & 1.3 & 0.91 & - & - & - \\
\hline
\end{tabular}




\section{High Performance Fiber-Reinforced Concrete}

$\underline{\text { Mix Design }}$

High performance fiber-reinforced concrete (HPFRC) is a type of high performance concrete that uses fibers to control cracking and in some cases improve tensile strength. The introduction of fibers into the concrete matrix enhances the durability and structural capacity of the material by controlling crack propagation by effectively bridging cracks as they begin to form (Bindiganavile and Banthia 2005). This allows concrete structures to last longer and provide higher ultimate strengths. Typically, these mixes resemble normal concrete mixes and synthetic or steel fibers are added in large quantities (1-2\% by volume). While some ductility is sacrificed because of the inclusion of coarse aggregates, these mixes are still able to achieve deflection hardening and obtain tight cracks when placed in flexure while using a low mortar fraction. Fibers with varying lengths, aspect ratios, and material properties have been used in HPFRC to control cracking and in some cases exhibit deflection hardening.

\section{Types of High-Performance Fiber-Reinforced Concrete}

One type of HPFRC is called Hybrid FRC (HyFRC). HyFRC is named so because it includes more than one type of fiber in the same mix. These mixes typically use less steel fibers and more synthetic fibers. Using less steel fibers reduces safety risks when mixing and allows the hardened concrete to maintain deflection hardening properties with low steel fiber content. Including fibers of different lengths in a concrete mix assists with crack control at both the micro- and macro-crack levels. When micro-cracks begin to form, the smaller fibers inhibit the development of these cracks. When several micro-cracks come together to form a macro-crack, the larger fibers then begin to resist the growth of these macro-cracks. There are essentially three types of hybridization: hybridization based on varying fiber material properties, hybridization based on fibers with differing dimensions, and hybridization based on the fiber function (i.e., which concrete properties they are intended to enhance) (Banthia and Sappakittipakorn 2007).

\section{Synthetic and Steel Fiber Combinations}

Some HyFRC mixes contain both steel and synthetic fibers of varying lengths. This type

of HyFRC merges the types of hybridization and utilizes long steel fibers to provide ductility and control macro-cracking while short, flexible synthetic fibers improve toughness and deflection capacity of the material in the post crack region. Research in 2007 showed that using a 
combination of large diameter steel fibers and short, small diameter steel fibers could provide an economically efficient way to improve the durability and flexural toughness of a concrete mix, but the flexural toughness failed to meet that of HyFRC mixes utilizing only the small diameter steel fibers (Banthia and Sappakittipakorn 2007). Fibers with a smaller diameter are generally more expensive to produce. More recent research conducted on HyFRC shows that the use of polyvinyl alcohol micro-fibers in addition to large and medium sized diameter steel fibers in concrete provides better flexural toughness than mixes using only steel fibers and even displays deflection hardening characteristics when placed in flexure (Blunt and Ostertag 2009). In that study, the mix which provided the most impressive deflection hardening behavior included large diameter steel fibers to provide constant resistance and ductility from first crack to peak strength, small PVA fibers to reduce the loss of flexural strength after first cracking and increase toughness, and intermediate sized steel fibers to increase the ductility of the mix. The total volume of fibers for this mix was $1.5 \%$. The maximum aggregate size was reduced to produce a higher mortar fraction in the mix, enabling the mixture to accommodate a high percentage of fibers.

\section{Synthetic Fiber Combinations}

Some HyFRC mixes contain only synthetic fibers. The deflection hardening properties in these mixes are generally less significant than those of HyFRC mixes that contain steel fibers because of the decrease in ductility caused by the absence of steel and the presence of coarse aggregate in the mix. However, deflection hardening can still be achieved with these mixes. HyFRC mixes that contain only synthetic fibers eliminate issues caused by steel fibers such as discoloration of the concrete surface and injuries during mixing and handling of the concrete. Mixes using only synthetic fibers generally require high amounts of fibers ( $2.0 \%$ by volume) to consistently exhibit deflection hardening and are slightly lighter than traditional concrete mixes because of the low density of the fibers. The addition of fibers exceeding $2.0 \%$ by volume to a mix further pronounces issues with workability and makes it very difficult to mix.

\section{High-Performance Fiber-Reinforced Cementitious Composite}

\section{$\underline{\text { Mix Design }}$}

High performance fiber-reinforced cementitious composite (HPFRCC) differs from HPFRC in that is does not contain coarse aggregate. Therefore, it is not technically classified as a 
concrete mix, but instead referred to as a cementitious composite or mortar mix. HPFRCC relies on the gradation of fine particles such as sand, quartz, fly ash, slag cement, and silica fume to create an extremely dense and very cohesive mix. These types of mixes employ fibers of different types and sizes.

\section{Engineered Cementitious Composite}

Engineered cementitious composite (ECC) is a type of HPFRCC that uses fly ash and sand as its fine aggregate and polyvinyl alcohol (PVA) microfibers. This mix is able to achieve extreme deflection hardening without the use of steel fibers and uses a high fly ash-to-cement ratio to improve the cost efficiency of the mix while maintaining low permeability. The microfibers used in ECC improve the durability of the material as multiple tight cracks are also characteristic of ECC mixes.

Due to the hydrophilic nature of PVA microfibers, difficulties in achieving uniform fiber distribution can be an issue during mixing. Research was conducted in Michigan to determine how the rheological properties of ECC could be adjusted during mixing to promote even distribution of the fibers (Zhou, et al. 2012). In order to accommodate large volumes (2\%) of PVA fibers and achieve even fiber distribution in a large mix, the optimum water-tocementitious material ratio was found to be $0.25 \pm 0.05$. 


\section{PURPOSE AND SCOPE}

There were two objectives for this project. The first was to determine the best and most cost effective HPFRC or HPFRCC system to be used in closure pours and bridge joints to prevent cracking of these sections as well as solving issues with separation at the bond interface. The secondary goal was to determine the reliability of various bond strength tests for research and quality control or quality assurance purposes.

Several tests were performed on the various HPFRC and HPFRCC systems created in the laboratory, including both fresh and hardened concrete tests. Fresh concrete tests included tests for workability, density, and air content. Hardened tests included four different bond strength tests, flexural tests to determine the deflection hardening properties and cracking behavior of each mix, shrinkage tests, and standard compression tests to ensure that these mixes achieved desirable compressive strengths. A cost assessment was then completed to decide which of these mixes provide the best results for the cost. 


\section{METHODS}

\section{Literature Review}

First, a literature review was completed in which a majority of the information acquired on the topics being researched was compiled and terms and concepts particular to the project were discussed in detail. The purpose of this task was to gain an understanding of previous research conducted on related material systems. Identification of issues with these systems and the relationships between materials and performance was used for determining which materials should be evaluated for use in closure pours. Previous research was also used as a basis for comparison of the results acquired in this study.

\section{Determining Potential Mixes}

Once the goals were established, mixes with the highest potential were determined, based on results from previous testing and research on various materials. Desired mixtures were required to possess deflection hardening, exceptional bond strength, and minimal volumetric shrinkage, in addition to basic strength characteristics. Very little information could be found on bond strength of potential closure pour materials; therefore, deflection hardening was the main criterion used to determine potential materials for this project. The use of several different concrete systems was considered. These mixes employ various types and lengths of steel and synthetic fibers as described in detail below.

\section{$\underline{\text { Engineered Cementitious Composite }}$}

The first of these systems is engineered cementitious composite (ECC), which has properties similar to that of fiber reinforced concrete (FRC) but differs from FRC in that it produces deflection hardening. ECC conventionally contains polyvinyl alcohol (PVA) microfibers or polyethylene fibers in very small amounts and omits coarse aggregate in order to achieve high ductility (Sahmaran et. al. 2007). The ECC mixes in this project contain high doses of PVA microfibers ( $2 \%$ by volume). ECC is fairly cost efficient as compared with similar materials. This system was previously tested and proven to exhibit deflection hardening in the laboratory (Ozyildirim and Vieira 2008). ECC has very low permeability due to the density of the material, and since it does not contain coarse aggregate it is generally classified as a mortar $\operatorname{mix}$. 
$\underline{\text { Hybrid Fiber-Reinforced Concrete (Steel and Synthetic Fibers) }}$

The second system that was considered is a hybrid fiber reinforced concrete (HyFRC) system, in which two different types of discontinuous fibers - generally steel and PVA - are added to the concrete matrix to achieve deflection hardening. In contrast to ECC, coarse aggregates are typically used in HyFRC mixtures. The presence of coarse aggregate necessitates less paste in the mixture, thus this option also presents an economically efficient possible solution. Minimizing paste content will also decrease the amount of shrinkage of the material. Research has been conducted at VCTIR to show that these mixtures also achieve deflection hardening using a nominal maximum aggregate size (NMAS) of 3/8 in. (Ozyildirim unpublished data) Low permeability is also characteristic of this system.

\section{$\underline{\text { Hybrid Fiber-Reinforced Concrete (Synthetic Fibers) }}$}

A third system that was considered was a HyFRC system using only synthetic fibers. One of these systems contains only PVA macro- and microfibers while a second system employs $50 \mathrm{~mm}$ polypropylene fibers in addition to PVA fibers. These mixes were explored in an attempt to eliminate the use of steel fibers yet maintain the flexural and crack control characteristics seen in both the HyFRC and ECC mixes. This system used 3/8 in NMAS pea gravel for the coarse aggregate portion of the mix. Elements of the HyFRC system with steel and the ECC system were combined to create this mix. The pea gravel contributes strength, while a modification of the deflection hardening ECC mix was used as the mortar fraction of the system. Instead of using PVA and steel or just PVA microfibers, two types of PVA fibers (macrofibers and microfibers) and polypropylene fibers were used.

\section{Ultra-High Performance Concrete (UHPC)}

The fourth system that was investigated was Ductal JS1000 ${ }^{\mathrm{TM}}$, a proprietary ultra highperformance concrete (UHPC) field-cast joint fill solution for precast deck panel bridges. This mixture has enhanced bond capacity and is very durable. It exhibits decreased chloride ion penetration and increased resistance to freeze-thaw cycles and chemical attack as compared to conventional HPFRC. This UHPC uses brass-coated steel microfibers for reinforcement, which reduces plastic shrinkage cracking and is said to increase deflection hardening capabilities. Like ECC, UHPC is a mortar mix. 


\section{Evaluating Preliminary Laboratory Batches}

Small trial batches were tested for each mix before final mixes were cast and tested in order to determine whether or not each mix would achieve the desired compressive and deflection hardening properties. These mixes were expected to have a minimum compressive strength of 3,000 psi at 7 days after casting and exhibit substantial deflection hardening characteristics. A series of 4 in $\times 4$ in $\times 16$ in beams were tested to determine the presence or absence of deflection hardening, and 2-in mortar cubes as well as 4-in diameter cylinders were tested to measure compressive strength.

\section{Engineered Cementitious Composite}

Two small batches of ECC were reproduced, each using a different type of sand. These mixes were variations of mixes developed in previous research, but were recreated with materials local to Virginia. (Sahmaran and Li 2007) Each batch was tested for deflection hardening and compressive strength to ensure that the desired properties could be achieved with local natural materials. The different sand types offered different densities for the ECC mix, but each mix performed similarly well in flexure and compression. Locally produced mortar sand was used in the final mix design because this sand provided the highest density of the sands tested. The mix proportions can be seen in Table 4.1. A large stand mixer was used for both ECC trial batches.

Table 4.1 ECC mix design.

\begin{tabular}{|l|c|}
\hline \multicolumn{1}{|c|}{ Component } & Weight $\left(\mathbf{l b} / \mathbf{y d}^{\mathbf{3}}\right)$ \\
\hline Water & 656 \\
\hline Cement & 961 \\
\hline Fly Ash (Class F) & 1153 \\
\hline FA: Sand & 767 \\
\hline RECS15 PVA Micro-fibers & $44(2 \%$ by volume $)$ \\
\hline ADVAcast 575 SP & $1 \mathrm{oz} / \mathrm{cwt}$ \\
\hline Fly ash/cement ratio & 1.2 \\
\hline w/cm ratio & 0.31 \\
\hline
\end{tabular}

For the first trial batch of ECC, Aylett sand (FM = 2.9, SSD S.G. = 2.62) from Aylett, VA was sieved through a No. 16 sieve before being added to the mix to eliminate large particles because of the small size of the specimens to be cast. Cement, fly ash, and sand were mixed together in the mixer. Then water was added and mixed until a firm, doughy consistency was achieved. The slump flow was measured to ensure that the consistency was suitable for the 
addition of fibers. The slow flow was measured again after the addition of fibers to ensure that the material was still workable. Acceptable flow values after the addition of fibers are approximately 5 to 6 in.

After 7 days of curing, 2 compression cubes and 2 beams (one of each thickness) were removed from the moisture room and tested. Test ASTM C109 was performed on the cubes, and the 1 in-thick beam was subjected to third point loading per ASTM C78 with a 12 in span and 4 in between the loading points as shown in Figure 4.1. Third-point loading of thin ECC beams determined the presence of multiple tight cracks in flexure. The 1/2-in-thick beam was loaded manually with circular weights at mid-span because of the expected low modulus of rupture. The weights being applied were placed on a hanging weight mount which allowed the load to be applied directly at mid-span. The loads applied were just large enough to observe deflection (Figure 4.2) and tight cracking (Figure 4.2 and Figure 4.3) of the beams.

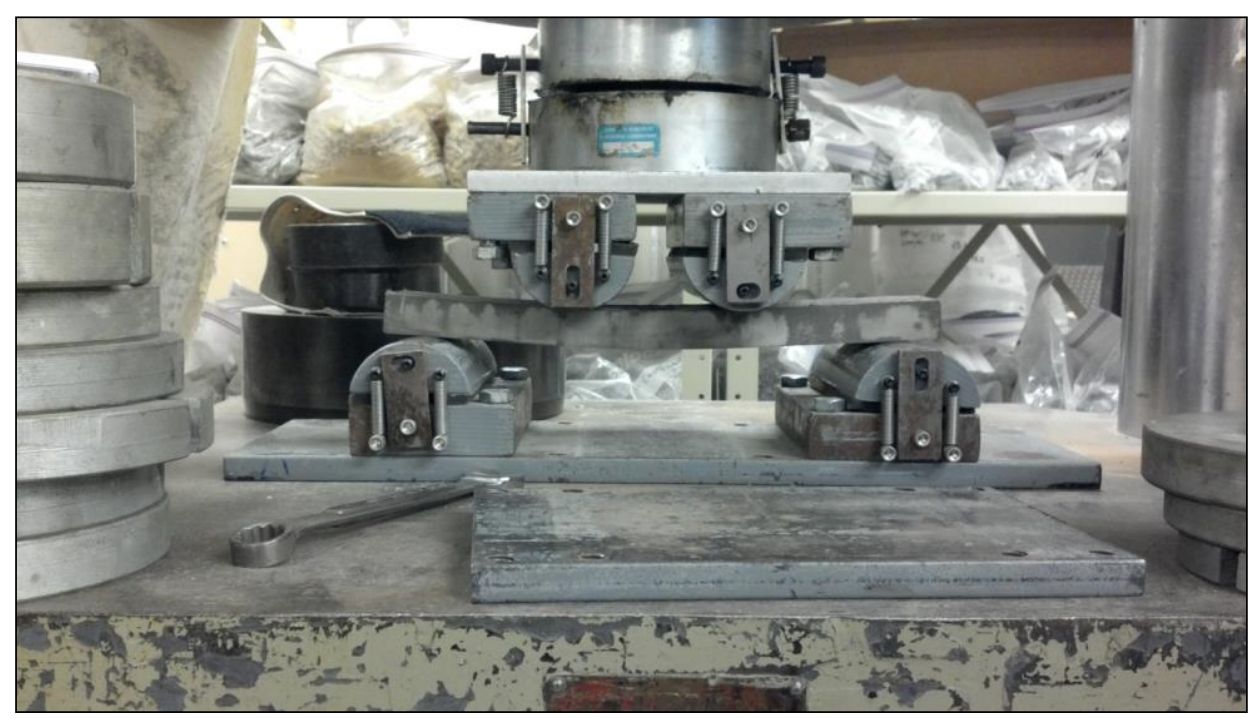

Figure 4.1 Third-point loading for thin ECC beams. 


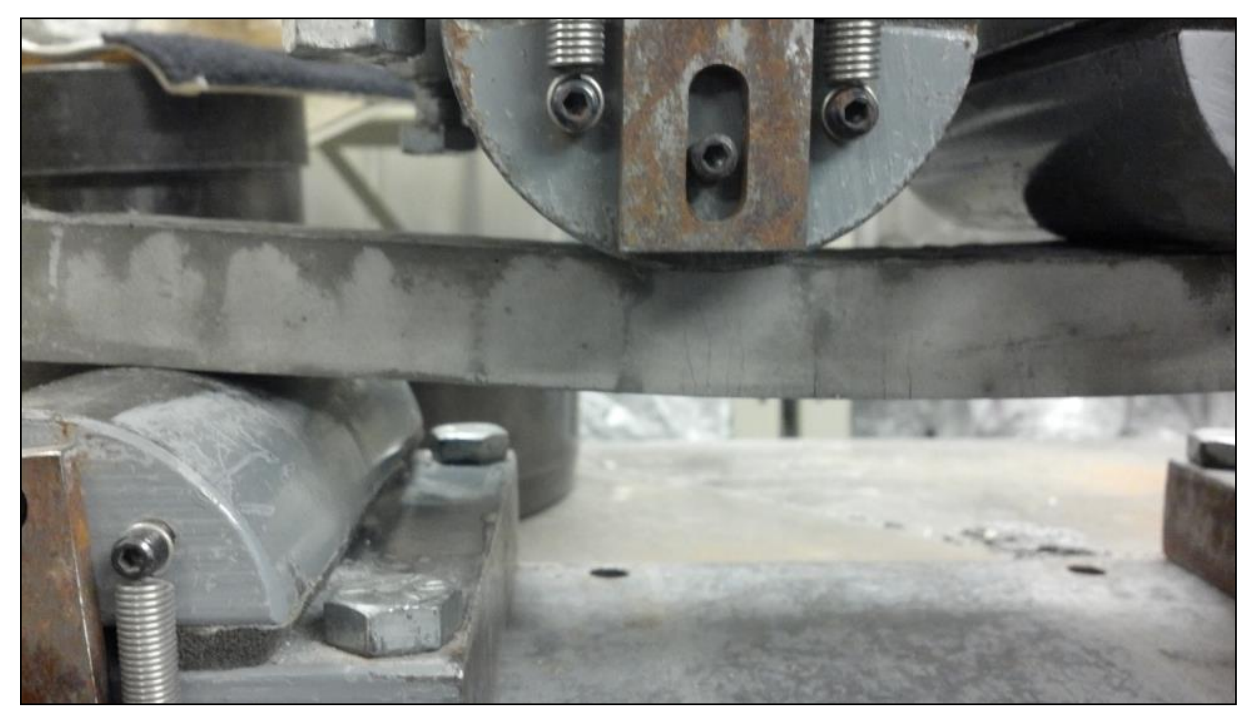

Figure 4.2 Deflection and tight cracking during third-point loading of ECC beams.

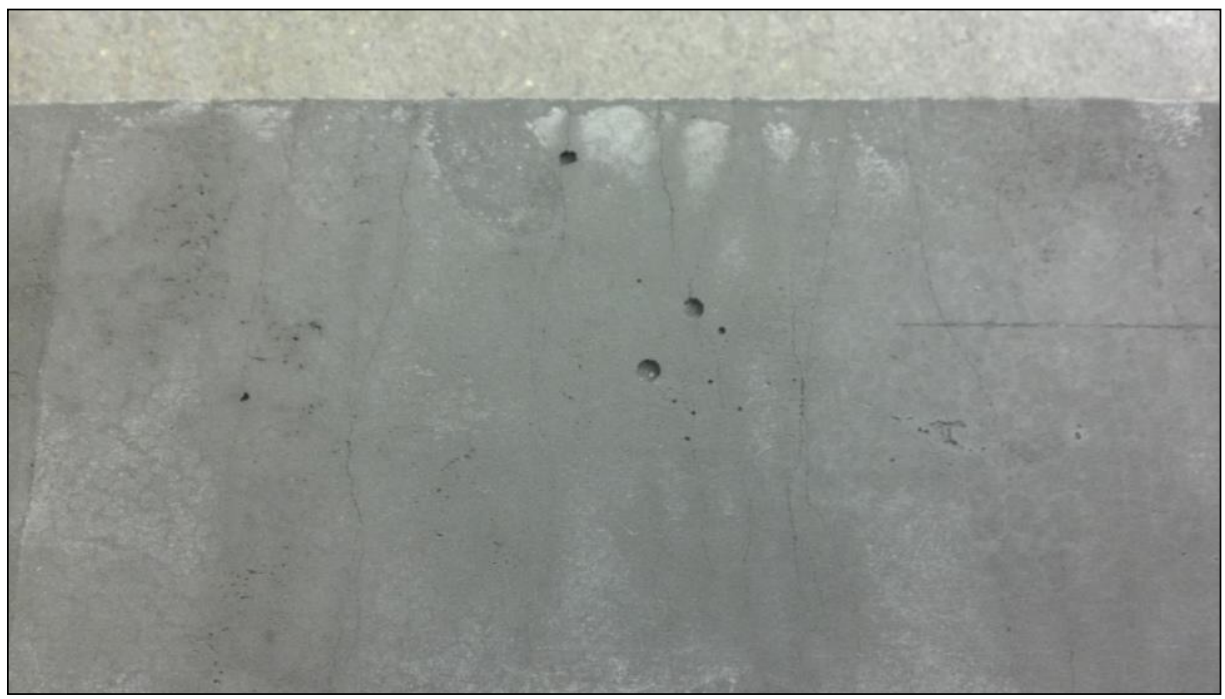

Figure 4.3 Tight cracking during third-point loading of ECC beam.

The procedure for testing at 7 days after casting was repeated for the remaining specimens after 28 days of curing. The $1 / 2$-in-thick beam was loaded with the machine at a very low loading rate ( $2 \mathrm{lb}$ per minute) this time to improve accuracy of results.

The same mixing process was completed for the second trial batch of ECC using Glover sand $(\mathrm{FM}=3.0, \mathrm{SSD}$ S.G. = 2.62), which is located in Margarettesville, NC. The sand was sieved through a No. 16 sieve before mixing. The specimens cast and tests completed for the second trial batch can be seen in Table 4.2. 
Table 4.2 ECC trial batch specimens.

\begin{tabular}{|c|c|c|}
\hline Specimen & Quantity (B1/B2) & Test \\
\hline 2 in $\times 2$ in $\times 2$ in Cube & $3 / 3$ & ASTM C109/C109M \\
\hline 1 in $\times 3$ in $\times 14$ in Beam & $2 / 4$ & ASTM C78/C78M \\
\hline $1 / 2$ in $\times 3$ in $\times 14$ in Beam & $2 / 2$ & ASTM C78/C78M \\
\hline
\end{tabular}

$\mathrm{B} 1=$ trial batch $1, \mathrm{~B} 2=$ trial batch 2

\section{HyFRC (Synthetic and Steel)}

The hybrid concrete mixes explored in this project focus on the addition of fibers to typical concrete mixes. This allows for the addition of fibers to standard mixes to achieve deflection hardening in a mix that uses typical concrete components, representing a somewhat cost efficient solution to the prevention of cracking in closure pours.

HyFRC mixes including varying amounts of steel and synthetic fibers followed methods developed in California (Blunt and Ostertag 2009) while using materials local to Virginia and typical VDOT mix designs. These mixes closely resemble standard VDOT mixes and can be developed using standard mix design criteria, so no trial batches were created for this system.

\section{HyFRC (Synthetic Only)}

HyFRC mixes using only synthetic fibers to obtain deflection hardening required much experimentation in order to develop a mix that could exhibit the necessary deflection hardening and crack control properties. Several trial mixes were tested - altering fiber combinations, paste content, and the w/cm ratio - to create a satisfactory mix containing only synthetic fibers. Mix designs for these trial mixes can be seen in Table 4.3. Beams measuring 4 in $\times 4$ in $\times 14$ in and 4-in diameter cylinders were cast and tested for each mix to evaluate deflection hardening capabilities and compressive strength.

Three different types of fibers were used when developing synthetic hybrid mixes. The first is Nycon-PVA RSC15, an $8 \mathrm{~mm}$ (0.375 in) long PVA micro-fiber. This fiber functions to prevent the propagation of micro-cracks and improve the durability of the concrete. The second type of fiber is Nycon-PVA RF4000, a 30 mm (1.25 in) long PVA macro-fiber. This type of fiber attempts to control the growth of macro-cracks that form when micro-cracks coalesce into larger cracks. Both PVA fibers have a specific gravity of 1.3. The largest fiber in this project, STRUX BT50, measures $50 \mathrm{~mm}$ ( 2 in) long and is designed to improve post-crack performance of concrete. This fiber is made of polypropylene and has a specific gravity of 0.91 . 
When beginning the process of developing a satisfactory synthetic hybrid mix, only PVA fibers were used. Following fiber ratios used in Nycon's TUFF-MIX ${ }^{\mathrm{TM}}$ mix design to control cracking and increase durability of concrete slabs, the first synthetic hybrid mix (HyFRC- B) utilized a 2:1 ratio of RF4000 to RSC15 fibers (Nycon 2012). Subsequent mix designs sought to improve upon the preceding mix by improving individual characteristics of the mix. Fiber volumes, types, and combinations were altered along with concrete properties such as the $\mathrm{w} / \mathrm{cm}$ ratio and paste content. The results of tests ASTM C 1609M and ASTM C 78 governed the alterations made for subsequent mix designs. This process was complicated by the large volume of fibers and the hydrophilic nature of the RSC15 PVA micro-fibers. The paste content of each system was adjusted to accommodate the fibers, and water reducing admixture was used to improve mixing and workability once the RSC15 fibers were added to the mix. 
Table 4.3 Mix designs for HyFRC containing only synthetic fibers.

\begin{tabular}{|l|c|c|c|c|c|}
\hline \multicolumn{1}{|c|}{ Component } & HyFRC-E & HyFRC-F & HyFRC-G & HyFRC-H & HyFRC-I \\
\hline Cement Type & Type I/II & Type I/II & Type I/II & Type I/II & Type I/II \\
\hline Water & 315 & 315 & 315 & 315 & 315 \\
\hline Cement & 490 & 490 & 490 & 490 & 490 \\
\hline Fly Ash (Class F) & 210 & 210 & 210 & 210 & 210 \\
\hline Aylett Sand & 1589 & 1589 & 1176 & 1311 & 1311 \\
\hline 3/8" Pea Gravel & 1060 & 1060 & 1454 & 1319 & 1319 \\
\hline RSC15 PVA Micro-fibers & $7.3(0.33 \%)$ & $14.6(0.67 \%)$ & $7.3(0.33 \%)$ & - & $7.3(0.33 \%)$ \\
\hline RF4000 PVA Macro-fibers & $14.6(0.67 \%)$ & $14.6(0.67 \%)$ & $11.0(0.50 \%)$ & - & $11.0(0.50 \%)$ \\
\hline BT50 Polypropylene Macro-Fibers & $13.8(0.90 \%)$ & $10.2(0.67 \%)$ & $17.9(1.17 \%)$ & $30.6(2.00 \%)$ & $8.7(0.57 \%)$ \\
\hline w/cm & 0.45 & 0.45 & 0.45 & 0.45 & 0.45 \\
\hline Fiber Content (\% volume) & 1.90 & 2.00 & 2.00 & 2.00 & 1.40 \\
\hline Number of Beams Tested & 3 & 3 & 3 & 3 & 3 \\
\hline Deflection Hardening & Yes & No & Yes & Yes & No \\
\hline
\end{tabular}




\section{$\underline{\mathrm{UHPC}}$}

Ductal JS1000"TM (hereafter "UHPC") is a self-leveling fiber-reinforced UHPC premix (commercially available prepackaged mixture) that includes cement, silica fume, silica sand, and ground quartz to optimize particle size distribution and decrease permeability. To mix UHPC, the necessary amount of premix is added to water and superplasticizer and mixed thoroughly before the addition of fibers. When the mix reaches an appropriate level of workability and selflevels when the mixer is stopped, the fibers are added. Once the fibers appear to be evenly distributed in the mix, water or premix is added in small amounts to adjust the workability of the mix. A high-shear mortar mixer is generally used for mixing UHPC in order to achieve the necessary rheological properties and sufficient mixing of materials throughout the mixing process.

Ductal is a specialized mix, so the mixing of trial batches was supervised by trained technical representatives from LaFarge, the company that develops and distributes UHPC. Only a $2 \mathrm{ft}^{3}$ pan type mixer was available for mixing in the laboratory, so extra care was taken to ensure proper mixing techniques were exercised and the proper adjustments were made to guarantee consistency of the mixes. One trial batch of UHPC was mixed in the laboratory using

3 bags of premix, which equates to a $1.095 \mathrm{ft}^{3}$ batch. Brass-coated steel fibers measuring $14 \mathrm{~mm}$ long are standard for the UHPC mix and were added to the mix by using plastic tongs to avoid injury. Specimens cast for this trial batch included two 4 in $\times 4$ in $\times 14$ in beams tested in flexure after 7 and 28 days of curing and four 4-in diameter compression cylinders that were also tested after 7 and 28 days of curing in a moisture room. The results of these tests are displayed in the Results section of this paper.

\section{Evaluating Large Laboratory Batches}

After all necessary trial batches were tested and analyzed, large laboratory mixes were created in order to test the materials for bond strength and shrinkage in addition to flexural behavior and compressive strength. Large laboratory mixes were tested for ECC, HyFRC with steel and synthetic fibers, HyFRC with only synthetic fibers, and UHPC. A reasonable number of specimens (at least three, if possible) was desired for each test for all subject materials. To achieve this - and to ensure mixes could be recreated easily - two batches were mixed for each material using a pan type mixer with a maximum capacity of $2 \mathrm{ft}^{3}$. 
$\underline{\text { Fresh and Hardened Concrete Tests }}$

\section{Fresh Concrete Tests}

All four systems were expected to be workable so they could be easily placed in the molds. To ensure suitability for field application, the laboratory mixtures were evaluated for relevant fresh properties, as outlined in Table 4.4.

Table 4.4 Fresh concrete tests.

\begin{tabular}{|l|c|}
\hline Test & Specification \\
\hline Density of Fresh Concrete & ASTM C138 \\
\hline Slump Cone Test (for A4 concrete) & ASTM C143 \\
\hline Mini Slump Flow Test (for ECC mixes) & ASTM C230 \\
\hline Air Content & ASTM C231 \\
\hline Inverted Slump Cone Test (for FRC mixes) & ASTM C995 (withdrawn, 2008) \\
\hline Mix Temperature & ASTM C1064 \\
\hline
\end{tabular}

In addition to specific concerns about cracking toughness and bond, the subject materials were tested to ensure that they exhibit basic structural properties such as acceptable compressive strength and elastic modulus, as well as volume stability. The characteristics were expected to meet the minimum requirements of, and be compatible with, conventional class A4 deck concrete. (Virginia Department of Transportation 2007) Thus, the tests outlined in Table 4.5 were conducted on companion specimens from each large laboratory test batch.

Table 4.5 Hardened concrete tests.

\begin{tabular}{|l|c|}
\hline Test & Specification \\
\hline Compressive Strength (concrete mixes) & ASTM C39 \\
\hline Third-Point Flexure Test for Simple Beams & ASTM C78 \\
\hline Compressive Strength (mortar mixes) & ASTM C109 \\
\hline Shrinkage Test & ASTM C157 \\
\hline Static Modulus of Elasticity & ASTM C469 \\
\hline Flexure Test for Fiber-Reinforced Concrete & ASTM C1609 \\
\hline
\end{tabular}

\section{Bond Strength Tests}

Bond strength was of critical importance in this project because of the desired application of the subject materials in closure pours and joints. The secondary goal of this project focuses on the reliability and comparison of various bond strength tests in order to offer some insight into which tests will provide dependable results for bond strength. In choosing which tests to 
compare, both standard and more recently developed non-standard tests were considered. The various tests for bond strength are described in detail in the following sections.

\section{ASTM C1404: Direct-Tension Bond Test}

ASTM C1404 is a bond strength test that measures the bond strength in direct tension. This test is performed on a composite cylindrical specimen of either 4-in or 3-in diameter. The length of the cylinder is at least 4 in long and is composed of a base portion and an overlay portion. A cap is attached to each end of the specimen at least 24 hours before testing. For this experiment, 4-in diameter specimens were used in order to increase the area of the bond surface in hopes of improving the accuracy of the results. Figure 4.4 shows how the specimen is set up for testing. The specimen is always oriented so that the base portion of the specimen is on the bottom.

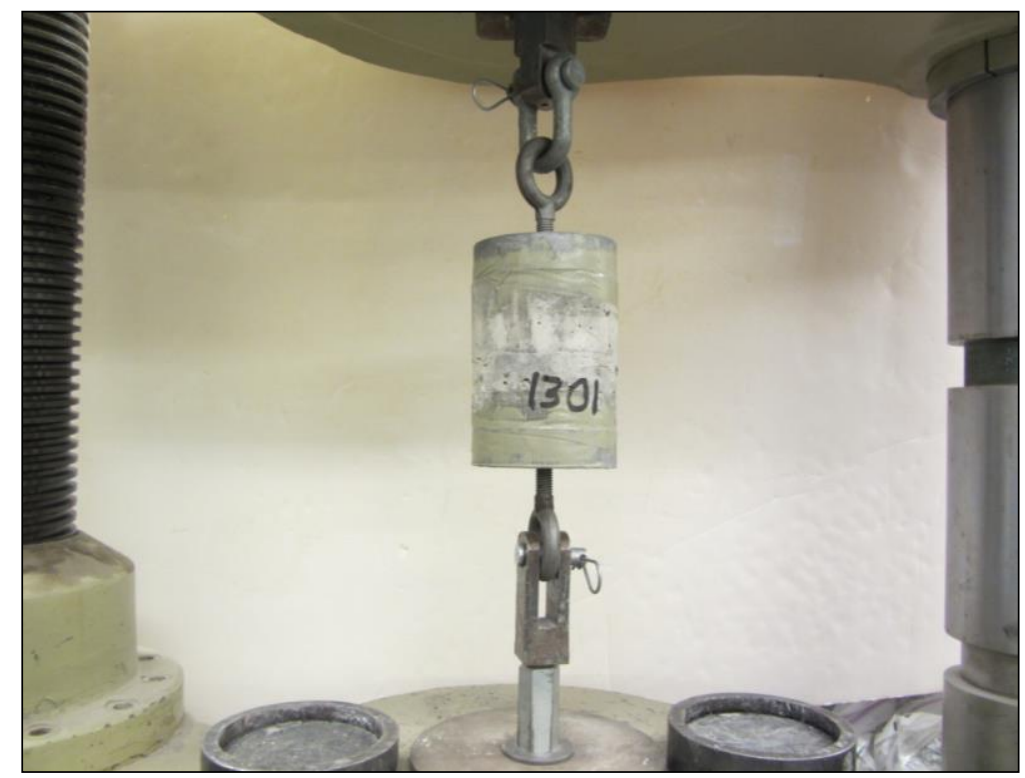

Figure 4.4 ASTM C1404: Direct-Tension Bond Test.

\section{California Test 551}

California Test 551 (hereafter "CA 551") outlines steps to take in determining the suitability of a material for use as an overlay. Part 4 of the test requires that the subject material be tested in accordance with ASTM C78 to determine the flexural strength of the overlay material. Part 5 of the test provides a method for testing the bonding strength of a concrete overlay to portland cement concrete (PCC). This method for testing bond strength requires that a 
3 in $\times 3$ in $\times 11$ in composite specimen be cast with one half containing the base material and the other half containing the overlay or bonded material. The bond interface is located at the middle of the specimen lengthwise, as shown in Figure 4.5. The specimen is placed on a roller and a pinned support 9 in apart as shown in Figure 4.5 with the top of the specimen as it was cast facing the operator. The specimen is then subjected to a center point loading through a loading bar, which is placed directly along the top bond face line. This loading induces a tension force across the bond interface that causes the bond to rupture. This test is one method of obtaining the bond strength of a material when the bond surface experiences direct tension. The modulus of rupture can be calculated as follows:

$$
R=\frac{3 P l}{2 b d^{2}}
$$

where: $\mathrm{R}=$ modulus of rupture, $\mathrm{psi}$

$\mathrm{P}=$ maximum applied load indicated by the testing machine, lbf

$1=$ span length, in.

$\mathrm{b}=$ average width of specimen, at the point of fracture, in.

$\mathrm{d}=$ average depth of specimen, at the point of fracture, in.

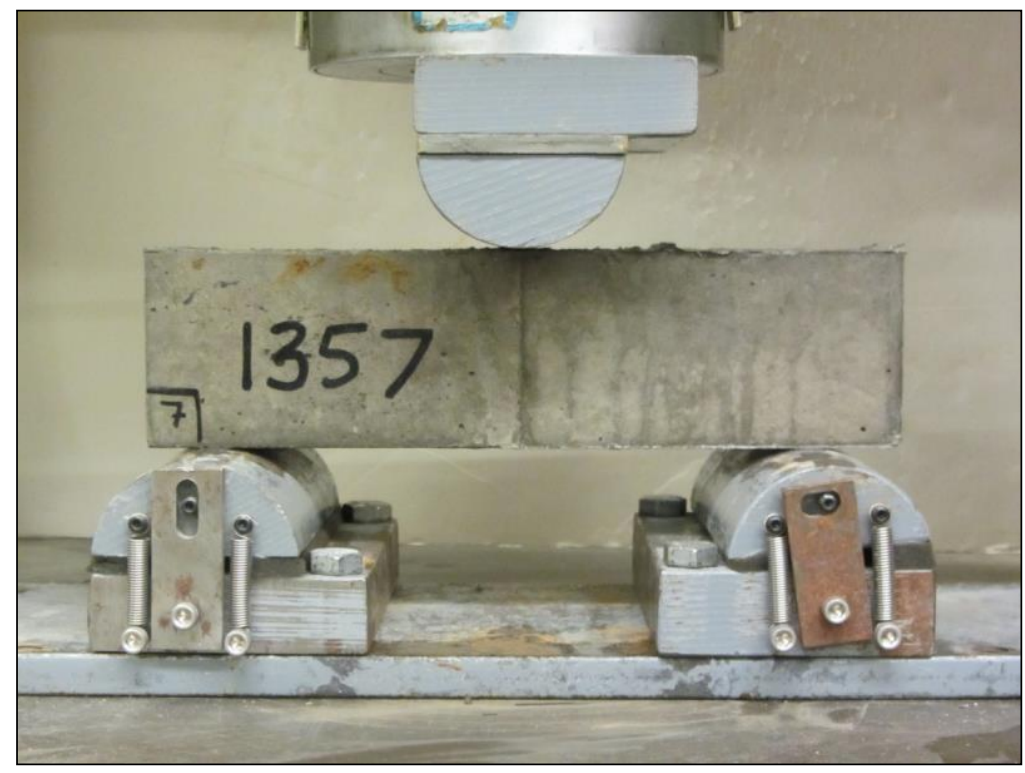

Figure 4.5 CA 551: California Bond Test. 


\section{Guillotine Shear Test}

The Guillotine Shear Test was developed as a method for measuring the shear bond strength of overlays on core samples. The test is also suitable for measuring shear bond strength of cylindrical laboratory specimens up to 4 in in diameter. While the other tensile and flexural bond tests discussed in this paper seek to quantify the tensile bond strength of the material, shear bond strength is an important property to address for materials being used in closure pours and joints in bridges.

The Guillotine Shear Test requires a cylindrically shaped specimen consisting of two different materials (a base material and an overlay or bonded material). The specimen is created by cutting a standard 4 in diameter compression cylinder of base material (A4 bridge deck concrete) into four 2-in-deep cylinder sections. The 2-in-deep cylinder sections are placed back into cylinder molds and the remaining volume is filled with the bonding material, in this case the closure pour material. A typical Guillotine Shear Test specimen is shown in Figure 4.6.

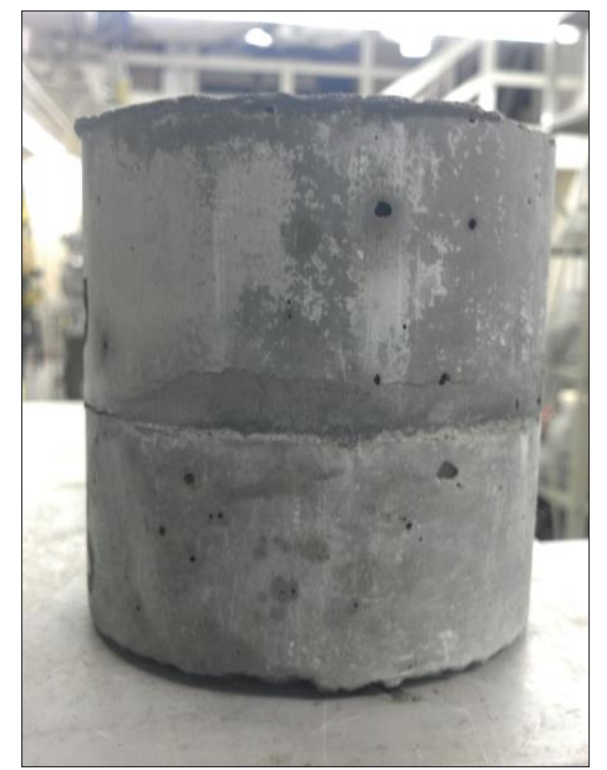

Figure 4.6 Guillotine Shear Test specimen.

The specimen is placed in the frame shown in Figure 4.7 so that the overlay material can be seen on the outside of the frame (Figure 4.8). The bond line must be in plane with the edge of the frame so that the load is applied only at the bond. The insert is placed inside the frame and a load is applied to the top of the insert. Figure 4.9 shows the frame with the specimen and insert 
in place as the specimen is being loaded. The shear bond strength is calculated by dividing the maximum load by the area of the bond interface. The minimum acceptable value for shear bond strength is 200 psi.

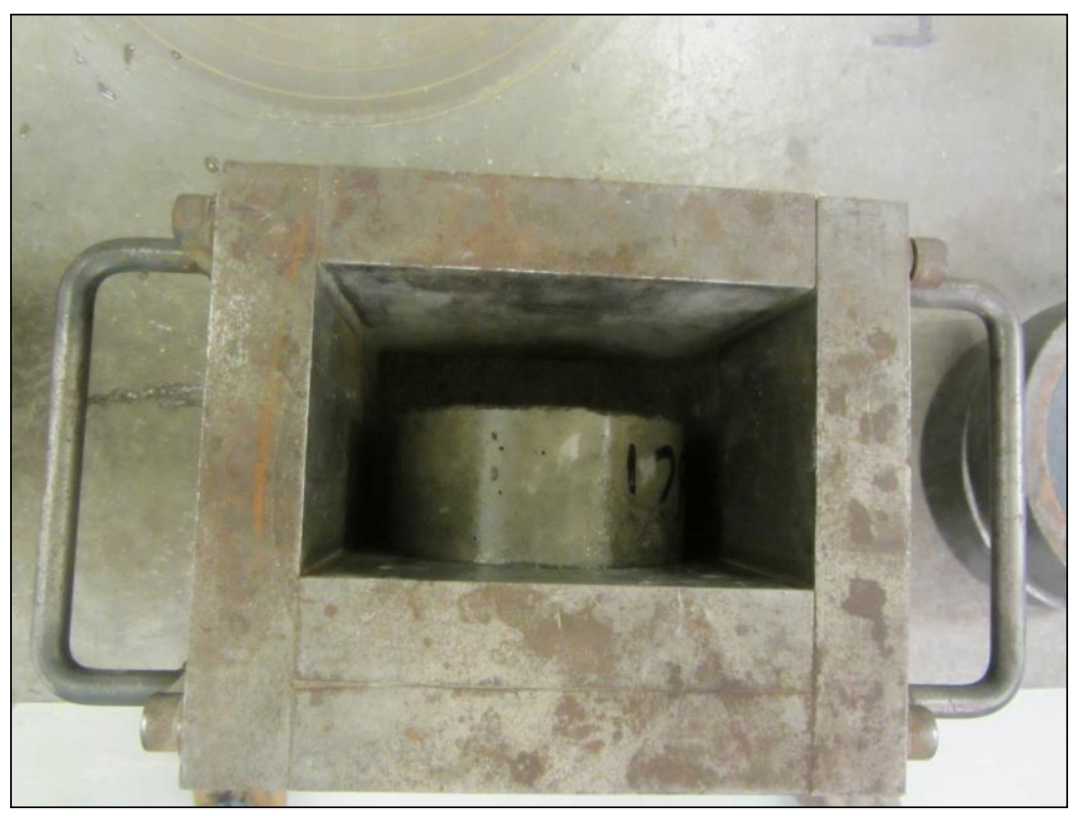

Figure 4.7 Guillotine Shear Test: top view.

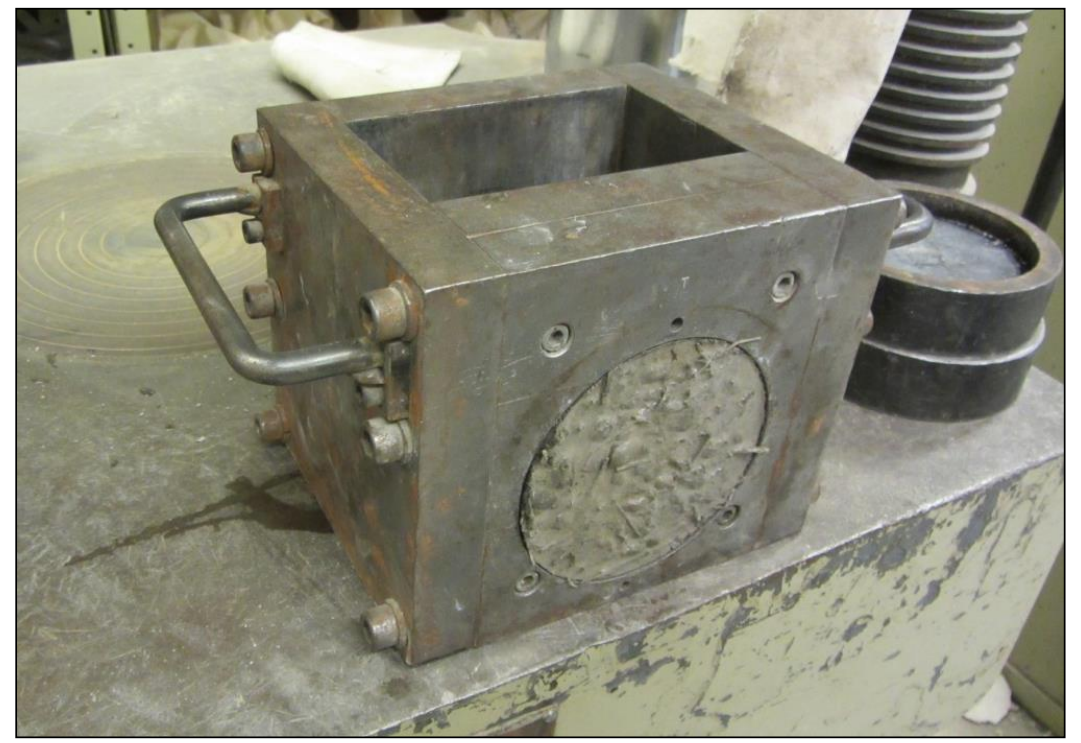

Figure 4.8 Guillotine Shear Test: device setup. 


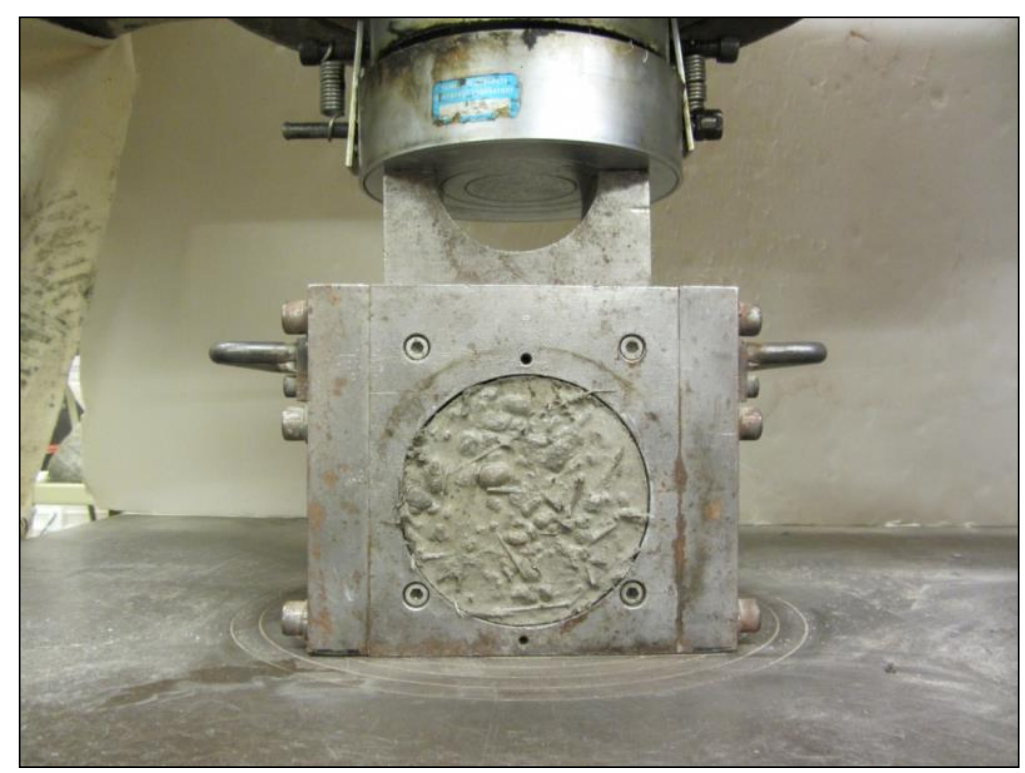

Figure 4.9 Guillotine Shear Test: front view.

\section{Splitting Prism Test}

The Splitting Prism Test is a modification of ASTM C496 splitting tensile test. Instead of using cylindrical specimens consisting of a single material, composite rectangular prism specimens are used (see Figure 4.10). A loading bar is placed along the top surface of the bond interface and loaded, inducing a tensile force resulting from the Poisson effect perpendicular to the bond plane.

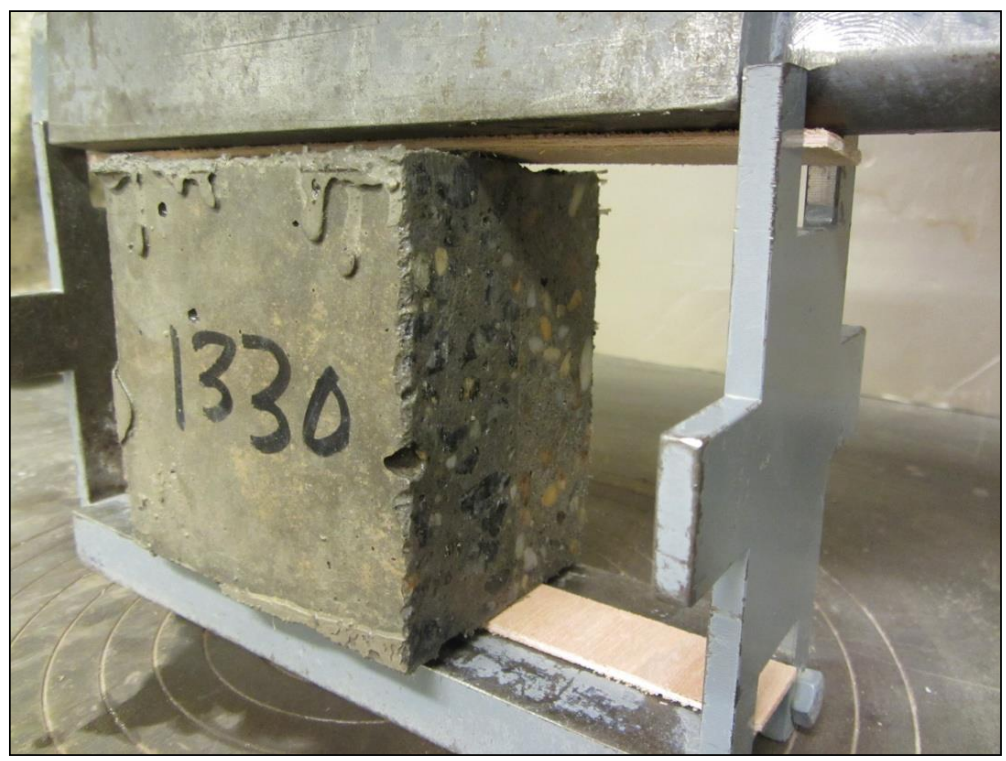

Figure 4.10 Splitting Prism Test: device setup. 
Specimens for this test were created using a 3 in wide $\times 4$ in deep $\times 16$ in long beam mold (typically used for freeze-thaw durability testing of concrete). Half of the mold (lengthwise) was cast with base concrete. The base concrete was removed from the mold, cured for at least 56 days, and placed back into the mold so the closure pour material could be cast against it. The composite specimen was placed in the moisture room for curing. After 7 days of curing, the specimens were removed from the moist room and cut into four segments so that the dimensions of the remaining four composite sections were 3 in wide $\times 4$ in deep $\times 4$ in long (see Figure 4.10 through Figure 4.12).

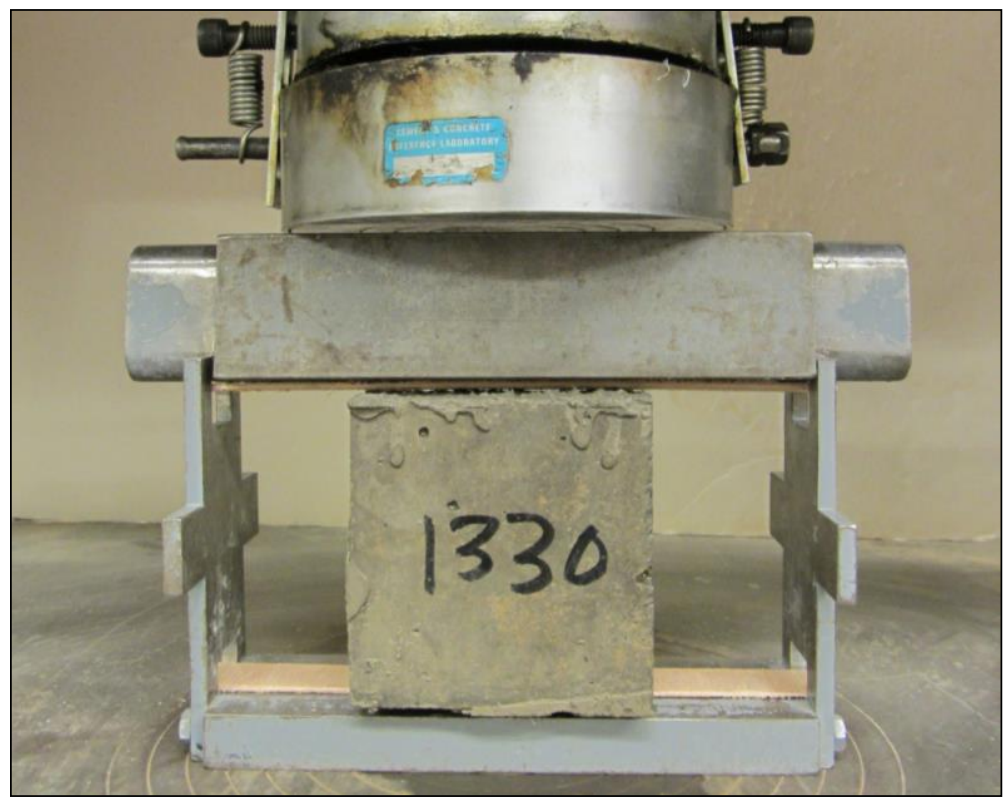

Figure 4.11 Splitting Prism Test: front view.

Figure 4.11 shows how the Splitting Prism Test specimen is placed in the loading device. The wooden slats at the top and bottom of the specimen help distribute the load along the surface, reducing the effects of any irregularities on the surface of the specimen. Figure 4.12 shows a side view of a Splitting Prism Test specimen after being loaded to failure. The material on the left is the base and the material on the right is HyFRC. 


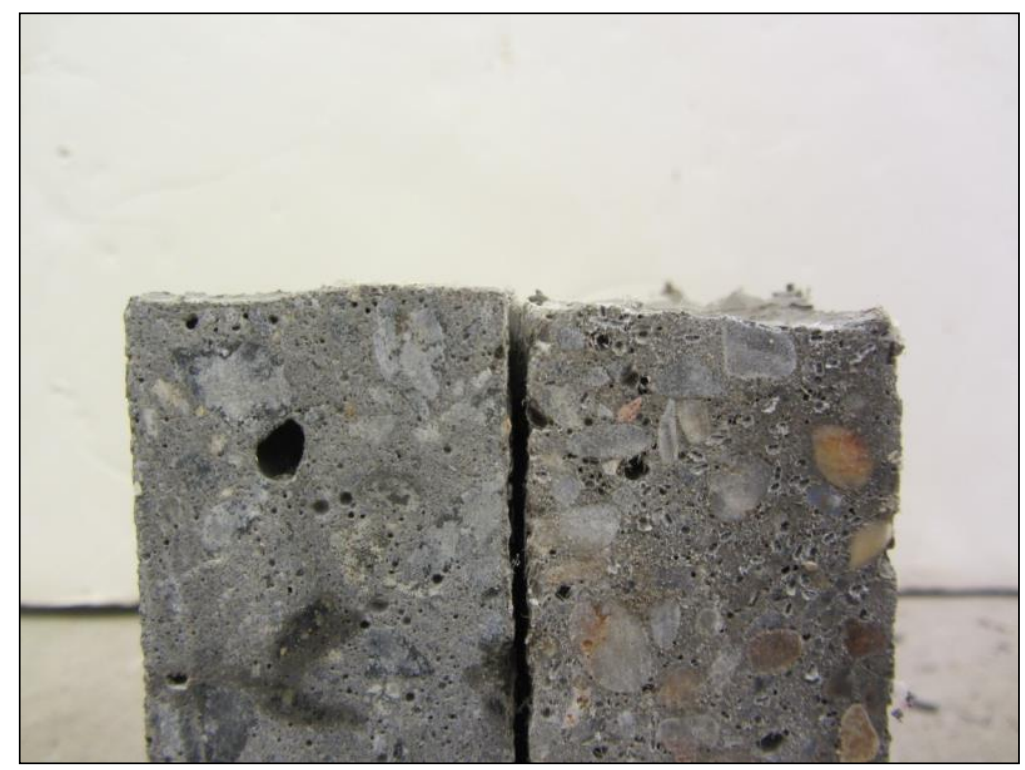

Figure 4.12 Splitting Prism Test: failed specimen.

\section{Base Concrete Preparation for Bond Strength Specimens}

Preparation of the specimens for bond strength tests was kept consistent for all mixes and was intended to simulate field conditions for closure pour and joint placement. Specimens were kept in the moisture room for at least 56 days after casting. The day before placement of the closure pour material, the surface of each A4 specimen intended to serve as a bond surface was cut (if necessary) and sandblasted. Bond surfaces were SSD upon placement of the closure pour material.

\section{$\underline{\text { Base Material }}$}

Base concrete representing a typical bridge deck surface for creating bond specimens was mixed and cured before closure pour materials could be cast. A standard VDOT A4 Post \& Rail mix with $20 \%$ class $\mathrm{F}$ fly ash and a $0.45 \mathrm{w} / \mathrm{cm}$ ratio was selected. This mix met VDOT workability and strength standards for fresh and hardened concrete used in bridge decks. Three identical batches were mixed to provide enough material to create the necessary bond strength specimens and compressive strength cylinders. The bond strength specimens created from these three batches were randomly assigned to each of the large batches of closure pour material. The compressive strength after 28 days of curing was tested to ensure that the mix would achieve the desired strengths. 


\section{$\underline{\text { Engineered Cementitious Composite }}$}

All of the ingredients for the large ECC batches mirrored those that were used for the preliminary test batch except for the type of fine aggregate. To eliminate the need to sieve the sand before mixing to obtain small particles, a naturally fine sand type was used. This sand type, Puddledock concrete sand, is typically found in Petersburg, VA and has a fineness modulus of 3.0. Previous research concluded that sand type has little or no effect on the strength of engineered cementitious composites. (Ozyildirim and Vieira 2008) The ECC mixes in that study utilized various different sand types but displayed very similar deflection hardening behavior and achieved comparable strengths.

Creating small trial batches of ECC did not pose any issues while mixing or casting of specimens. However, materials can behave very differently when mixed in large quantities at a slower rate. Large amounts of small, hydrophilic PVA fibers can drastically reduce the amount of water available to react with the cement in the mix, and it can be difficult to ensure an even distribution of fibers throughout the matrix. This may cause problems when it is necessary to mix ECC in a cement truck for large ECC placements.

To achieve the proper viscosity in each mix before the addition of fibers, the amount of water was split into two components as seen in the mix design in Table 4.6.

Table 4.6 ECC large laboratory batch mix design.

\begin{tabular}{|l|c|}
\hline \multicolumn{1}{|c|}{ Mix Component } & Batch Weight (lb/yd ${ }^{\mathbf{3}}$ ) \\
\hline Water: Part 1 & 570 \\
\hline Water: Part 2 & 86 \\
\hline Cement & 961 \\
\hline Fly Ash (Class F) & 1153 \\
\hline Sand (Puddledock) & 767 \\
\hline RECS15 PVA Fibers & $44(2.0 \%$ by volume) \\
\hline ADVAcast 575 Superplasticizer & 5.4 oz/cwt \\
\hline w/cm ratio & 0.31 \\
\hline
\end{tabular}

The mixing program for the two large batches of ECC was carried out as follows:

1. Part 1 of the water (with water-to-powder ratio of 0.27 ) was mixed with solid materials for approximately 2 minutes so that a dough-like consistency was reached.

2. Fibers were then added and mixed for 4-8 minutes.

3. The remaining water was added and mixed for another 4-6 minutes. 
The two batches were identical except for the timing of the addition of superplasticizer. For the first batch, the superplasticizer was added and mixed in step 1 of the mixing sequence outlined above; superplasticizer was added to the second batch in step 3. For each mix, three 2-in compression cubes and two 4-in diameter compression cylinders were tested at both 7 days after casting and 28 days after casting. Each batch of ECC included six 4 in $\times 4$ in $\times 14$ in beams, three of which were tested after 7 days of curing and 3 of which were tested after 28 days of curing for flexural performance. The stresses at the center point of each beam were calculated based upon third-point loading and deflections were measured by linear variable displacement transducers (LVDTs) per ASTM C1404. The stress at first crack and peak stress values were recorded for each beam. The four bond strength tests previously mentioned were performed for each batch.

\section{HyFRC (Synthetic and Steel): HyFRC-A}

Small trial batches of hybrid fiber-reinforced concrete containing both synthetic and steel fibers were unnecessary because a successful mix design had already been developed in California, as previously mentioned (Blunt and Ostertag 2009). The challenge for this project was creating these mixes using materials local to Virginia. A mix was designed using a combination of RECS15 PVA fibers along with Dramix 30mm- and 60mm-long steel fibers. The volumes of fibers can be seen in Table 4.7. This mix will be referred to as "HyFRC-A" throughout the remainder of this paper.

Table 4.7 HyFRC-A large laboratory batch mix design.

\begin{tabular}{|l|c|}
\hline \multicolumn{1}{|c|}{ Mix Component } & Batch Weight $\left(\mathbf{l b} / \mathbf{y d} \mathbf{~}^{\mathbf{3}}\right)$ \\
\hline Water & 289 \\
\hline Cement & 508 \\
\hline Fly Ash (Class F) & 127 \\
\hline FA: Sand (Aylett) & 1587 \\
\hline CA: 3/8-in Pea Gravel & 1223 \\
\hline RECS15 PVA Fibers & $4.4(0.20 \%$ by volume $)$ \\
\hline Dramix ZP305 Steel Fibers (30 mm) & $66.1(0.50 \%$ by volume $)$ \\
\hline Dramix RC80/60BN Steel Fibers $(60 \mathrm{~mm})$ & $105.8(0.80 \%$ by volume $)$ \\
\hline w/cm ratio & 0.45 \\
\hline
\end{tabular}

The HyFRC-A mixes followed a test regimen similar to that of the ECC mixes. Because HyFRC is a concrete mix and not a mortar mix, some of the tests required different specimen sizes or different ASTM test procedures to quantify the same material characteristics. The 
various ASTM test procedures are outlined in Table 4.4 and Table 4.5. Per ASTM C39, 4 in diameter, 8 in long compression cylinders were used for both HyFRC mixes to find the compressive strength of the mix. The strength after 7 days of curing was assumed to exceed 4,000 psi because a standard A4 mix design was used. The compressive strength was tested after 28 days of curing for comparison to the other mixes. ASTM C1609 requires 6 in $\times 6$ in $\times 20$ in specimens for concrete mixes because of the larger particle size. Larger specimens are also ideal

when long fibers are used in a mix because the large volume facilitates the random orientation of the fibers in the specimen. The number of specimens per batch was limited due to the increase in specimen size, so flexural capacity was only tested at 28 days.

The mixing process for HyFRC-A with synthetic and steel fibers was very similar to a concrete mix because it contains all of the typical components of concrete but with small adjustments to account for the effects of fibers on workability and air content. Generally fibers will decrease the workability of the mix and tend to ball together during the early stages of mixing. For the two large batches, all of the components excluding fibers were mixed for 1 to 2 minutes before the addition of fibers. The fibers were lightly sprinkled into the mix from the top of the mixer. Small amounts of water reducing admixture were added to the mix to improve workability.

\section{HyFRC (Synthetic Only): HyFRC-G}

The testing sequence for HyFRC-G followed that of HyFRC-A. The number of specimens was also limited for this mix because of the size requirements for some of the specimens. A mix was chosen from the multiple trial batches containing only synthetic fibers based on the deflection hardening capabilities of the various mixes. The mix that provided the most consistent deflection hardening behavior and contained micro-fibers to improve the durability of the matrix was HyFRC-G. Three different sizes of synthetic fibers are utilized in the HyFRC-G mix: 8-mm-long NYCON-PVA RECS15 micro-fibers, 30-mm-long NYCON-PVA RF4000 macro-fibers, and 50-mm-long STRUX BT50 polypropylene macro-fibers. The mix was reproduced in the large pan mixer in the laboratory using the mix design in Table 4.8. 
Table 4.8 HyFRC-G large laboratory batch mix design.

\begin{tabular}{|l|c|}
\hline \multicolumn{1}{|c|}{ Mix Component } & Batch Weight (lb/yd $\left.\mathbf{3}^{\mathbf{3}}\right)$ \\
\hline Water & 315 \\
\hline Cement & 490 \\
\hline Fly Ash & 210 \\
\hline Aylett Sand & 1176 \\
\hline 3/8 in Pea Gravel & 1454 \\
\hline RECS15 PVA Micro-fibers & $7.3(0.33 \%$ by volume $)$ \\
\hline Nycon RF4000 PVA Macro-fibers & $11.0(0.50 \%$ by volume $)$ \\
\hline STRUX BT50 Fibers & $17.9(1.17 \%$ by volume $)$ \\
\hline w/cm & 0.45 \\
\hline
\end{tabular}

\section{$\underline{\text { UHPC }}$}

The test regimen for UHPC followed that of the large ECC batches, excluding compression tests. Although UHPC is considered a mortar mix due to the absence of coarse aggregates, 4 in diameter compression cylinders were specified for testing the compressive strength of the mixes. The larger specimens allow for the desired random orientation of the steel fibers in the mix, more accurately representing the compressive strength of the mix as it would function in the field in a large closure pour. To ensure that accurate measurements are being taken, it is required that the ends of the cylinders be grinded to be exactly perpendicular to the sides of the specimen so that the specimen is centrically loaded. A total of seven beams were tested per ASTM C1609. Three beams were tested after 7 days of curing and the remaining four beams were tested after 28 days of curing. No thin ( 1 in-thick) beams were tested because UHPC has already been used in the field and proven to exhibit tight cracks. 


\section{RESULTS}

\section{A4 Bridge Deck Concrete}

The slump for the base mix was 3.5 in and the air content was 5.5\%. The average density was measured at $144 \mathrm{lb} / \mathrm{ft}^{3}$. The average 28 -day average for both base mixes is shown in Table 5.1. Tests on the composite specimens were conducted after 7 days and 28 days of curing.

Table 5.1 Base mix 28-day compressive strengths.

\begin{tabular}{|c|c|}
\hline Overlay Mixes & Average (psi) \\
\hline ECC and HyFRC-A & 4,740 \\
\hline UHPC and HyFRC-G & 5,240 \\
\hline
\end{tabular}

Both base mixes exceeded the 4,000 psi minimum compressive strength requirement and met typical slump and air content requirements for a standard A4 Post \& Rail mix as specified by VDOT. (Virginia Department of Transportation 2007)

\section{Preliminary Laboratory Batches}

\section{Strength and Strain Hardening}

As previously mentioned, strain hardening is the criteria being used in the project to determine the ability of a mix to develop and maintain tight cracks up to first cracking of the material. Strain hardening is commonly observed in these materials when a specimen is placed in flexure (deflection hardening). On a plot of load versus deflection, this means that the load first increases somewhat linearly with increasing deflection. Once the material begins to undergo permanent deformations, the load either increases immediately (as seen in some mixes containing steel fibers) or decreases slightly (deflection softening) before increasing beyond the load at first cracking. Deflection softening is generally displayed in mixes containing synthetic fibers. For illustration, Figure 5.1 shows typical deflection hardening and softening behavior for a hybrid mix containing only synthetic fibers. 


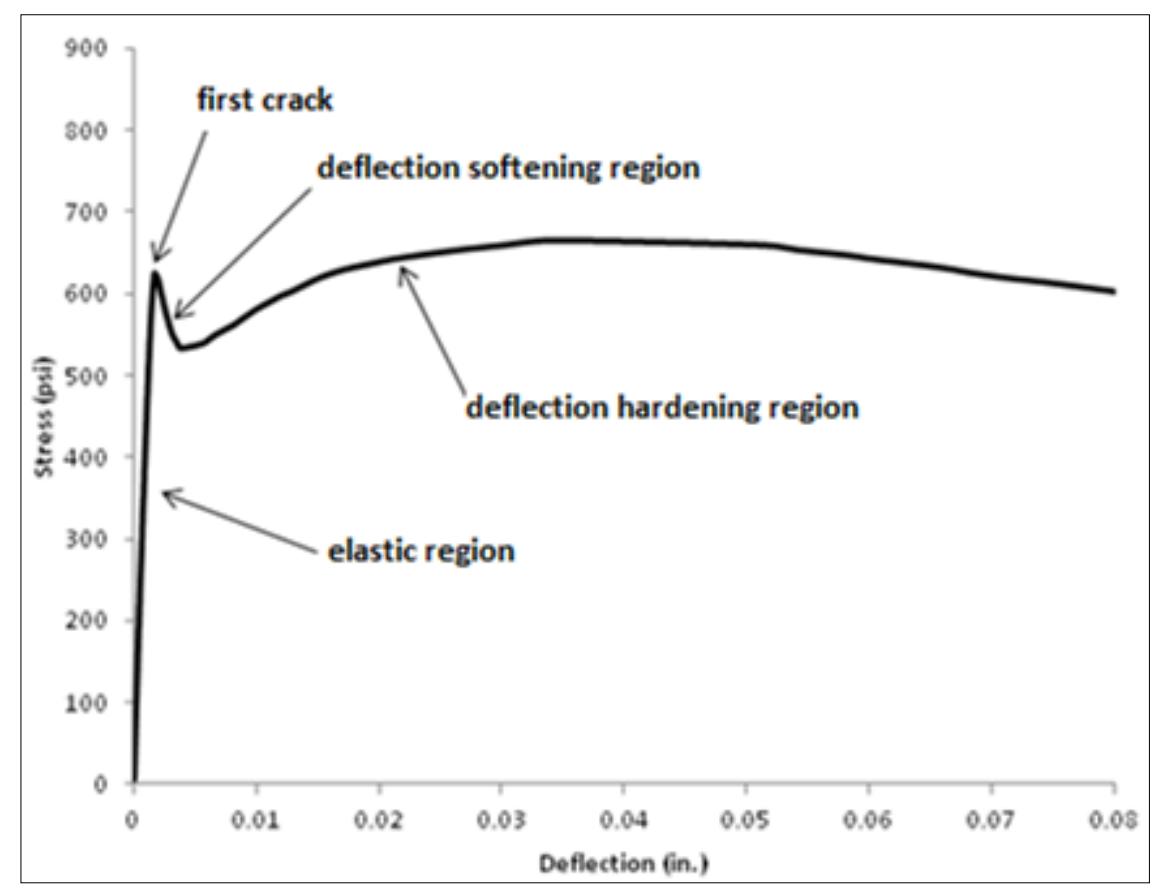

Figure 5.1 Typical deflection hardening and softening behavior.

\section{Engineered Cementitious Composite}

During mixing of ECC, the mini slump cone flow test diameter was measured to be 11 in before the addition of fibers. PVA fibers were added to the mix and the slump flow was taken again, this time yielding a diameter of $5 \frac{1 / 4}{\mathrm{in}}$. The air content was measured to be $9.9 \%$ and the density was $138 \mathrm{lb} / \mathrm{ft}^{3}$. The PVA fibers were found to be clumping together in the mix and had to be pulled apart by hand before placing the ECC in the molds. This was most likely due to the addition of all of the fibers at once because of the mixing screen on the mixer. This issue was avoided for the final mix because a large pan-type mixer was used and fibers were "sprinkled" into the mix during mixing. The consistency of the mix was also adjusted for the large batches to solve this problem.

Multiple tight cracks were observed in the thin beams that were tested for both preliminary batches of ECC. Compressive and flexural strengths are shown in Table 5.2. 
Table 5.2 Compressive and flexural strength of ECC preliminary batches.

\begin{tabular}{|c|c|c|c|}
\hline & $\begin{array}{c}\text { Specimen Age } \\
\text { (days) }\end{array}$ & Batch 1 & Batch 2 \\
\hline Compressive & 7 & 5,265 & 4,050 \\
\cline { 2 - 4 } Strength (psi) & 28 & 8,550 & 6,700 \\
\hline Flexural & 7 & 1,320 & 880 \\
\cline { 2 - 4 } Strength (psi) & 28 & 790 & 1,200 \\
\hline
\end{tabular}

The $1 / 2$-in-thick beam was loaded with the machine at a very low loading rate when tested in third-point loading configuration. For the first batch, the strength was affected by the formation of one crack that was larger than the others. Because the failure surface is so small for this specimen, the slightest discontinuity in the fiber cement matrix could cause premature failure. This is most likely the cause for the low flexural strength achieved at 28 days. Beams that were 1-in thick exhibited deflection hardening.

\section{$\underline{\text { HyFRC-A }}$}

Preliminary laboratory batches were not tested for HyFRC-A because the previously developed mix designs very closely resembled typical concrete mixtures.

\section{$\underline{\text { HyFRC-G }}$}

The preliminary laboratory batch for HyFRC-G was tested for fresh material properties as well as compressive strength and deflection hardening behavior under third-point loading. The inverted slump cone test yielded 7.5 seconds and the air content for the mixture was $4.0 \%$. To test hardened properties, three 4 in cylinder specimens were tested in compression and three 4 in $\times 4$ in $\times 14$ in beams were tested per ASTM C1609. Compressive strength at 7 days after casting was 2,900 psi, which is below the 3,000 psi expected for typical A4 concrete at 7 days. However, the compressive strength 28 days after casting was 4,080 psi. This value meets the 4,000 psi requirement for typical A4 concrete. The results of the three beam specimens are shown in Figure 5.2 and Figure 5.3. 


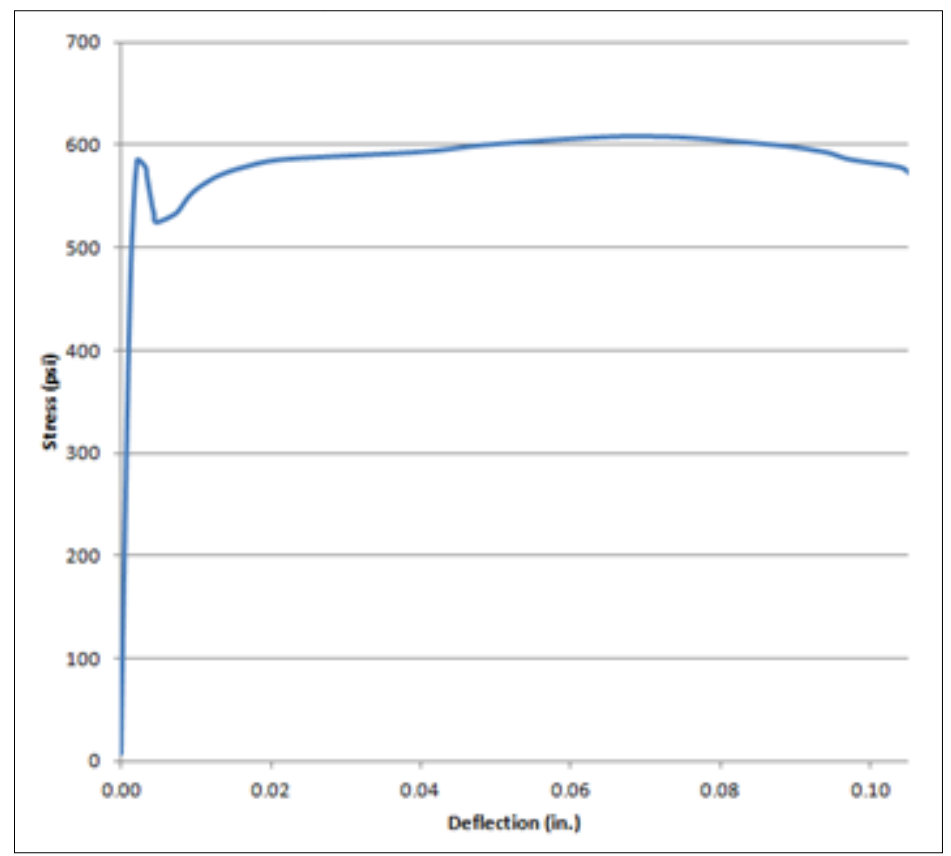

Figure 5.2 HyFRC-G preliminary batch 7-day flexure results.

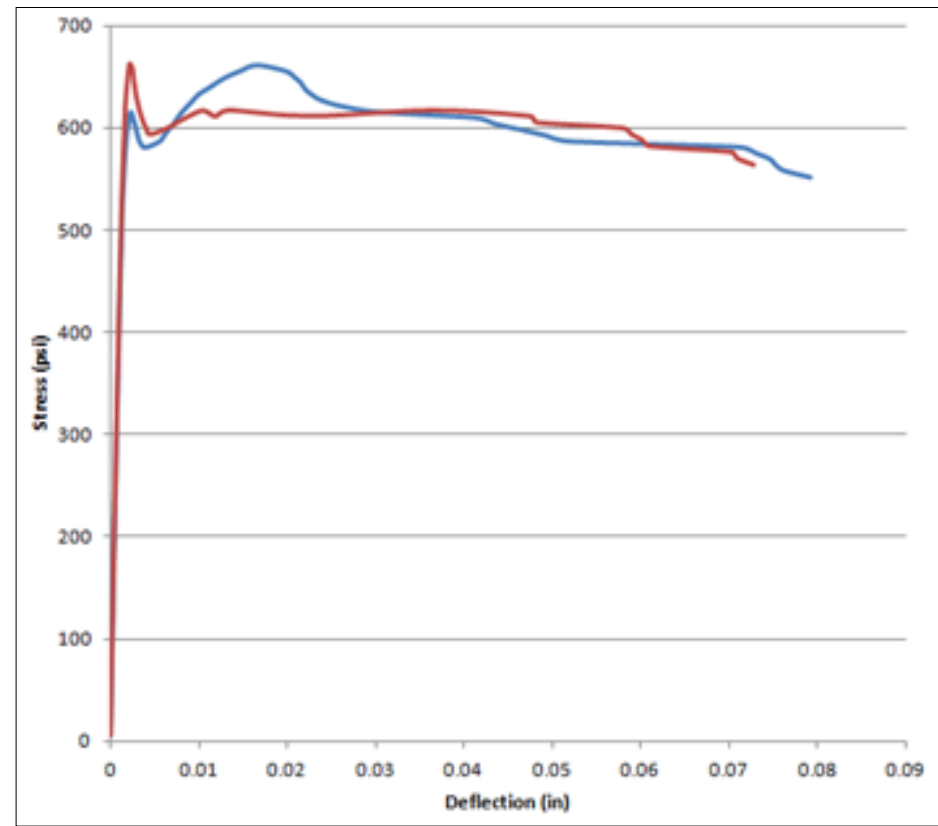

Figure 5.3 HyFRC-G preliminary batch 28-day flexure results.

The flexure results clearly display the ability of the mixture to achieve deflection hardening at 7 days, but the results at 28 days vary. One specimen increases in stress following a period of softening. The other specimen never quite increases in stress after this period of softening directly following first cracking of the specimen. However, the average performance of 
the specimens tested at 28 days indicated deflection hardening behavior. Other preliminary HyFRC batches which displayed deflection hardening either required the use of more expensive fibers or proved very difficult to mix because of the fiber combinations being used.

\section{$\underline{\text { UHPC }}$}

The preliminary test batch for UHPC was also tested for compressive strength and deflection hardening capability. Fresh properties were not measured for this mixture because it is a premix. The average compressive strengths were 16,055 psi and 22,480 psi for 7 and 28 day strengths, respectively. The flexural results 7 days after casting are shown in Figure 5.4.

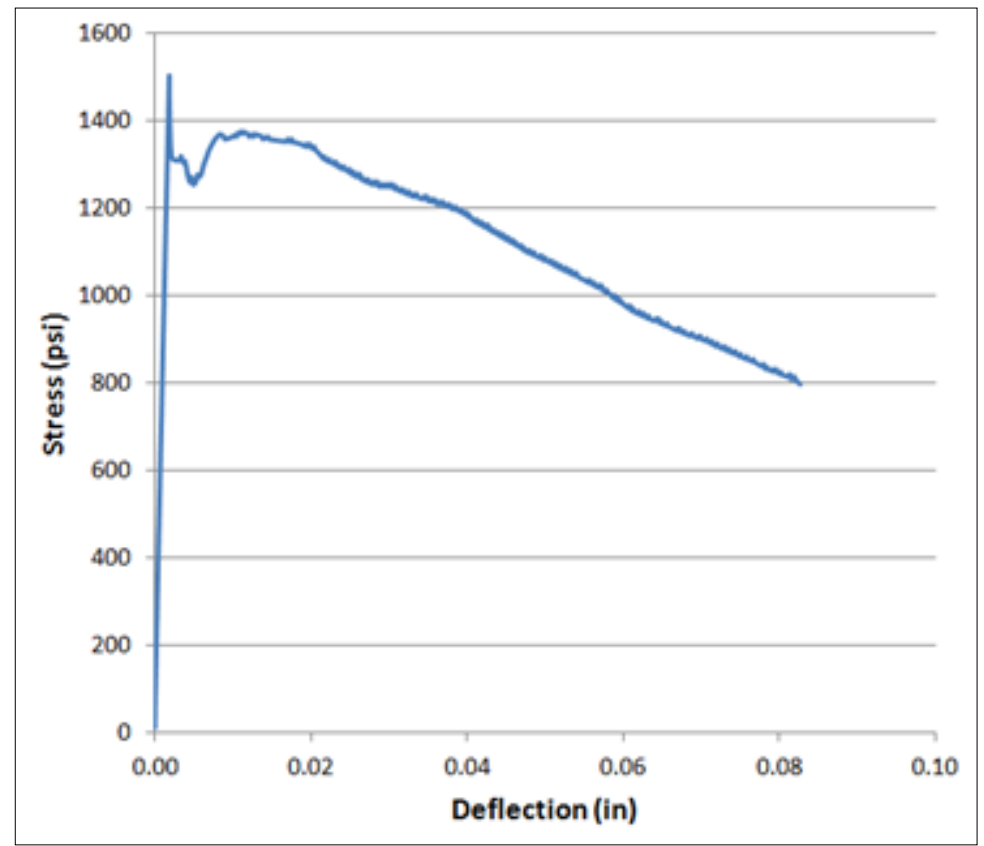

Figure 5.4 UHPC preliminary batch 7-day flexure results.

The preliminary laboratory batch specimens exhibited very high strengths at 7 and 28 days but the mixture failed to achieve desired deflection hardening behavior. Although UHPC did not achieve desired deflection hardening, large laboratory batches of UHPC were still created for comparing bond strength results with the performance of the other systems.

\section{Large Laboratory Batches}

\section{$\underline{\text { Engineered Cementitious Composite }}$}

Two final laboratory batches of ECC were mixed. The first batch experienced balling before the addition of fibers, but still achieved the expected slump flow. The mini slump flow 
test was performed before the addition of fibers using a miniature brass slump cone as used in ASTM C230. The cone was placed on a flat surface and filled with ECC. The cone was then lifted from the surface and the ECC was allowed to flow outwards on the flat surface, forming a circular shape. The diameter of the circle for the first batch was measured to be $57 / 8$-in after the addition of fibers. This value was consistent with the mini slump flow values measured for the preliminary ECC batches. The second batch achieved a similar slump flow and experienced less balling before the addition of fibers. The absence of balling, which indicates a more consistent mix, caused better fiber dispersion. Both batches were found to be workable and easily placed in the molds. The air content was 3.0\% and 3.6\% for the first and second batches, respectively, and the average density for both batches was $120 \mathrm{lb} / \mathrm{ft}^{3}$.

The two large laboratory batches of ECC were tested for deflection hardening and compressive strength. Beams measuring 4 in $\times 4$ in $\times 14$ in and 2 in compression mortar cubes were used. Compressive strengths measured with 2 in compression cubes indicated adequate 28-day compressive strengths of 6,920 psi for the first batch and 7,865 psi for the second batch. The results at 7 days indicate high deflection hardening capability for both batches. The 7-day results for the second batch are more consistent than those for the first batch.

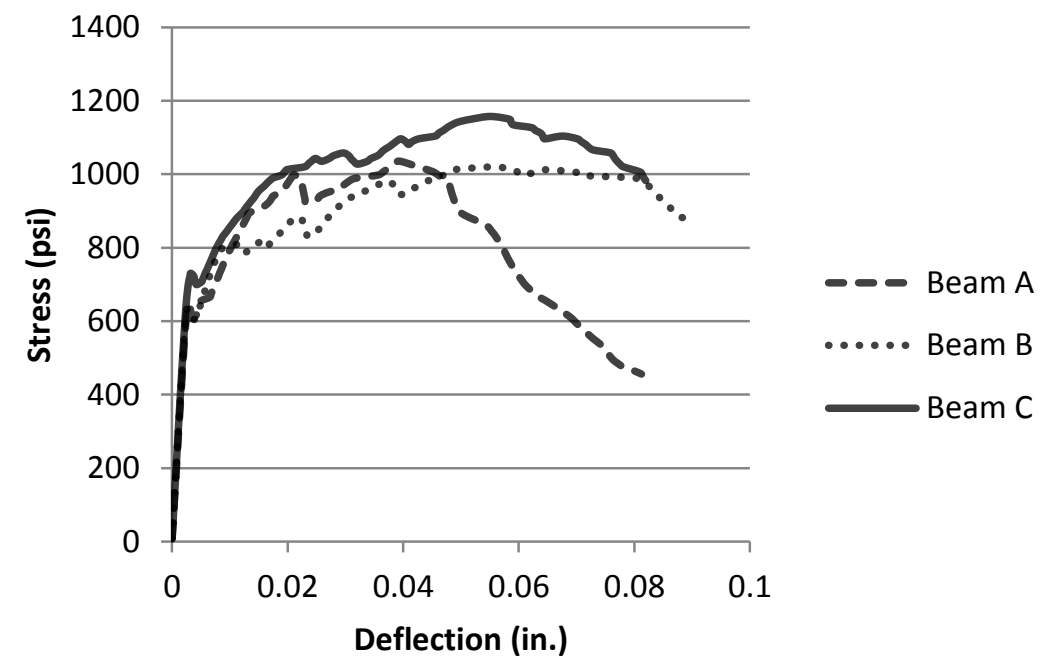

Figure 5.5 ECC batch 17-day flexural performance. 


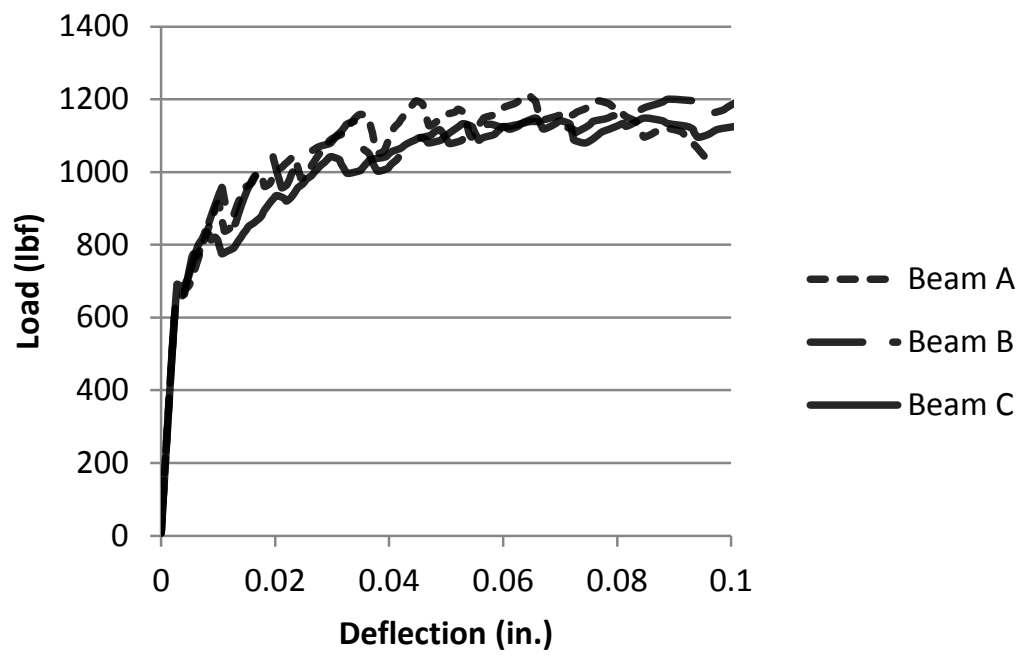

Figure 5.6 ECC batch 1 7-day flexural performance.

The results at 28 days also indicate the presence of deflection hardening but the second batch shows greater variability of results at 28 days than at 7 days. Both batches included two beams which experienced a rapid decrease in stress after reaching a specific deflection. For the first batch this deflection is approximately 0.06 in, and for the second batch this value is approximately 0.04 in. Flexural performance at 28 days is shown in Figure 5.7 and Figure 5.8.

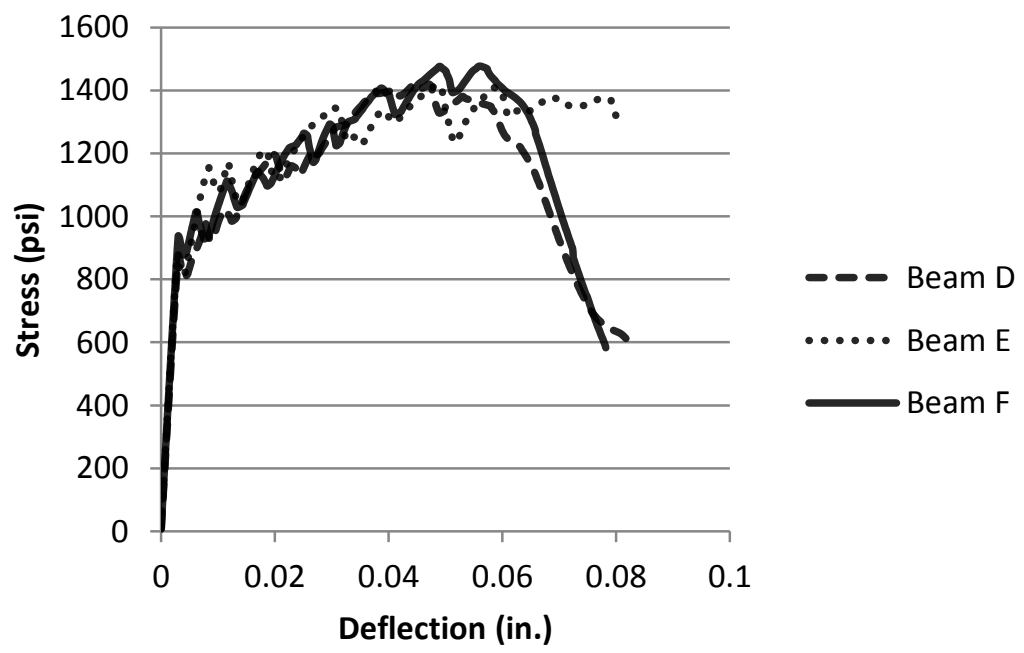

Figure 5.7 ECC batch 1 28-day flexural performance. 


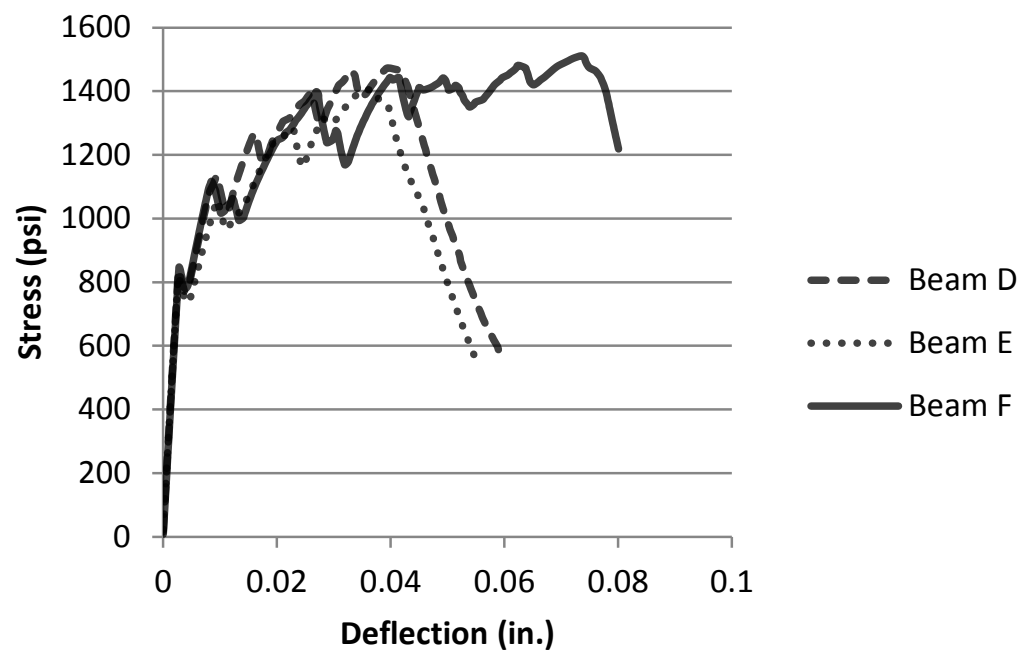

Figure 5.8 ECC batch 2 28-day flexural performance.

The average flexural toughness was determined to be $340 \mathrm{lb}$-in for the first batch and 330 lb-in for the second batch. While the load-deflection behavior and deflection hardening capacity appear to differ somewhat, flexural toughness of the two batches indicates similarity in the amount of energy required to fail the specimens in flexure. Thus the differences between the two batches of ECC may have a negligible effect on ability to control crack size.

Direct-Tension Bond Test results provide detailed information about the location of the failure of the specimen in tension. Values resulting from failure in the epoxy were excluded from the average strength calculation. For the bond test results, the portion of the specimen containing the closure pour material is referred to as the overlay. Based on the results for this test (seen in Table 5.3) all failures at 7 days were located across the bond interface. The strength values for these tests provide a more accurate indication of bond strength than those that occur only in one material. Many of the 7 day test results indicate that more of the failure surface area occurred in the base and bond than in the closure pour material. This could be due to either the high tensile strain capacity of the closure pour material or an uneven strain distribution in the specimen. There was a high occurrence of failures in the closure pour material for composite specimens tested at 28 days for both batches. This could be why lower strengths were achieved at 28 days than at 7 days. 
Table 5.3 ECC Direct-Tension Bond Test data.

\begin{tabular}{|c|c|c|c|c|c|c|c|}
\hline \multirow[b]{2}{*}{ Batch } & \multirow{2}{*}{$\begin{array}{l}\text { Age of } \\
\text { Specimen } \\
\text { (days) }\end{array}$} & \multirow{2}{*}{$\begin{array}{l}\text { Strength } \\
\text { (psi) }\end{array}$} & \multirow{2}{*}{$\begin{array}{c}\text { Average } \\
\text { Strength } \\
\text { (psi) }\end{array}$} & \multicolumn{4}{|c|}{ Failure Area (\%) } \\
\hline & & & & Overlay & Bond & Base & Epoxy \\
\hline 1 & 7 & 325 & \multirow{3}{*}{340} & 45 & 25 & 30 & 0 \\
\hline 1 & 7 & 380 & & 5 & 15 & 80 & 0 \\
\hline 1 & 7 & 315 & & 0 & 20 & 80 & 0 \\
\hline 2 & 7 & 325 & \multirow{3}{*}{310} & 5 & 30 & 65 & 0 \\
\hline 2 & 7 & 325 & & 0 & 45 & 55 & 0 \\
\hline 2 & 7 & 280 & & 0 & 55 & 45 & 0 \\
\hline 1 & 28 & 290 & \multirow{3}{*}{285} & 5 & 5 & 90 & 0 \\
\hline 1 & 28 & 300 & & 100 & 0 & 0 & 0 \\
\hline 1 & 28 & 265 & & 100 & 0 & 0 & 0 \\
\hline 2 & 28 & 380 & \multirow{3}{*}{295} & 0 & 5 & 95 & 0 \\
\hline 2 & 28 & 215 & & 100 & 0 & 0 & 0 \\
\hline 2 & 28 & 285 & & 5 & 40 & 55 & 0 \\
\hline
\end{tabular}

The results of California Bond Test 551 are shown in Table 5.4. Both batches exhibit higher bond strengths at 28 days than at 7 days as expected, and the results show very little variation. Thus, California Bond Test 551 appears to be an appropriate means of measuring bond strength for ECC.

Table 5.4 ECC California Test 551 results.

\begin{tabular}{|c|c|c|c|}
\hline Batch & $\begin{array}{c}\text { Age of } \\
\text { Specimen (days) }\end{array}$ & $\begin{array}{c}\text { Bond } \\
\text { Strength (psi) }\end{array}$ & $\begin{array}{c}\text { Avg. Bond } \\
\text { Strength (psi) }\end{array}$ \\
\hline 1 & 7 & 580 & \multirow{2}{*}{590} \\
\hline 1 & 7 & 595 & \\
\hline 1 & 28 & 810 & \multirow{2}{*}{825} \\
\hline 1 & 28 & 840 & \multirow{2}{*}{625} \\
\hline 2 & 7 & 600 & \\
\hline 2 & 7 & 650 & \multirow{2}{*}{755} \\
\hline 2 & 28 & 785 & \\
\hline 2 & 28 & 720 & \\
\hline
\end{tabular}

Results for the Splitting Prism Test are shown in Table 5.5. Higher variability of bond strengths was apparent in the first batch, but further testing would need to be completed in order to determine a difference in variability between the batches with confidence. Bond strengths for both ECC batches were fairly high and exceeded minimum bond strengths specified for overlay materials. However, high shrinkage of ECC may increase the bond strengths required for adequate performance as a joint closure in the field. 
Table 5.5 ECC Splitting Prism Test results.

\begin{tabular}{|c|c|c|c|}
\hline Batch & $\begin{array}{c}\text { Age of } \\
\text { Specimen (days) }\end{array}$ & $\begin{array}{c}\text { Bond Strength } \\
\text { (psi) }\end{array}$ & $\begin{array}{l}\text { Avg. Bond } \\
\text { Strength (psi) }\end{array}$ \\
\hline 1 & 7 & 685 & \multirow{4}{*}{800} \\
\hline 1 & 7 & 845 & \\
\hline 1 & 7 & 895 & \\
\hline 1 & 7 & 770 & \\
\hline 1 & 28 & 1,015 & \multirow{4}{*}{935} \\
\hline 1 & 28 & 840 & \\
\hline 1 & 28 & 955 & \\
\hline 1 & 28 & 925 & \\
\hline 2 & 7 & 760 & \multirow{4}{*}{800} \\
\hline 2 & 7 & 855 & \\
\hline 2 & 7 & 770 & \\
\hline 2 & 7 & 820 & \\
\hline 2 & 28 & 1,195 & \multirow{4}{*}{1,100} \\
\hline 2 & 28 & 1,020 & \\
\hline 2 & 28 & 1,120 & \\
\hline 2 & 28 & 1,055 & \\
\hline
\end{tabular}

Guillotine Shear Test results for ECC indicate higher average bond strengths at 28 days than at 7 days. Difference in bond strengths between batches was greater at 7 days than at 28 days, indicating a significant increase in shear bond strength for the first batch from 7 days to 28 days. The second batch achieved higher bond strengths than the first batch both at 7 days and 28 days.

Table 5.6 ECC Guillotine Shear Test results.

\begin{tabular}{|c|c|c|c|}
\hline Batch & $\begin{array}{c}\text { Age of } \\
\text { Specimen (days) }\end{array}$ & $\begin{array}{c}\text { Bond } \\
\text { Strength (psi) }\end{array}$ & $\begin{array}{c}\text { Avg. Bond } \\
\text { Strength (psi) }\end{array}$ \\
\hline 1 & 7 & 675 & \multirow{3}{*}{560} \\
\hline 1 & 7 & 520 & \\
\hline 1 & 7 & 480 & \\
\hline 1 & 28 & 1,025 & \multirow{4}{*}{990} \\
\hline 1 & 28 & 910 & \\
\hline 1 & 28 & 985 & \\
\hline 1 & 28 & 1,040 & \\
\hline 2 & 7 & 850 & \multirow{3}{*}{760} \\
\hline 2 & 7 & 630 & \\
\hline 2 & 7 & 795 & \\
\hline 2 & 28 & 1,130 & \multirow{4}{*}{1,065} \\
\hline 2 & 28 & 1,085 & \\
\hline 2 & 28 & 885 & \\
\hline 2 & 28 & 1,155 & \\
\hline
\end{tabular}




\section{$\underline{\text { HyFRC-A }}$}

During mixing of large batches of HyFRC-A, the workability slightly decreased almost immediately due to the micro-fibers. The final average unit weight was measured to be 147.2 $\mathrm{lb} / \mathrm{ft}^{3}$, which is slightly higher than typical concrete, as expected, due to the added weight of the steel fibers in the mix. The average air content with fibers in the mix was 3.3\%. This air content was considered acceptable because of the presence of fibers in the mix. The inverted slump test was performed, and the average time was 8.85 seconds.

The HyFRC-A large batch was only tested for deflection hardening capability at 28 days due to the large specimen sizes (primarily 6 in $\times 6$ in $\times 20$ in beams) and limited capacity of the mixer. The results (Figure 5.9) displayed deflection hardening wherein hardening occurred immediately following first crack without deflection softening. This behavior can be attributed to the steel fibers in the mix. The steel fibers bond well to the paste within the concrete matrix and have hooked ends that allow for immediate resistance across cracks as they form, whereas synthetic fibers slightly deform lengthwise when placed in tension. This slight elongation causes deflection softening in mixes that exclude steel fibers.

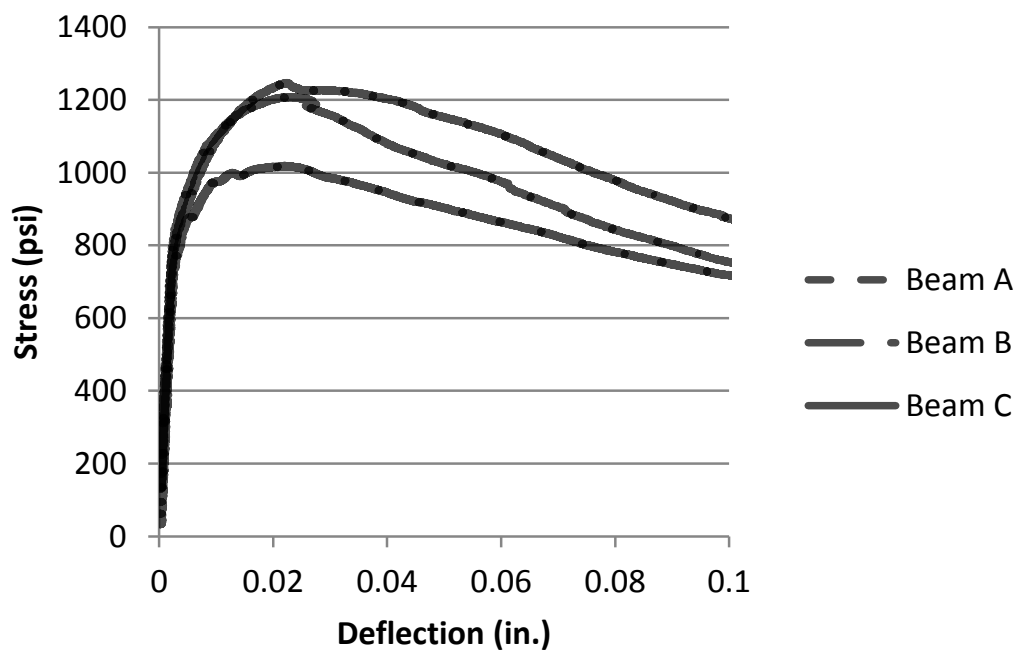

Figure 5.9 HyFRC-A 28-day flexural performance.

The flexural toughness of the HyFRC-A beams was examined and the average toughness was found to be $980 \mathrm{lb}$-in. In comparison to the flexural toughness found for ECC and UHPC, this value is extremely high. However, this is expected because larger beam specimens were used for HyFRC-A and HyFRC-G mixes. Because of the two different geometries for the beam 
specimens in this study, the flexural toughness can only be compared between systems using the same beam geometry. Flexural toughness of HyFRC-A is higher than that of the HyFRC-G system. This is primarily attributed to the long steel fibers used in the HyFRC-A system.

The Direct-Tension Bond Test results for HyFRC-A noted several epoxy failures, and these results were excluded from the average calculations. The specimens that displayed a partial epoxy failure at 7 days also failed in the closure pour material. Five out of the six specimens tested at 28 days failed partially or fully within the epoxy, possibly resulting in an inaccurate bond strength value for 28 days. This makes it difficult to determine the suitability of this test for measuring bond strength of fiber-reinforced concrete mixes.

Table 5.7 HyFRC-A Direct-Tension Bond Test data.

\begin{tabular}{|c|c|c|c|c|c|c|c|}
\hline \multirow{2}{*}{ Batch } & \multirow{2}{*}{$\begin{array}{c}\text { Age of } \\
\text { Specimen } \\
\text { (days) }\end{array}$} & \multirow{2}{*}{$\begin{array}{c}\text { Strength } \\
\text { (psi) }\end{array}$} & \multirow{2}{*}{$\begin{array}{c}\text { Average } \\
\text { Strength } \\
\text { (psi) }\end{array}$} & \multicolumn{4}{|c|}{ Failure Area (\%) } \\
\hline & & & & Overlay & Bond & Base & Epoxy \\
\hline 1 & 7 & 420 & \multirow{6}{*}{410} & 100 & 0 & 0 & 0 \\
\hline 1 & 7 & 415 & & 95 & 0 & 0 & 5 \\
\hline 1 & 7 & 385 & & 55 & 15 & 30 & 0 \\
\hline 2 & 7 & 455 & & 95 & 0 & 0 & 5 \\
\hline 2 & 7 & 450 & & 95 & 0 & 0 & 5 \\
\hline 2 & 7 & 425 & & 30 & 45 & 25 & 0 \\
\hline 1 & 28 & 340 & \multirow{6}{*}{385} & 5 & 0 & 0 & 95 \\
\hline 1 & 28 & 340 & & 50 & 0 & 0 & 50 \\
\hline 1 & 28 & 400 & & 0 & 0 & 40 & 60 \\
\hline 2 & 28 & 385 & & 0 & 0 & 35 & 65 \\
\hline 2 & 28 & 385 & & 0 & 5 & 95 & 0 \\
\hline 2 & 28 & 415 & & 70 & 0 & 0 & 30 \\
\hline
\end{tabular}

The bond strengths for HyFRC-A were similar to those of ECC. California Bond Test 551 showed average bond strength of $900 \mathrm{psi}$ at 28 days, which is significantly higher than that of ECC using the same test. The results for one of the beams tested at 28 days were excluded because the specimen was accidentally subjected to impact loading. 
Table 5.8 HyFRC-A California Test 551 results.

\begin{tabular}{|c|c|c|c|}
\hline Batch & $\begin{array}{c}\text { Age of } \\
\text { Specimen (days) }\end{array}$ & $\begin{array}{c}\text { Bond } \\
\text { Strength (psi) }\end{array}$ & $\begin{array}{c}\text { Avg. Bond } \\
\text { Strength (psi) }\end{array}$ \\
\hline 1 & 7 & 790 & \multirow{2}{*}{820} \\
\hline 1 & 7 & 845 & \multirow{2}{*}{890} \\
\hline 1 & 28 & 810 & \multirow{2}{*}{755} \\
\hline 1 & 28 & 965 & \multirow{2}{*}{910} \\
\hline 2 & 7 & 665 & \\
\hline 2 & 7 & 840 & \\
\hline 2 & 28 & 910 & \\
\cline { 1 - 3 } & 28 & N/A & \multirow{2}{*}{} \\
\hline \multicolumn{2}{|c|}{ N/A - test disqualified due to irregular loading of specimen } \\
\end{tabular}

The results from the Splitting Prism Test had much less variability than the Guillotine Shear Test and indicated an increase in bond strength for both batches from 7 days to 28 days as expected. The consistency of the results for this test suggests that this is a suitable test for measuring bond strength of fiber-reinforced concrete mixes.

Table 5.9 HyFRC-A Splitting Prism Test results.

\begin{tabular}{|c|c|c|c|}
\hline Batch & $\begin{array}{c}\text { Age of } \\
\text { Specimen (days) }\end{array}$ & $\begin{array}{c}\text { Bond } \\
\text { Strength (psi) }\end{array}$ & $\begin{array}{c}\text { Avg. Bond } \\
\text { Strength (psi) }\end{array}$ \\
\hline 1 & 7 & 765 & \multirow{4}{*}{735} \\
\hline 1 & 7 & 705 & \\
\hline 1 & 7 & 745 & \\
\hline 1 & 7 & 715 & \\
\hline 1 & 28 & 960 & \multirow{4}{*}{1,010} \\
\hline 1 & 28 & 1,050 & \\
\hline 1 & 28 & 1,010 & \\
\hline 1 & 28 & 1,020 & \\
\hline 2 & 7 & 570 & \multirow{4}{*}{665} \\
\hline 2 & 7 & 730 & \\
\hline 2 & 7 & 695 & \\
\hline 2 & 7 & 655 & \\
\hline 2 & 28 & 1,010 & \multirow{4}{*}{975} \\
\hline 2 & 28 & 990 & \\
\hline 2 & 28 & 960 & \\
\hline 2 & 28 & 930 & \\
\hline
\end{tabular}

The results for the Guillotine Shear Test indicated a decrease in bond strength from 7 days to 28 days for the first batch. This was a result of the variability of results at 28 days. Further testing should be done to determine whether or not this is an accurate representation of 
the bond strength development for this system. The results from the second batch are also variable at 7 days. This may indicate that the Guillotine Shear Test is not suitable for measuring the bond strength of fiber-reinforced concrete mixes.

Table 5.10 HyFRC-A Guillotine Shear Test results.

\begin{tabular}{|c|c|c|c|}
\hline Batch & $\begin{array}{c}\text { Age of } \\
\text { Specimen (days) }\end{array}$ & $\begin{array}{c}\text { Bond } \\
\text { Strength (psi) }\end{array}$ & $\begin{array}{c}\text { Avg. Bond } \\
\text { Strength (psi) }\end{array}$ \\
\hline 1 & 7 & 635 & \multirow{3}{*}{740} \\
\hline 1 & 7 & 735 & \\
\hline 1 & 7 & 850 & \\
\hline 1 & 28 & 415 & \multirow{3}{*}{580} \\
\hline 1 & 28 & 465 & \\
\hline 1 & 28 & 865 & \\
\hline 2 & 7 & 710 & \multirow{3}{*}{700} \\
\hline 2 & 7 & 845 & \\
\hline 2 & 7 & 550 & \\
\hline 2 & 28 & 700 & \multirow{3}{*}{795} \\
\hline 2 & 28 & 855 & \\
\hline 2 & 28 & 835 & \\
\hline
\end{tabular}

\section{$\underline{\text { HyFRC-G }}$}

The effects of synthetic fibers on workability of the mix due to the absorption of water led to the addition of too much water-reducing admixture. The excess admixture caused the fibers to segregate and ball and caused large amounts of air to become mixed into the material. To solve these issues, some of the air was removed from the mix to achieve an air content of 4.3\%. The mixture appeared to have a reasonable consistency, but achieved an inverted slump time of 19.3 seconds, which is far longer than expected. Because the mix was still workable and easily placed in the molds, it was used for testing. For the second batch, water-reducing admixture was added in smaller increments to ensure that segregation did not occur. An air content of $6.4 \%$ was achieved. The inverted slump test time was much more reasonable (7.9 seconds), but there was some minor bleeding of the mix. The densities were $125.2 \mathrm{lb} / \mathrm{ft}^{3}$ and $136.4 \mathrm{lb} / \mathrm{ft}^{3}$ for the first and second batches, respectively. The unit weight was expected to be lighter than standard PCC because of the use of $2.0 \%$ synthetic fibers in the mix. However, based on the air content, the second batch should have been less dense than the first batch. This inconsistency may be due to the effects of the fibers on the mix, particularly the tendency of the 
fibers to separate from the mix. This behavior may have caused inaccurate measurements of air content to be obtained.

Deflection hardening behavior was achieved by the first batch of the HyFRC-G mix but the second batch failed to demonstrate this quality, as shown by Figure 5.10. As with the HyFRC-A mix, HyFRC-G beams were only tested at 28 days after casting due to the use of large specimens and limited batch size dictated by available mixer capacity.

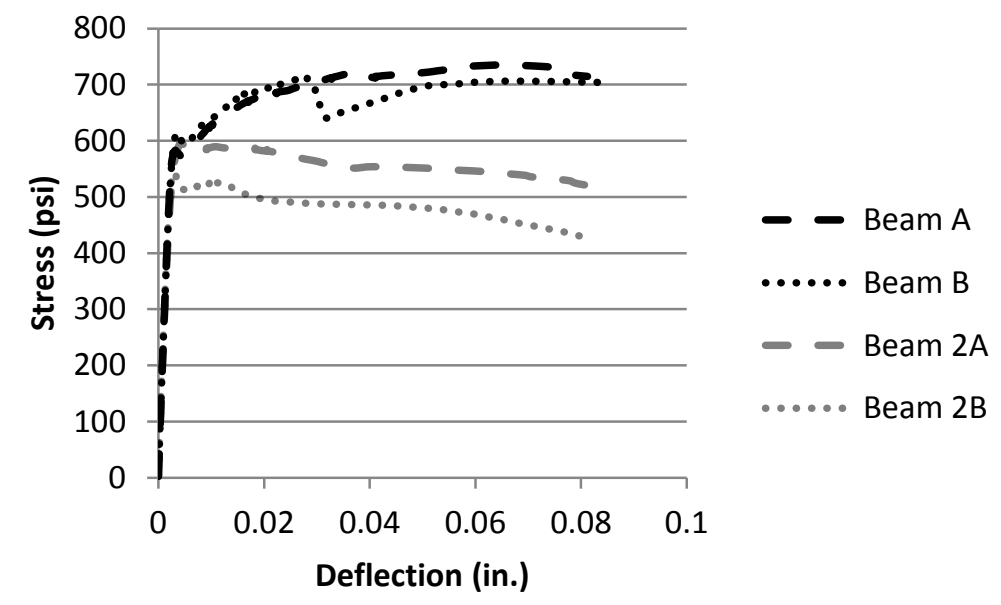

Figure 5.10 HyFRC-G 28-day flexural performance.

The flexural performance of this system varied greatly due to variations in the mixing process for each batch. Additional experimentation is necessary to obtain a more workable solution that is easy to mix and maintain consistency across batches. Flexural toughness was examined for this system. The average toughness for the first batch was found to be $670 \mathrm{lb}$-in while the average toughness for the second batch was $490 \mathrm{lb}$-in. The primary difference between batches was the absence of deflection hardening in the second batch, which resulted in a lower flexural toughness.

Direct-Tension Bond Test results show that the bond strength increases from 7 days to 28 days, but the exclusion of all test results wherein epoxy failure was evident subtracts from the relevance of the average bond strengths calculated. The failure of a greater number of specimens at 28 days than at 7 days is a result of lower strength for the epoxy applied to the specimens for testing at 28 days. The epoxy is applied the day before testing for all specimens, so the epoxy may have been mixed poorly for the specimens tested at 28 days. The results for HyFRC-G 
indicate that the Direct-Tension Bond Test may not be suitable for fiber-reinforced concrete mixes, as also displayed by the Direct-Tension Bond Test results for the HyFRC-A system.

Table 5.11 HyFRC-G Direct-Tension Bond Test data.

\begin{tabular}{|c|c|c|c|c|c|c|c|}
\hline \multirow[b]{2}{*}{ Batch } & \multirow{2}{*}{$\begin{array}{c}\text { Age of } \\
\text { Specimen } \\
\text { (days) }\end{array}$} & \multirow{2}{*}{$\begin{array}{l}\text { Strength } \\
\quad \text { (psi) }\end{array}$} & \multirow{2}{*}{$\begin{array}{c}\text { Average } \\
\text { Strength } \\
\text { (psi) }\end{array}$} & \multicolumn{4}{|c|}{ Failure Area (\%) } \\
\hline & & & & Overlay & Bond & Base & Epoxy \\
\hline 1 & 7 & 320 & \multirow{6}{*}{310} & 85 & 15 & 0 & 0 \\
\hline 1 & 7 & 330 & & 60 & 20 & 20 & 0 \\
\hline 1 & 7 & 320 & & 50 & 50 & 0 & 0 \\
\hline 2 & 7 & 275 & & 100 & 0 & 0 & 0 \\
\hline 2 & 7 & 315 & & 100 & 0 & 0 & 0 \\
\hline 2 & 7 & 280 & & 40 & 0 & 0 & 60 \\
\hline 1 & 28 & 375 & \multirow{6}{*}{375} & 95 & 5 & 0 & 0 \\
\hline 1 & 28 & 285 & & 30 & 0 & 0 & 70 \\
\hline 1 & 28 & 325 & & 50 & 0 & 0 & 50 \\
\hline 2 & 28 & 220 & & 5 & 0 & 0 & 95 \\
\hline 2 & 28 & 280 & & 50 & 0 & 0 & 50 \\
\hline 2 & 28 & 295 & & 70 & 0 & 0 & 30 \\
\hline
\end{tabular}

Bond strengths exhibited by HyFRC-G when subjected to California Bond Test 551 show that this system exceeds the minimum bond strength requirement for overlays. The difference in strength of the two batches of HyFRC-G may be a result of minor bleeding observed in the second batch during mixing.

Table 5.12 HyFRC-G California Test 551 results.

\begin{tabular}{|c|c|c|c|}
\hline Batch & $\begin{array}{c}\text { Age of } \\
\text { Specimen (days) }\end{array}$ & $\begin{array}{c}\text { Bond } \\
\text { Strength (psi) }\end{array}$ & $\begin{array}{c}\text { Avg. Bond } \\
\text { Strength (psi) }\end{array}$ \\
\hline 1 & 7 & 490 & \multirow{2}{*}{500} \\
\hline 1 & 7 & 505 & \multirow{2}{*}{525} \\
\hline 1 & 28 & 630 & \multirow{2}{*}{450} \\
\hline 1 & 28 & 420 & \multirow{2}{*}{470} \\
\hline 2 & 7 & 445 & \\
\hline 2 & 7 & 455 & \\
\hline 2 & 28 & 555 & \\
\hline
\end{tabular}

The Splitting Prism Test provided results with somewhat high variability at 28 days. This is most likely due to the small number of specimens being tested. The values obtained indicate that the minimum bond strength required for overlays is met. Because of the minimal shrinkage 
exhibited by the HyFRC-G system, the required bond strength for use in closure pours may not be substantially higher than the minimum required bond strength for overlays.

Table 5.13 HyFRC-G Splitting Prism Test results.

\begin{tabular}{|c|c|c|c|}
\hline Batch & $\begin{array}{c}\text { Age of } \\
\text { Specimen (days) }\end{array}$ & $\begin{array}{c}\text { Bond } \\
\text { Strength (psi) } \\
\end{array}$ & $\begin{array}{c}\text { Avg. Bond } \\
\text { Strength (psi) }\end{array}$ \\
\hline 1 & 7 & 485 & \multirow{4}{*}{510} \\
\hline 1 & 7 & 570 & \\
\hline 1 & 7 & 540 & \\
\hline 1 & 7 & 445 & \\
\hline 1 & 28 & 635 & \multirow{4}{*}{555} \\
\hline 1 & 28 & 575 & \\
\hline 1 & 28 & 345 & \\
\hline 1 & 28 & 660 & \\
\hline 2 & 7 & 515 & \multirow{4}{*}{550} \\
\hline 2 & 7 & 585 & \\
\hline 2 & 7 & 620 & \\
\hline 2 & 7 & 485 & \\
\hline 2 & 28 & 550 & \multirow{4}{*}{530} \\
\hline 2 & 28 & 530 & \\
\hline 2 & 28 & 635 & \\
\hline 2 & 28 & 410 & \\
\hline
\end{tabular}

Results for the Guillotine Shear Test appear to be somewhat variable for the first batch, but this does not necessarily mean that the test is not suitable for use on fiber-reinforced concrete systems. The method of failure (shear stress along the bond interface) may potentially provide results with higher variability than other methods of failure. 
Table 5.14 HyFRC-G Guillotine Shear Test results.

\begin{tabular}{|c|c|c|c|}
\hline Batch & $\begin{array}{c}\text { Age of } \\
\text { Specimen (days) }\end{array}$ & $\begin{array}{c}\text { Bond } \\
\text { Strength (psi) }\end{array}$ & $\begin{array}{c}\text { Avg. Bond } \\
\text { Strength (psi) }\end{array}$ \\
\hline 1 & 7 & 425 & \multirow{3}{*}{515} \\
\hline 1 & 7 & 715 & \\
\hline 1 & 7 & 400 & \\
\hline 1 & 28 & 605 & \multirow{3}{*}{625} \\
\hline 1 & 28 & 530 & \\
\hline 1 & 28 & 740 & \\
\hline 2 & 7 & 505 & \multirow{3}{*}{510} \\
\hline 2 & 7 & 560 & \\
\hline 2 & 7 & 470 & \\
\hline 2 & 28 & 530 & \multirow{3}{*}{515} \\
\hline 2 & 28 & 565 & \\
\hline 2 & 28 & 455 & \\
\hline
\end{tabular}

\section{$\underline{\mathrm{UHPC}}$}

UHPC is a premix and the mix design is the same for each batch, so the results from both large laboratory batches are combined. Fresh properties were not measured for UHPC because it is a premix and the mix proportions are set by the manufacturer. 4-in compression cylinders were used to determine compressive strength. The average compressive strength at 7 days was 15,355 psi and the average at 28 days was 22,180 psi, which far exceeds the minimum strength requirements and is much greater than the compressive strengths exhibited by the other systems. The stress versus deflection of 4 in $\times 4$ in $\times 14$ in beams at 7 and 28 days after casting is displayed in Figure 5.11 and Figure 5.12. Deflection hardening was not exhibited by any of the UHPC specimens tested. 


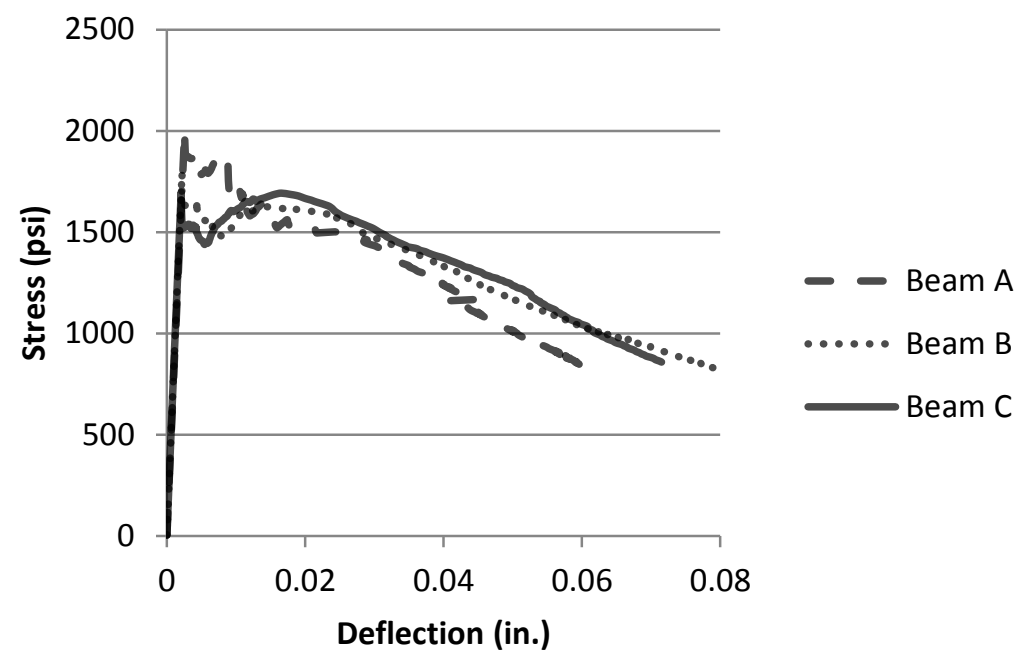

Figure 5.11 UHPC 7-day flexural performance.

Flexural toughness of UHPC was calculated and found to be $400 \mathrm{lb}$-in and $460 \mathrm{lb}$-in at 7 days and 28 days, respectively. These values are higher than those of ECC despite the absence of deflection hardening.

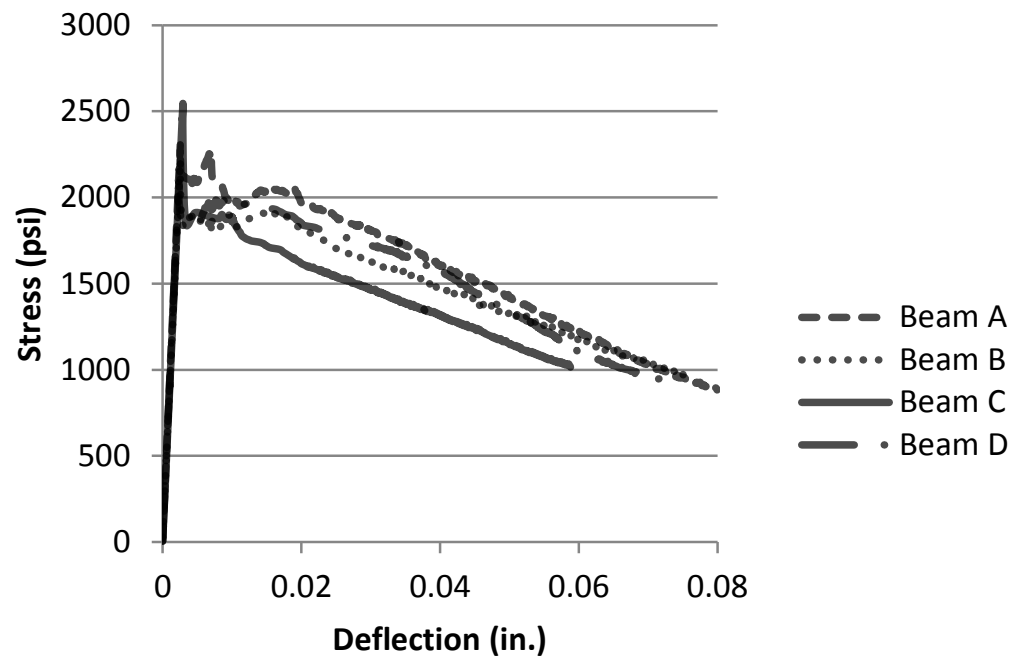

Figure 5.12 UHPC 28-day flexural performance.

The Direct-Tension Bond Test results for UHPC do not provide an accurate representation of the bond strength at 7 days because five out of the six specimens experienced epoxy failure. The results for 28 day tests exhibited low variability and accurately represent the bond strength at 28 days. 
Table 5.15 UHPC Direct-Tension Bond Test data.

\begin{tabular}{|c|c|c|c|c|c|c|c|}
\hline \multirow{2}{*}{ Batch } & \multirow{2}{*}{$\begin{array}{c}\text { Age of } \\
\text { Specimen } \\
\text { (days) }\end{array}$} & \multirow{2}{*}{$\begin{array}{c}\text { Strength } \\
\text { (psi) }\end{array}$} & \multirow{2}{*}{$\begin{array}{c}\text { Average } \\
\text { Strength } \\
\text { (psi) }\end{array}$} & \multicolumn{4}{|c|}{ Failure Area (\%) } \\
\hline & & & & Overlay & Bond & Base & Epoxy \\
\hline 1 & 7 & 225 & \multirow{6}{*}{200} & 0 & 0 & 5 & 95 \\
\hline 1 & 7 & 200 & & 100 & 0 & 0 & 0 \\
\hline 1 & 7 & 295 & & 95 & 0 & 0 & 5 \\
\hline 2 & 7 & 295 & & 0 & 0 & 15 & 85 \\
\hline 2 & 7 & 210 & & 90 & 0 & 0 & 10 \\
\hline 2 & 7 & 235 & & 0 & 0 & 5 & 95 \\
\hline 1 & 28 & 450 & \multirow{5}{*}{455} & 0 & 0 & 100 & 0 \\
\hline 1 & 28 & 460 & & 0 & 0 & 100 & 0 \\
\hline 1 & 28 & 430 & & 0 & 0 & 100 & 0 \\
\hline 2 & 28 & 475 & & 0 & 0 & 100 & 0 \\
\hline 2 & 28 & 460 & & 0 & 0 & 90 & 10 \\
\hline
\end{tabular}

The results from California Bond Test 551 show that bond strengths exceeded the minimum requirement for overlays. The test results showed differing variability both between 7 days and 28 days and between batches, thus it is difficult to determine whether or not this test method is suitable for measuring bond strength for UHPC.

Table 5.16 UHPC California Test 551 results.

\begin{tabular}{|c|c|c|c|}
\hline Batch & $\begin{array}{c}\text { Age of } \\
\text { Specimen (days) }\end{array}$ & $\begin{array}{c}\text { Bond } \\
\text { Strength (psi) }\end{array}$ & $\begin{array}{c}\text { Avg. Bond } \\
\text { Strength (psi) }\end{array}$ \\
\hline 1 & 7 & 825 & \multirow{2}{*}{745} \\
\hline 1 & 7 & 665 & \\
\hline 1 & 28 & 950 & \multirow{2}{*}{940} \\
\hline 1 & 28 & 925 & \multirow{2}{*}{630} \\
\hline 2 & 7 & 340 & \\
\hline 2 & 7 & 920 & \multirow{2}{*}{1,050} \\
\hline 2 & 28 & 1,045 & \\
\hline 2 & 28 & 1,055 & \\
\hline
\end{tabular}

Splitting Prism Test results also showed some variability, but the strengths recorded were much higher than those of other systems. The average strength at 28 days is lower than the average strength at 7 days, which is a result of the variability of the results. 
Table 5.17 UHPC Splitting Prism Test results.

\begin{tabular}{|c|c|c|c|}
\hline Batch & $\begin{array}{c}\text { Age of } \\
\text { Specimen (days) }\end{array}$ & $\begin{array}{c}\text { Bond } \\
\text { Strength (psi) }\end{array}$ & $\begin{array}{c}\text { Avg. Bond } \\
\text { Strength (psi) }\end{array}$ \\
\hline 1 & 7 & 920 & \multirow{4}{*}{1,060} \\
\hline 1 & 7 & 1,270 & \\
\hline 1 & 7 & 820 & \\
\hline 1 & 7 & 1,225 & \\
\hline 1 & 28 & 1,095 & \multirow{4}{*}{1,145} \\
\hline 1 & 28 & 1,235 & \\
\hline 1 & 28 & 1,275 & \\
\hline 1 & 28 & 975 & \\
\hline 2 & 7 & 1,445 & \multirow{4}{*}{1,460} \\
\hline 2 & 7 & 1,400 & \\
\hline 2 & 7 & 1,355 & \\
\hline 2 & 7 & 1,645 & \\
\hline 2 & 28 & 1,050 & \multirow{4}{*}{1,305} \\
\hline 2 & 28 & 1,420 & \\
\hline 2 & 28 & 1,465 & \\
\hline 2 & 28 & 1,290 & \\
\hline
\end{tabular}

The Guillotine Shear Test results for UHPC also indicate very high bond strengths and slightly less variability than the results recorded for the Splitting Prism Test. This may be due to the failure mechanism. The Guillotine Shear Test subjects the bond interface to shear stresses while the other bond tests performed all measure bond strength under direct tension as induced by different load scenarios (direct-tension, flexure, and induced tension due to the Poisson effect).

Table 5.18 UHPC Guillotine Shear Test results.

\begin{tabular}{|c|c|c|c|}
\hline \multirow{2}{*}{ Batch } & $\begin{array}{c}\text { Age of } \\
\text { Specimen (days) }\end{array}$ & $\begin{array}{c}\text { Bond } \\
\text { Strength (psi) }\end{array}$ & $\begin{array}{c}\text { Avg. Bond } \\
\text { Strength (psi) }\end{array}$ \\
\hline 1 & 7 & 1,200 & \multirow{2}{*}{1,190} \\
\hline 1 & 7 & 1,185 & \\
\hline 1 & 7 & 1,190 & \\
\hline 1 & 28 & 970 & \multirow{2}{*}{1,210} \\
\hline 1 & 28 & 1,500 & \\
\hline 1 & 28 & 1,155 & \multirow{2}{*}{1,045} \\
\hline 2 & 7 & 1,120 & \\
\hline 2 & 7 & 890 & \multirow{2}{*}{1,135} \\
\hline 2 & 7 & 1,120 & \\
\hline 2 & 28 & 1,205 & \multirow{2}{*}{} \\
\hline 2 & 28 & 1,085 & \multirow{2}{*}{} \\
\hline 2 & 28 & 1,115 & \multirow{2}{*}{} \\
\hline
\end{tabular}




\section{Summary of Results}

A summary of the results of the hardened tests is provided in Table 5.19. This table shows how each system performed for each test, excluding shrinkage of the material, which is shown in the appendix and discussed in the following chapter. The deflection hardening capacity of each system is quantified by dividing the average peak stress by the average stress at first crack for each mix. Thus, if the quantity is 1.0, deflection hardening was not achieved. For numbers exceeding 1.0, deflection hardening was achieved. Figure 5.13 shows the 28-day flexural behavior for each system, specifically the maximum theoretical stress as the beams are deflected at a constant rate of 0.005 inches/min. Flexural toughness was also used as a measure of the ability of a system to control cracks. These results can be seen in Table 5.19. 
Table 5.19 Summary of results.

\begin{tabular}{|c|c|c|c|c|c|c|c|}
\hline \multicolumn{3}{|c|}{ Test } & ECC (Batch 1) & ECC (Batch 2) & HyFRC-A & HyFRC-G & UHPC \\
\hline \multirow{2}{*}{\multicolumn{2}{|c|}{ Compressive Strength (psi) }} & 7 Days & 4,315 & 4,780 & - & - & 15,355 \\
\hline & & 28 Days & 6,920 & 7,865 & 6,115 & 3,895 & 22,180 \\
\hline \multirow{8}{*}{ 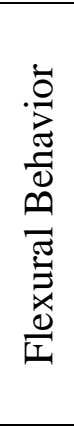 } & \multirow{2}{*}{$\begin{array}{l}\text { Flexural Stress at } \\
\text { First Crack (psi) }\end{array}$} & 7 Days & 670 & 645 & - & - & 1,835 \\
\hline & & 28 Days & 895 & 835 & 760 & 575 & 2,290 \\
\hline & \multirow{2}{*}{$\begin{array}{l}\text { Peak Flexural Stress } \\
\text { (psi) }\end{array}$} & 7 Days & 1,070 & 1,190 & - & - & 1,835 \\
\hline & & 28 Days & 1,440 & 1,465 & 1,160 & 650 & 2,290 \\
\hline & \multirow{2}{*}{$\begin{array}{l}\text { Deflection } \\
\text { Hardening Capacity }\end{array}$} & 7 Days & 1.60 & 1.84 & - & - & 1.00 \\
\hline & & 28 Days & 1.61 & 1.75 & 1.53 & 1.13 & 1.00 \\
\hline & & 7 Days & 260 & 280 & - & - & 400 \\
\hline & & 28 Days & 340 & 330 & 980 & 580 & 460 \\
\hline \multirow{8}{*}{ 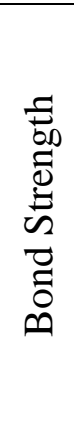 } & \multirow{2}{*}{$\begin{array}{l}\text { Guillotine Shear Test } \\
\text { (psi) }\end{array}$} & 7 Days & 560 & 760 & 720 & 515 & 1,120 \\
\hline & & 28 Days & 990 & 1,065 & 690 & 625 & 1,170 \\
\hline & \multirow{2}{*}{$\begin{array}{l}\text { Splitting Prism Test } \\
\text { (psi) }\end{array}$} & 7 Days & 800 & 800 & 700 & 510 & 1,260 \\
\hline & & 28 Days & 935 & 1,100 & 990 & 555 & 1,225 \\
\hline & \multirow{2}{*}{$\begin{array}{l}\text { California Bond Test } \\
\text { (psi) }\end{array}$} & 7 Days & 590 & 625 & 785 & 500 & 690 \\
\hline & & 28 Days & 825 & 755 & 895 & 525 & 1,050 \\
\hline & \multirow{2}{*}{$\begin{array}{l}\text { Direct-Tension Bond } \\
\text { Test (psi) }\end{array}$} & 7 Days & 340 & 310 & 410 & 310 & 200 \\
\hline & & 28 Days & 285 & 295 & 385 & 375 & 455 \\
\hline
\end{tabular}




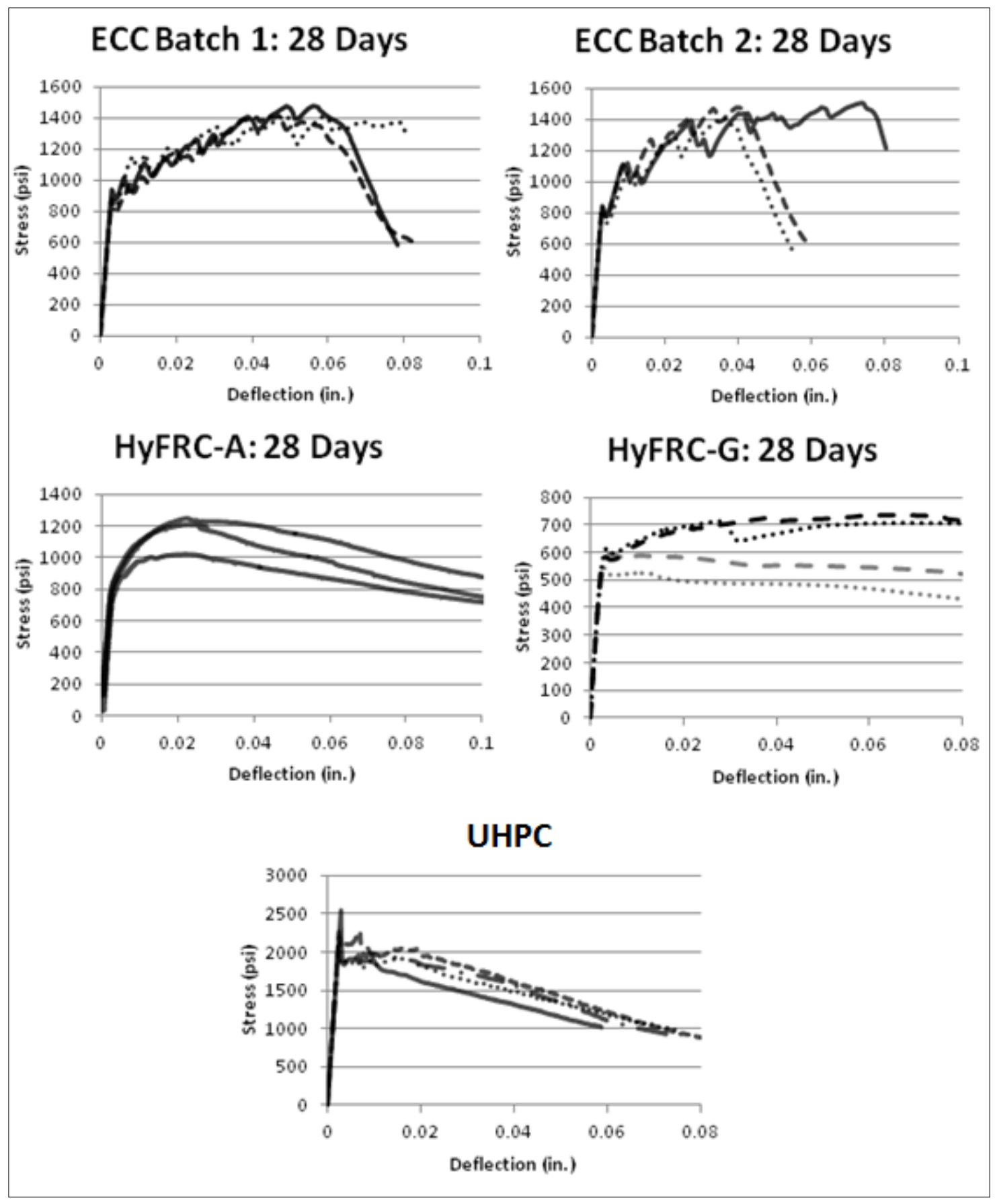

Figure 5.13 Stress vs. deflection for beam specimens at 28 days. 


\section{DISCUSSION}

\section{Bond Strength}

CA 551 is a standard used by the California Department of Transportation for testing the bond strength of overlay materials to concretes. ASTM C1404 (Direct-Tension Bond Test) was withdrawn as a standard in 2010 due to limited use of the test. The Splitting Prism Test and Guillotine Shear Test are not standard tests but have been used in past research as a measure of bond strength under different load scenarios.

CA 551 determines the tensile bond strength at the overlay-to-base interface by calculating the force in the tension face when the composite beam specimen is placed in flexure. The specimen under this test, unlike in the Splitting Prism Test and Guillotine Shear Test, undergoes an immediate failure as the bond fails. The capacity of the specimen immediately drops sharply upon fracture at the bond. CA 551 also promotes failure at the bond (as opposed to in either the overlay material or the base material) by utilizing a center point load configuration. Results from this test varied by material, but yielded fairly consistent results for each system.

The specimen for the Direct-Tension Bond Test is bonded to caps at the ends by an epoxy. In some cases, the specimen fails at the epoxy bond interface instead of the overlay-tobase bond interface. The failure can also occur entirely in either the overlay material or the base material. The location of the failure is determined by the location in the specimen with the least tensile capacity or the location with the highest stress concentration. In order to obtain the actual strength of the overlay-to-base bond, the failure must occur at the bond interface. When failure occurs at another location, this simply means that the strength of the overlay-to-base bond is either higher than the recorded failure tensile capacity of the specimen or that the highest concentration of stresses did not occur at the bond interface. While care is made to center the end caps for this test, the stress distribution may be uneven if the cap is horizontally skewed to the end of the specimen or if the cap is not exactly on-center. Thus, the average strength reported by this test may not provide an accurate measurement of the strength of the bond.

The Splitting Prism Test is a modification to the splitting tensile test for cylindrical specimens (ASTM C496). This test seeks to quantify the bond strength of two materials when placed under a simulated tensile load. It provides a large failure surface ( 4 in $\times 4$ in) and promotes failure at the bond interface when the specimen is loaded directly along the edge of the bond. However, if the specimen is not loaded directly along the bond line, the compressive 
strength of either the overlay or base material may influence the results as the portion of the specimen supporting the majority of the load begins to crush in compression. During the test, when the bond fails, the sustained compressive load only slightly decreases before continuing to increase as the separated base and overlay components continue to resist the compressive force. This can sometimes be confused with minor fluctuations in load resistance that are observed as the wooden loading strips are crushed, making it challenging to obtain an accurate reading. This issue may affect the accuracy of this test.

The Guillotine Shear Test was developed as a method for determining the shear bond strength of overlay materials. The configuration of this test is fairly involved when setting up for loading and has very particular specimen size requirements. The frame shown in Figure 4.8 (the guillotine) has a hole that is just large enough for a 4-in diameter specimen. Any irregularities in the specimen cross-section may alter the result of the test. For example, when the hardened base material portions of some of these specimens were placed back into the cylinder molds, the molds deformed slightly, causing the overlay material to form an elliptical prism. This was the case for few specimens. For specimens in which this occurred, the oblong shape did not fit into the hole in the guillotine and the edges had to be ground off before testing. This not only added to the time required for testing but may have slightly decreased the cross-sectional area of the affected specimens, thereby slightly reducing the load required to fail the specimen. Another difficulty regarding the size of the specimens arose when specimens were slightly smaller than 4 in in diameter. When these specimens were placed in the guillotine, the unsupported portion of the specimen (seen in Figure 4.7) tilted downwards because of the loose fit of the specimen. This caused the failure plane to be skewed away from the bond interface by an amount proportional to the angle at which the specimen tilts. One of the major benefits of the Guillotine Shear Test is the tendency of the failure to occur at or near the bond interface. Issues with specimen skew may be solved by creating a female mold that fits inside of the guillotine and holds the specimen tightly in the circular hole. This would force the failure to occur closer to the overlay-to-base bond interface.

ASTM C496, under Significance and Use states "Splitting tensile strength is generally greater than direct tensile strength and lower than flexural strength (modulus of rupture)." This may suggest that the strengths determined by the Splitting Prism Test should be greater than those of the Direct-Tension Bond Test and less than those of CA 551. The Direct-Tension Bond 
Test and CA 551 follow this, but the Spitting Prism Test results tend to be higher than those of CA 551. This may be due to the aforementioned possibility that the compressive strength of either the base or overlay material could influence the results and produce higher strength results for the Splitting Prism Test.

With the small sample sizes tested, it is difficult to tell which of the tests provides the most dependable results and suitability of each test must be determined individually for each system being tested. Accuracy of bond strength tests was determined by comparing the results with results from previous research completed with each test on similar materials. Previous research completed to determine the strength of the bond between ultra high performance fiber concrete (UHPFC) and normal concrete with a sandblasted surface indicated average 28-day bond strength of approximately 510 psi for composite splitting tensile test specimens (Tayeh et. al. 2013). This test method most accurately compares to the Splitting Prism Test performed in this study. The average 28-day bond strength for the Splitting Prism Test was between 555 psi (for HyFRC-G) and 1,225 psi (for UHPC). This range is higher than the average strength of this test found by others. Additional research found that the results from the Splitting Prism Test and pull-off test (a variation of the Direct-Tension Bond Test) were lower than other bond strength tests (Momayez, et al. 2005). This observation holds true for the Direct-Tension Bond Test, but the results for the Splitting Prism Test are much higher than those found by others. This further supports speculation about closure pour material or base material compressive strengths increasing the bond strength results for this test. Bond strengths of 400-500 psi were achieved bonding standard PCC using CA 551. (Shatnawi 2011) The values obtained using that test for bond strength of the systems in this study were larger, but this can be expected because of the high performance characteristics of these systems. Because the Guillotine Shear Test is not commonly used, past results of this test for comparison in which similar overlay materials were used were not found.

\section{Workability and Set Time}

Workability of cementitious mixtures can be critical, especially when the material is cast in a closure pour and reinforcement limits methods of consolidation. Several observations were made about the workability of each system in this study. ECC is highly workable and is selfconsolidating, but the workability is critically dependent on the mix sequence. UHPC was also highly workable and self-consolidating, but there were issues with set time. For both batches of 
UHPC, the specimens required three days to set before they were hard enough to be removed from the molds and placed in the moisture room to cure. The mix proportions directly followed the supplied mix design, so the w/cm ratio most likely was not the cause for extended set time. One potential source for the long set time was the type of mixer that was used. It is recommended that a high shear mixer is used when mixing UHPC, but a pan type mixer was used in the laboratory.

The workability of the HyFRC systems varied greatly. HyFRC-A was fairly workable and was easily placed in the molds. External vibration was required to consolidate the mixture in the molds. Internal vibration for fiber-reinforced systems causes fibers to disperse from the location of the vibrator, which disrupts the even distribution of fibers throughout the mixture. Thus internal vibration is avoided when consolidating fiber-reinforced mixtures. The workability of HyFRC-G was greatly reduced by the large synthetic fibers and the system required more external vibration than the HyFRC-A mixture. The deformations along the large polypropylene fibers may have an effect on the workability of this mix. It was observed during mixing of the HyFRC-G mix that the large fibers were locking together and separating portions of the mixture.

\section{Crack Control}

The criteria used in this study to determine the ability of a material to maintain tight cracks $(<0.1 \mathrm{~mm})$ beyond its first crack were deflection hardening capacity and flexural toughness. These characteristics are summarized for each material in Table 5.19. The deflection hardening capacity of each system in this study is evaluated as the proportional peak load, or percent of total load at first crack. Typically, deflection hardening capacity is measured by calculating the flexural toughness, but the deflections of some of the specimens being tested were not great enough (at least L/150 in) to perform the correct calculation for this property. Therefore, a modified calculation for flexural toughness based on a minimum deflection of L/220 was used to compare the flexural behavior of each system. Only systems with similar specimen size could be compared, so ECC and UHPC were compared and the fiber-reinforced concrete mixes were compared. For HyFRC-A, the location of first crack based on the load-deflection curve was difficult because deflection softening did not occur. To determine the location of first crack, the load-deflection trend was observed and the first point which expressed clear nonlinear behavior was used to define first crack. This is appropriate because first crack in concrete separates linear elastic behavior from nonlinear inelastic behavior. Based on the results from this 
test regimen, all of the systems being considered achieved some degree of strain hardening with the exception of UHPC, which significantly dropped in strength after first cracking. While UHPC did not achieve strain hardening, the material also did not experience a brittle failure. UHPC achieved very high stress at first crack compared to the other systems, and the energy required to fail these specimens was high as indicated by the modified flexural toughness.

The system that achieved the greatest deflection hardening capacity based on these results was ECC Batch 2, which was able to attain a peak flexural stress $75 \%$ higher than the stress at first crack. The compressive strengths and deflection hardening capacity were slightly higher than those of ECC Batch 1. As previously mentioned, the only difference between these two systems is the timing of the addition of water reducing admixture during mixing. For Batch 1, the superplasticizer was added along with the first part of water; for Batch 2, it was added with the remaining water as outlined in the METHODS section. This suggests that the addition of superplasticizer before fibers are added to the mix may cause the workability of the paste to be greater than the optimum workability for even fiber distribution. Adding superplasticizer to the mix too early in the process can also result in loss of workability and ability to consolidate. This behavior may also affect the strength and flexural behavior of the mix.

Flexural toughness could only be compared between systems that utilized beam specimens with the same geometry. Thus, flexural toughness was compared between UHPC and ECC and between the two HyFRC mixes. The average flexural toughness of UHPC at 7 days and 28 days was $400 \mathrm{lb}$-in and $460 \mathrm{lb}$-in respectively. In comparison with the $260 \mathrm{lb}$-in and $340 \mathrm{lb}$-in for ECC, UHPC displayed much greater toughness. This means that greater energy is required to fail the specimen. UHPC did not achieve deflection hardening, but the high flexural strength reached before the first crack coupled with the residual strength provided by the fibers contributed to the high flexural toughness of the system. This is a possible indication of crack control in this system. The fiber-reinforced concrete mixes were compared and it was found that HyFRC-A had higher average flexural toughness than the HyFRC-G system - as expected because of the presence of steel fibers in the matrix.

A goal for this study was to produce a HyFRC mix containing only synthetic fibers that would exhibit deflection hardening. The HyFRC-G system in Figure 5.13 represents a successful attempt to do this. The deflection hardening capacity was 1.25 (for the first batch) after 28 days of moist curing even with the absence of steel fibers. The average stress including both batches 
of HyFRC-G shows deflection hardening behavior despite failure to achieve deflection hardening with the second batch. Tight cracks were also observed beyond first cracking for each specimen during testing of the beam specimens. Only hairline cracks were visible at first crack. However, this system was unable to attain multiple cracks in each specimen. This could be attributed to the presence of coarse aggregates in the mix or the depth of the beam specimens being tested. The behavior of all four HyFRC-G beams can be seen in Figure 6.1, where beams $\mathrm{A}$ and $\mathrm{B}$ represent specimens from the first batch and beams $2 \mathrm{~A}$ and $2 \mathrm{~B}$ indicate the stress in the specimens from the second batch. The difference in behavior of the two batches may be due to the effects of minor bleeding observed during mixing in the second batch. Bleeding can cause the bond of the paste component of the system to be weaker. This would not only affect the paste-toaggregate bond but also the paste-to-fiber bond strength. Comparing the stress plot results, the stress at first cracking does not appear to differ greatly between batches, but there is a clear distinction between the deflection hardening behavior of the two batches. It is possible that this is due to the slippage of fibers in the second batch.

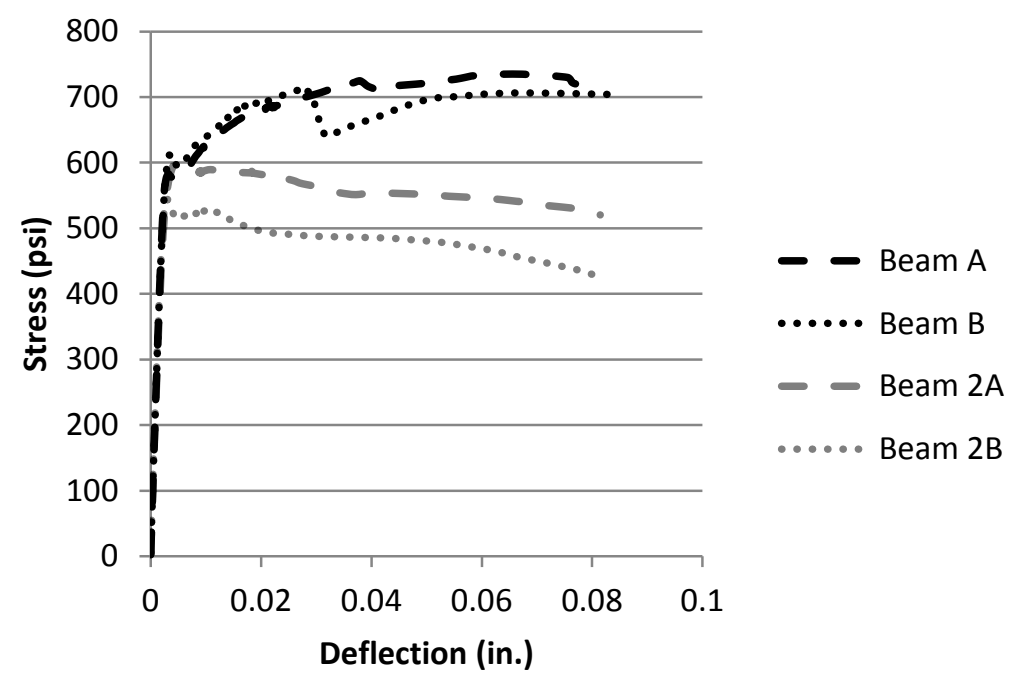

Figure 6.1 HyFRC-G flexural stress versus deflection.

\section{Differences in Material Results}

The reliability of the various tests for bond strength is discussed previously. Although some tests seem to be less reliable than others for providing the actual bond strength of two materials, all of these tests yield somewhat consistent results and can still be used as a means of 
comparing the bond strength of the systems being analyzed. The method for determining flexural stress is the same for all specimens excepting specimen size adjustments to accommodate larger mix components and longer fibers. These two criteria were the most important to consider for this analysis. The two mortar systems (ECC and UHPC) had very high bond strengths, as expected. This is because the bond strength is governed by the paste portion of the mix and the mortar mixes provide a much higher paste surface area for bonding because of the absence of coarse aggregate. This also reduces the potential for weak bond areas. While these two systems provide the highest bond strengths, the HyFRC systems still achieved bond strengths above the required 150 psi.

The ECC systems are far superior to the others in terms of amount of deflection hardening relative to stress at first cracking. The UHPC system tested in the laboratory did not deflection harden, though they exhibited superior strength at first cracking. It was noted that for the UHPC beam specimens, segregation of the fibers was an issue. After being tested to failure, the cracks in the beams revealed that the majority of the fibers had settled to the bottom of the beams as they were cast. Figure 6.2 shows a cross-section of one of the UHPC beams that was tested. The fibers can be seen in the lower half of the cross-section. Because ASTM C1609 requires that the top of the specimen as it was cast be placed on the side of the span facing the operator during testing, the fibers only provided enhanced tensile capacity for half of the beam when placed in flexure. Although the pan type mixer was approved by technical representatives from the UHPC manufacturer, one may conjecture that the type of mixer that was used may have influenced mixture behavior, including segregation of fibers. It is recommended that a high-shear mixer be used for mixing UHPC. UHPC specimens required 2 to 3 days to fully set before the specimens could be removed from the molds. This characteristic may have contributed to the sinking of fibers in the material. Both HyFRC systems (with and without steel fibers) exhibited deflection hardening. 


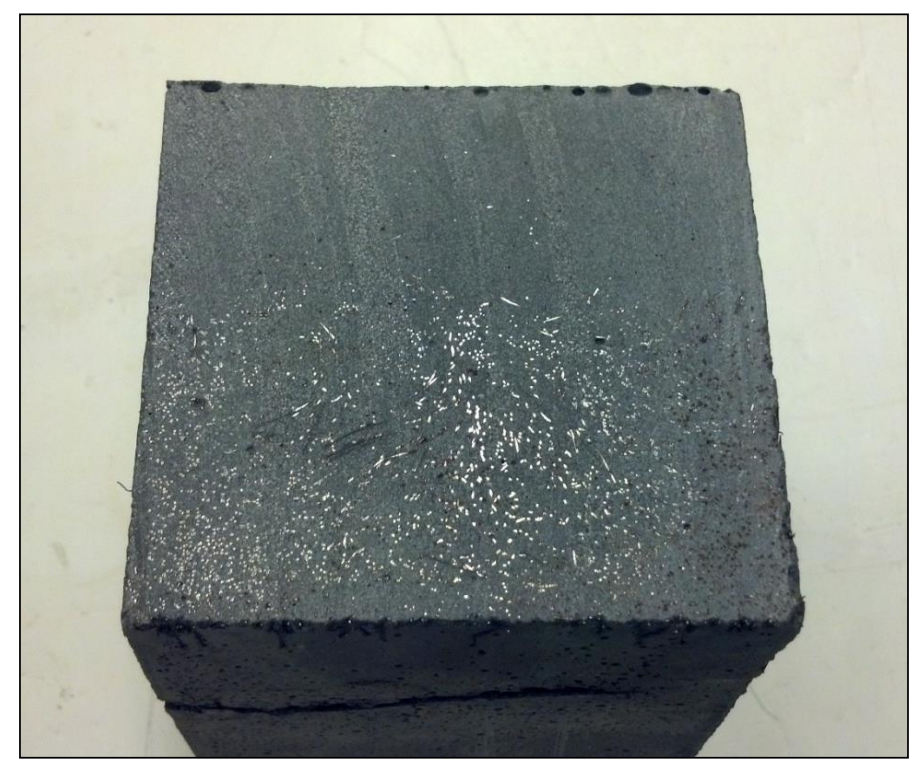

Figure 6.2 UHPC beam cross-section exhibits uneven fiber distribution.

\section{$\underline{\text { Volume Stability (Shrinkage) }}$}

Shrinkage was another factor that was tested for each system. Large volumetric changes can cause cracking of the material and unwanted tensile forces at the bond interface between the closure pour and deck. At 28 days, HyFRC-A had the least volumetric change and decreased by $0.030 \%$. ECC had the highest volumetric change of $-0.146 \%$, which is fairly high as compared to the range for normal weight concrete $(0.01 \%$ to $0.08 \%)$. This is a result of the paste content in the mix and the particle size distribution. UHPC optimizes the particle size distribution to decrease permeability and this characteristic may reduce shrinkage. Shrinkage of the HyFRC systems was within typical range of volumetric change for normal weight concrete. While ECC undergoes significant shrinkage, the behavior caused by the high fiber content prevents the formation of large cracks and promotes the formation of several tight cracks when shrinkage occurs. The fiber content in the other systems ensures crack control as the material shrinks because there is minimal shrinkage.

Table 6.1 Average drying shrinkage.

\begin{tabular}{|c|c|c|c|}
\hline \multirow{2}{*}{ System } & \multicolumn{3}{|c|}{ Shrinkage (\%) } \\
\cline { 2 - 4 } & 7 Days & 28 Days & 16 Weeks \\
\hline ECC & -0.1108 & -0.1457 & -0.1840 \\
\hline HyFRC-A & -0.0148 & -0.0298 & -0.0540 \\
\hline HyFRC-G & -0.0180 & -0.0520 & - \\
\hline UHPC & -0.0230 & -0.0350 & - \\
\hline
\end{tabular}




\section{Compressive Properties}

For each of the mixtures tested, the elastic modulus and Poisson's ratio were within the typical ranges for cementitious materials, except for the elastic modulus of UHPC that was expectedly higher due to the extremely high strength of the system.

Table 6.2 Average elastic modulus and Poisson's ratio.

\begin{tabular}{|c|c|c|}
\hline System & E-mod & P/R \\
\hline ECC & 2.42 & 0.24 \\
\hline HyFRC-A & 3.82 & 0.19 \\
\hline HyFRC-G & 2.78 & 0.24 \\
\hline UHPC & 8.20 & 0.22 \\
\hline
\end{tabular}




\section{COSTS AND BENEFITS ASSESSMENT \\ Table of Comparable Material Costs}

One of the major components used for determining systems to be used for closure pours is material costs. A rough estimate of the cost of each of these systems was done based on the cost of each material component and the amount of each material that is used in each system. (Celik Ozyildirim, personal communication, June 17, 2013) Fiber costs were obtained from price quotes directly from fiber distributors. The cost for each system is presented in Table 7.1.

Table 7.1 Cost summary.

\begin{tabular}{|c|c|}
\hline System & Cost $\mathbf{( \$ / C Y )}$ \\
\hline ECC & 325 \\
\hline HyFRC-A & 230 \\
\hline HyFRC-G & 170 \\
\hline UHPC & 2150 \\
\hline
\end{tabular}

Based on the performance of each system and the respective costs, the HyFRC systems present an economical means for crack control and corrosion resistance in closure pours in bridges. The most economical system (HyFRC-G) presents a solution that can be mixed in large quantities more easily than a mortar mix. In addition to these benefits, HyFRC-G lacks steel fibers that can cause injuries during handling and cause discoloration of the concrete surface. Each system has its own benefits and drawbacks and the correct material must be chosen based on the application. 


\section{CONCLUSIONS}

\section{Evaluation of Materials for Use in Closure Pours}

Based on the findings in this experiment, all of the systems except for UHPC achieve satisfactory deflection hardening behavior. The failure of UHPC to achieve deflection hardening could be attributed to the long set time and the resulting poor distribution of fibers. Although UHPC failed to achieve deflection hardening, the flexural toughness was much higher than that of the other systems, indicating the potential for crack control. All systems exhibited adequate bond strength as specified for overlays, with UHPC displaying the highest values. Further analysis of the stresses occurring at the bond in the field under specific design configurations should be done before determining whether or not the bond strengths are adequate for use in closure pours.

If the desired property for a particular application is deflection hardening, ECC is the best material to use. If a project requires a material with exceptional bond strength and minimal volumetric changes, UHPC may be more suitable. The HyFRC-A system achieves adequate bond strength and achieved results similar to ECC in deflection hardening capacity and compressive strength. HyFRC-G provides the least bond strength, but was able to achieve deflection hardening. HyFRC-G also eliminates the use of steel fibers and is more economical than the alternatives.

\section{Evaluation of Reliability of Bond Strength Tests}

The bond strength tests in this experiment are gauged by consistency and accuracy for each system. Accuracy is based on observations of the test method itself and ways the test can be improved upon. Upon investigation of the procedures for each test, the CA 551 was found to have the least possible sources for improvement. Failure at the bond interface was promoted but not forced and the specimen used a fairly small amount of material for the test. The DirectTension Bond Test may provide accurate bond strength measurements, but frequency of epoxy failures in this study inhibited investigation of the consistency of the test based on the results. The test frame for the Guillotine Shear Test could be altered as previously mentioned to provide more accurate results, and the Splitting Prism Test should include a way to more clearly determine that measured reduction in strength signifies failure of the bond in order to improve 
the accuracy of the test. While the theory behind the test is sound, the testing methods need to be refined. The determined suitability of each test for each of the systems was previously discussed.

\section{Field Application}

All of these specimens appear to achieve adequate crack control and bond strength based on this laboratory study. However, while ECC, HyFRC-A, and UHPC have been utilized in field applications, further testing still needs to be completed on the HyFRC-G mix before this system is deemed appropriate for field application. Testing should be done to consider the effects of shrinkage and conventional reinforcement in the closure pour section on bond requirements. Specimens including conventionally reinforced spans with at least one bond surface should be tested to establish these effects. Also, further mixing and adjustment of mix proportions must be completed for HyFRC-G to achieve adequate workability and consistency of the mix. 


\section{RECOMMENDATIONS}

1. Develop a HyFRC solution that is workable and will easily flow into small joints. One of the major drawbacks of using HyFRC over ECC or UHPC is that it contains coarse aggregates and must be vibrated to completely fill a space. Excessive internal vibration may disperse the fibers and cause regions with no fibers in the mix; external vibration can be expensive and is not always feasible. Creating a self-consolidating HyFRC mix would solve this problem.

\section{Determine other methods for selecting materials capable of tight crack control.}

While deflection hardening is the main criterion that was used in this project to determine that materials are capable of exhibiting multiple tight cracks in flexure, it is not absolutely necessary that a material achieve deflection hardening if it is to be used in closure pours. For example, UHPC has been used in field applications previously and was found to form several tight cracks when placed in tension, though it did not achieve deflection hardening under the conditions in this experiment.

\section{Further evaluate bond tests through increased sample size.}

The conclusions drawn about the performance of bond strength tests in this report were based on the specimens tested for each system. The sample size that was used for calculating the statistical parameters ranged from 4 to 8 specimens each, which is a relatively small sample size for statistical purposes. Further testing will need to be done before accurate conclusions can be drawn about these tests.

\section{Conduct field trials of closure pour materials in structures.}

UHPC, ECC, and variants of HyFRC-A have all been applied to field structures previous to the writing of this paper, and their performance is being monitored. Once HyFRC-G has reached its final development and consistency of the mix has been achieved in the laboratory, the system will need to be applied to a structure to monitor how well it performs in the field. The development of a self-consolidating HyFRC mix (as previously mentioned) is another step towards creating a more widely applicable and economical solution for closure pours in bridges. 


\section{REFERENCES}

1. American Concrete Institute. ACI Terminology. 2013. http://www.concrete.org/Technical/CCT/ACI-Terminology.aspx (accessed July 15, 2013).

2. ASTM C138/C138M-13, Standard Test Method for Density (Unit Weight), Yield, and Air Content (Gravimetric) of Concrete, ASTM International, Editor. 2013: West Conshohocken, PA.

3. ASTM C1404/C1404M - 98, Standard Test Method for Bond Strength of Adhesive Systems Used with Concrete as Measured by Direct Tension, ASTM International, Editor. 1998: West Conshohocken, PA.

4. ASTM C157/C157M-08, Standard Test Method for Length Change of Hardened HydraulicCement Mortar and Concrete, ASTM International, Editor. 2008: West Conshohocken, PA.

5. ASTM C1609/C1609M-12, Standard Test Method for Flexural Performance of FiberReinforced Concrete (Using Beam With Third-Point Loading), ASTM International, Editor. 2012: West Conshohocken, PA.

6. ASTM C231/C231M-10, Standard Test Method for Air Content of Freshly Mixed Concrete by the Pressure Method, ASTM International, Editor. 2010: West Conshohocken, PA.

7. ASTM C496/C496M-11, Standard Test Method for Splitting Tensile Strength of Cylindrical Concrete Specimens, ASTM International, Editor. 2011: West Conshohocken, PA.

8. ASTM C78/C78M-10e1, Standard Test Method for Flexural Strength of Concrete (Using Simple Beam with Third-Point Loading), ASTM International, Editor. 2010: West Conshohocken, PA.

9. ASTM C995-01 (Withdrawn 2008), Standard Test Method for Time of Flow of FiberReinforced Concrete Through Inverted Slump Cone, ASTM International, Editor. 2001: West Conshohocken, PA.

10. Au, Alexander, Clifford Lam, and Bala Tharmabala. "Investigation of closure-strip details for connecting prefabricated deck systems.” PCI Journal, 2011: 82-83.

11. Banthia, N., and M. Sappakittipakorn. “Toughness Enhancement In Steel Fiber Reinforced Concrete Through Fiber Hybridization.” Cement and Concrete Research 37 (May 2007): 1366-1372.

12. Banthia, Nemkumar. Fiber Reinforced Concrete. Advances in Concrete Technologies in the Middle East Conference Research Papers, Qatar: Al-Wataniya Concrete Corporate, 2008. 
Bindiganavile, V., and N. Banthia. "Generating Dynamic Crack Growth Resistance Curves for Fiber-reinforced Concrete." Experimental Mechanics 45, no. 2 (April 2005): 112-122.

13. Blunt, J., and C. P. Ostertag. "Performance-Based Approach for the Design of a Deflection Hardened Hybrid Fiber-Reinforced Concrete." Journal of Engineering Mechanics 135, no. 9 (September 2009): 978-986.

14. Blunt, Joshua D., and Claudia P. Ostertag. "Deflection Hardening and Workability of Hybrid Fiber Composites." ACI Materials Journal, 2009: 265-272.

15. CA 551. Method of Test for Determining Suitability of Materials for Overlayment and Repair of Portland Cement Concrete Pavement and Structures. California Department of Transportation, Sacramento, CA 2000.

16. Fantilli, Allessandro P., Hirozo Mihashi, and Paolo Vallini. "Multiple Cracking and Strain Hardening in Fiber-Reinforced Concrete Under Uniaxial Tension." Cement and Concrete Research, December 2009: 1217-1229.

17. Kosmatka, Steven H., and Michelle L. Wilson. Design and Control of Concrete Mixtures: The Guide to Applications, Methods, and Materials. Washington, DC: Portland Cement Association, 2011.

18. Li, Victor C., and Michael D Lepech. "Application of ECC for Bridge Deck Link Slabs." Materials and Structures, 2009: 1185-1195.

19. Momayez, A., M. R. Ehsani, A. A. Ramezanianpour, and H. Rajaie. "Comparison of Methods for Evaluating Bond Strength Between Concrete Substrate and Repair Materials." Cement and Concrete Research 35 (2005): 748-757.

20. Nycon. "Meanest Concrete on Earth: TUFF-SLAB." NYCON. 2012. http://www.nycon.com/ncwp/ (accessed January 28, 2013).

21. Ozyildirim, Celik. Fiber-Reinforced Concrete Investigations in Virginia. Charlottesville, VA: Virginia Center for Transportation Innovation and Research, 2011.

22. Ozyildirim, Celik, and Michael Vieira. Exploratory Investigation of High-Performance Fiber-Reinforced Cementitious Composites for Crack Control. Technical Report, Virginia Department of Transportation, Virginia Transportation Research Council, Charlottesville, VA: Virginia Transportation Research Council, 2008.

23. Prefabricated Bridge Elements and Systems. May 21, 2012. http://www.fhwa.dot.gov/bridge/prefab/if09010/01.cfm (accessed August 16, 2012). 
24. Rossi, Pierre. "Steel or Synthetic Fiber Reinforcement." Structure Magazine, 2011: 10-11.

25. Sahmaran, Mustafa, Mo Li, and Victor C. Li. "Transport Properties of Engineered Cementitious Composites Under Chloride Exposure." ACI Materials Journal, 2007: 604-611.

26. Sahmaran, Mustafa, and Victor C. Li. "De-icing Salt Scaling Resistance of Mechanically Loaded Engineered Cementitious Composites." Cement and Concrete Research 37 (April 2007): 1035-1046.

27. Shatnawi, Shakir. (2011, May). Dowel-Bar Retrofit Using Polyester Polymer Concrete. Presentation given at Pavement Preservation Expert Task Group, Oklahoma City, OK.

28. Tarr, Scott M., and James A. Farny. Concrete Floors on Ground, Fourth Edition, Portland Cement Association, Skokie, Illinois: 2008.

29. Tayeh, B. A., B. H. Abu Bakar, and M. A. Megat Johari. "Characterization of the Interfacial Bond Between Old Concrete Substrate and Ultra High Performance Fiber Concrete Repair Composite." Materials and Structures 46 (2013): 743-753.

30. The Concrete Society. Autogenous Shrinkage Cracks. http://www.concrete.org.uk/ (accessed July 12, 2013).

31. Virginia Department of Transportation (2007). 2007 Road and Bridge Specifications. Richmond, VA: Virginia Department of Transportation.

32. Virginia Department of Transportation (2002). Virginia Department of Transportation Special Provision for Determining Adjustments to Contract Compensation for Hydraulic Cement Concrete Overlays. Unpublished: Virginia Department of Transportation.

33. Zhou, Jian, Shunzhi Qian, Guang Ye, Oguzhan Copuroglu, Klass van Breugel, and Victor C Li. "Improved Fiber Distribution and Mechanical Properties of Engineered Cementitious Composites by Adjusting the Mixing Sequence." Cement \& Concrete Composites, 2012: 342-348. 


\section{APPENDICES}

\section{Engineered Cementitious Composite}

Table 11.1 ECC batch 1 compressive strength.

\begin{tabular}{|c|c|c|c|c|}
\hline Batch & $\begin{array}{c}\text { Specimen } \\
\text { Age (days) } \\
\end{array}$ & $\begin{array}{c}\text { Specimen } \\
\text { Type }\end{array}$ & $\begin{array}{l}\text { Compressive } \\
\text { Strength (psi) }\end{array}$ & $\begin{array}{c}\text { Average } \\
\text { Strength (psi) }\end{array}$ \\
\hline 1 & 7 & 2 in cube & 4,340 & \multirow{3}{*}{4,315} \\
\hline 1 & 7 & 2 in cube & 4,290 & \\
\hline 1 & 7 & 2 in cube & 4,315 & \\
\hline 1 & 7 & 4 in $\times 8$ in cylinder & 3,045 & \multirow{2}{*}{2,975} \\
\hline 1 & 7 & 4 in $\times 8$ in cylinder & 2,905 & \\
\hline 1 & 28 & 2 in cube & 7,225 & \multirow{3}{*}{6,920} \\
\hline 1 & 28 & 2 in cube & 6,875 & \\
\hline 1 & 28 & 2 in cube & 6,665 & \\
\hline 1 & 28 & 4 in $\times 8$ in cylinder & 4,620 & \multirow{2}{*}{4,875} \\
\hline 1 & 28 & 4 in $\times 8$ in cylinder & 5,130 & \\
\hline
\end{tabular}

Table 11.2 ECC batch 2 compressive strength.

\begin{tabular}{|c|c|c|c|c|}
\hline Batch & $\begin{array}{c}\text { Specimen } \\
\text { Age (days) }\end{array}$ & $\begin{array}{c}\text { Specimen } \\
\text { Type } \\
\end{array}$ & $\begin{array}{l}\text { Compressive } \\
\text { Strength (psi) } \\
\end{array}$ & $\begin{array}{c}\text { Average } \\
\text { Strength (psi) }\end{array}$ \\
\hline 2 & 7 & 2 in cube & 4,565 & \multirow{3}{*}{4,780} \\
\hline 2 & 7 & 2 in cube & 4,825 & \\
\hline 2 & 7 & 2 in cube & 4,950 & \\
\hline 2 & 7 & 4 in $\times 8$ in cylinder & 4,000 & \multirow{2}{*}{4,090} \\
\hline 2 & 7 & 4 in $\times 8$ in cylinder & 4,180 & \\
\hline 2 & 28 & 2 in cube & 8,090 & \multirow{3}{*}{7,865} \\
\hline 2 & 28 & 2 in cube & 7,775 & \\
\hline 2 & 28 & 2 in cube & 7,725 & \\
\hline 2 & 28 & 4 in $\times 8$ in cylinder & 6,285 & \multirow{2}{*}{6,545} \\
\hline 2 & 28 & 4 in $\times 8$ in cylinder & 6,805 & \\
\hline
\end{tabular}


Table 11.3 ECC batch 1 flexural stresses.

\begin{tabular}{|c|c|c|c|c|c|c|}
\hline Batch & Specimen & $\begin{array}{l}\text { Age of } \\
\text { Specimen } \\
\text { (days) }\end{array}$ & $\begin{array}{c}\text { First } \\
\text { Cracking } \\
\text { Stress } \\
\text { (psi) }\end{array}$ & $\begin{array}{c}\text { Avg. First } \\
\text { Cracking } \\
\text { Stress (psi) }\end{array}$ & $\begin{array}{c}\text { Peak } \\
\text { Stress } \\
\text { (psi) }\end{array}$ & $\begin{array}{c}\text { Avg. Peak } \\
\text { Stress } \\
\text { (psi) }\end{array}$ \\
\hline 1 & $4 \mathrm{in} \times 4 \mathrm{in} \times 14 \mathrm{in}$ & 7 & 645 & \multirow{3}{*}{670} & 1,035 & \multirow{3}{*}{1,070} \\
\hline 1 & 4 in $\times 4$ in $\times 14$ in & 7 & 635 & & 1,020 & \\
\hline 1 & 4 in $\times 4$ in $\times 14$ in & 7 & 730 & & 1,155 & \\
\hline 1 & 1 in $\times 3$ in $\times 14$ in & 7 & - & \multirow[b]{2}{*}{ - } & 1,120 & \multirow{2}{*}{1,190} \\
\hline 1 & 1 in $\times 3$ in $\times 14$ in & 7 & - & & 1,260 & \\
\hline 1 & 4 in $\times 4$ in $\times 14$ in & 28 & 865 & \multirow{3}{*}{895} & 1,420 & \multirow{3}{*}{1,440} \\
\hline 1 & 4 in $\times 4$ in $\times 14$ in & 28 & 940 & & 1,475 & \\
\hline 1 & 4 in $\times 4$ in $\times 14$ in & 28 & 880 & & 1,420 & \\
\hline 1 & $\operatorname{lin} \times 3$ in $\times 14$ in & 28 & - & \multirow[b]{2}{*}{-} & 1,590 & \multirow{2}{*}{1,555} \\
\hline 1 & 1 in $\times 3$ in $\times 14$ in & 28 & - & & 1,520 & \\
\hline
\end{tabular}

Table 11.4 ECC batch 2 flexural stresses.

\begin{tabular}{|c|c|c|c|c|c|c|}
\hline Batch & Specimen & $\begin{array}{c}\text { Age of } \\
\text { Specimen } \\
\text { (days) }\end{array}$ & $\begin{array}{c}\text { First } \\
\text { Cracking } \\
\text { Stress } \\
\text { (psi) }\end{array}$ & $\begin{array}{c}\text { Avg. First } \\
\text { Cracking } \\
\text { Stress (psi) }\end{array}$ & $\begin{array}{l}\text { Peak } \\
\text { Stress } \\
(\text { psi) }\end{array}$ & $\begin{array}{c}\text { Avg. Peak } \\
\text { Stress } \\
\text { (psi) }\end{array}$ \\
\hline 2 & $4 \mathrm{in} \times 4 \mathrm{in} \times 14 \mathrm{in}$ & 7 & 630 & \multirow{3}{*}{645} & 1,210 & \multirow{3}{*}{1,190} \\
\hline 2 & 4 in $\times 4$ in $\times 14$ in & 7 & 615 & & 1,215 & \\
\hline 2 & 4 in $\times 4$ in $\times 14$ in & 7 & 690 & & 1,150 & \\
\hline 2 & 1 in $\times 3$ in $\times 14$ in & 7 & - & \multirow{2}{*}{-} & 1,175 & \multirow{2}{*}{1,265} \\
\hline 2 & 1 in $\times 3$ in $\times 14$ in & 7 & - & & 1,350 & \\
\hline 2 & 4 in $\times 4$ in $\times 14$ in & 28 & 840 & \multirow{3}{*}{835} & 1,475 & \multirow{3}{*}{1,465} \\
\hline 2 & 4 in $\times 4$ in $\times 14$ in & 28 & 820 & & 1,405 & \\
\hline 2 & 4 in $\times 4$ in $\times 14$ in & 28 & 850 & & 1,510 & \\
\hline 2 & 1 in $\times 3$ in $\times 14$ in & 28 & - & \multirow{2}{*}{-} & 1,175 & \multirow{2}{*}{1,145} \\
\hline 2 & 1 in $\times 3$ in $\times 14$ in & 28 & - & & 1,110 & \\
\hline
\end{tabular}




\section{HyFRC-A}

Table 11.5 HyFRC-A compressive strength.

\begin{tabular}{|c|c|c|c|c|}
\hline Batch & $\begin{array}{c}\text { Specimen } \\
\text { Age (days) }\end{array}$ & $\begin{array}{c}\text { Specimen } \\
\text { Type }\end{array}$ & $\begin{array}{c}\text { Compressive } \\
\text { Strength (psi) }\end{array}$ & $\begin{array}{c}\text { Average } \\
\text { Strength (psi) }\end{array}$ \\
\hline 1 & 28 & 4 in $\times 8$ in cylinder & 6,370 & \multirow{2}{*}{6,115} \\
\cline { 1 - 3 } 1 & 28 & 4 in $\times 8$ in cylinder & 6,010 & \\
\cline { 1 - 4 } 2 & 28 & 4 in $\times 8$ in cylinder & 5,810 & \\
\cline { 1 - 4 } 2 & 28 & 4 in $\times 8$ in cylinder & 6,270 & \\
\hline
\end{tabular}

Table 11.6 HyFRC-A flexural stresss.

\begin{tabular}{|c|c|c|c|c|c|c|}
\hline Batch & Specimen & $\begin{array}{c}\text { Age of } \\
\text { Specimen } \\
\text { (days) }\end{array}$ & $\begin{array}{c}\text { First } \\
\text { Cracking } \\
\text { Stress (psi) }\end{array}$ & $\begin{array}{c}\text { Avg. First } \\
\text { Cracking } \\
\text { Stress (psi) }\end{array}$ & $\begin{array}{c}\text { Peak } \\
\text { Stress } \\
\text { (psi) }\end{array}$ & $\begin{array}{c}\text { Avg. Peak } \\
\text { Stress } \\
\text { (psi) }\end{array}$ \\
\hline 1 & 1 in $\times 3$ in $\times 14$ in & 28 & - & \multirow{2}{*}{ ( } & 1,120 & \multirow{2}{*}{1,050} \\
\hline 2 & 1 in $\times 3$ in $\times 14$ in & 28 & - & & 980 & \\
\hline 1 & 6 in $\times 6$ in $\times 20$ in & 28 & 830 & \multirow{3}{*}{760} & 1,210 & \multirow{3}{*}{1,160} \\
\hline 2 & $6 \mathrm{in} \times 6 \mathrm{in} \times 20 \mathrm{in}$ & 28 & 735 & & 1,245 & \\
\hline 2 & 6 in $\times 6$ in $\times 20$ in & 28 & 720 & & 1,020 & \\
\hline
\end{tabular}

\section{HyFRC-G}

Table 11.7 HyFRC-G compressive strength.

\begin{tabular}{|c|c|c|c|c|}
\hline Batch & $\begin{array}{c}\text { Specimen } \\
\text { Age (days) }\end{array}$ & $\begin{array}{c}\text { Specimen } \\
\text { Type }\end{array}$ & $\begin{array}{c}\text { Compressive } \\
\text { Strength (psi) }\end{array}$ & $\begin{array}{c}\text { Average } \\
\text { Strength (psi) }\end{array}$ \\
\hline 1 & 7 & 4 in $\times 8$ in cylinder & 3,660 & 3,660 \\
\hline 1 & 28 & 4 in $\times 8$ in cylinder & 4,400 & 4,400 \\
\hline 2 & 7 & 4 in $\times 8$ in cylinder & 2,940 & \multirow{2}{*}{2,920} \\
\hline 2 & 7 & 4 in $\times 8$ in cylinder & 2,900 & \multirow{2}{*}{3,640} \\
\hline 2 & 28 & 4 in $\times 8$ in cylinder & 3,620 & \\
\hline 2 & 28 & 4 in $\times 8$ in cylinder & 3,660 & \\
\cline { 1 - 2 }
\end{tabular}


Table 11.8 HyFRC-G flexural stresses.

\begin{tabular}{|c|c|c|c|c|c|c|}
\hline Batch & Specimen & $\begin{array}{c}\begin{array}{c}\text { Age of } \\
\text { Specimen } \\
\text { (days) }\end{array} \\
\end{array}$ & $\begin{array}{c}\text { First } \\
\text { Cracking } \\
\text { Stress (psi) }\end{array}$ & $\begin{array}{c}\text { Avg. First } \\
\text { Cracking } \\
\text { Stress (psi) }\end{array}$ & $\begin{array}{c}\text { Peak } \\
\text { Stress } \\
(\text { psi) } \\
\end{array}$ & $\begin{array}{c}\text { Avg. Peak } \\
\text { Stress } \\
\text { (psi) } \\
\end{array}$ \\
\hline 1 & $6 \mathrm{in} \times 6 \mathrm{in} \times 20 \mathrm{in}$ & 28 & 555 & \multirow{2}{*}{580} & 735 & \multirow{2}{*}{725} \\
\hline 1 & $6 \mathrm{in} \times 6 \mathrm{in} \times 20 \mathrm{in}$ & 28 & 605 & & 710 & \\
\hline 2 & $6 \mathrm{in} \times 6 \mathrm{in} \times 20 \mathrm{in}$ & 28 & 595 & \multirow{2}{*}{570} & 595 & \multirow{2}{*}{570} \\
\hline 2 & $6 \mathrm{in} \times 6 \mathrm{in} \times 20 \mathrm{in}$ & 28 & 545 & & 545 & \\
\hline
\end{tabular}

\section{UHPC}

Table 11.9 UHPC compressive strength.

\begin{tabular}{|c|c|c|c|}
\hline $\begin{array}{c}\text { Specimen } \\
\text { Age (days) }\end{array}$ & $\begin{array}{c}\text { Specimen } \\
\text { Type }\end{array}$ & $\begin{array}{c}\text { Compressive } \\
\text { Strength }(\mathbf{p s i})\end{array}$ & $\begin{array}{c}\text { Average } \\
\text { Strength (psi) }\end{array}$ \\
\hline 7 & 4 in $\times 8$ in cylinder & 16,190 & \multirow{2}{*}{15,355} \\
\hline 7 & 4 in $\times 8$ in cylinder & 14,520 & \\
\hline 28 & 4 in $\times 8$ in cylinder & 19,970 & \multirow{2}{*}{22,180} \\
\hline 28 & 4 in $\times 8$ in cylinder & 24,390 & \\
\hline
\end{tabular}

Table 11.10 UHPC flexural stresses.

\begin{tabular}{|c|c|c|c|c|c|}
\hline Specimen & $\begin{array}{l}\text { Age of } \\
\text { Specimen } \\
\text { (days) }\end{array}$ & $\begin{array}{c}\text { First } \\
\text { Cracking } \\
\text { Stress } \\
\text { (psi) }\end{array}$ & $\begin{array}{c}\text { Avg. First } \\
\text { Cracking } \\
\text { Stress (psi) }\end{array}$ & $\begin{array}{c}\text { Peak } \\
\text { Stress } \\
\text { (psi) }\end{array}$ & $\begin{array}{c}\text { Avg. Peak } \\
\text { Stress } \\
\text { (psi) }\end{array}$ \\
\hline $4 \mathrm{in} \times 4 \mathrm{in} \times 14 \mathrm{in}$ & 7 & 2010 & \multirow{3}{*}{1835} & 2010 & \multirow{3}{*}{1835} \\
\hline $4 \mathrm{in} \times 4 \mathrm{in} \times 14 \mathrm{in}$ & 7 & 1790 & & 1790 & \\
\hline 4 in $\times 4$ in $\times 14$ in & 7 & 1700 & & 1700 & \\
\hline $4 \mathrm{in} \times 4 \mathrm{in} \times 14 \mathrm{in}$ & 28 & 2305 & \multirow{4}{*}{2290} & 2305 & \multirow{4}{*}{2290} \\
\hline 4 in $\times 4$ in $\times 14 i n$ & 28 & 2215 & & 2215 & \\
\hline $4 \mathrm{in} \times 4 \mathrm{in} \times 14 \mathrm{in}$ & 28 & 2545 & & 2545 & \\
\hline 4 in $\times 4$ in $\times 14$ in & 28 & 2085 & & 2085 & \\
\hline
\end{tabular}




\section{Flexural Toughness}

Table 11.11 Flexural toughness of beam specimens.

\begin{tabular}{|c|c|c|c|c|c|}
\hline \multirow[t]{2}{*}{ System } & \multirow[t]{2}{*}{ Batch } & \multicolumn{2}{|c|}{$\begin{array}{l}\text { 7-Day Flexural } \\
\text { Toughness (lb-in) }\end{array}$} & \multicolumn{2}{|c|}{$\begin{array}{l}\text { 28-Day Flexural } \\
\text { Toughness (lb-in) }\end{array}$} \\
\hline & & Individual & Average & Individual & Average \\
\hline \multirow{6}{*}{$\mathrm{ECC}$} & \multirow{3}{*}{1} & 255 & \multirow{3}{*}{260} & 337 & \multirow{3}{*}{340} \\
\hline & & 251 & & 341 & \\
\hline & & 280 & & 338 & \\
\hline & \multirow{3}{*}{2} & 285 & \multirow{3}{*}{280} & 336 & \multirow{3}{*}{330} \\
\hline & & 278 & & 306 & \\
\hline & & 265 & & 343 & \\
\hline \multirow{4}{*}{ UHPC } & \multirow{4}{*}{-} & 390 & \multirow{4}{*}{400} & 498 & \multirow{4}{*}{460} \\
\hline & & 403 & & 463 & \\
\hline & & 414 & & 413 & \\
\hline & & - & & 469 & \\
\hline \multirow{3}{*}{ HyFRC-A } & \multirow{3}{*}{-} & \multirow{3}{*}{ - } & \multirow{3}{*}{-} & 993 & \multirow{3}{*}{980} \\
\hline & & & & 1080 & \\
\hline & & & & 875 & \\
\hline \multirow{4}{*}{ HyFRC-G } & \multirow{2}{*}{1} & \multirow{2}{*}{-} & \multirow{2}{*}{ - } & 688 & \multirow{2}{*}{670} \\
\hline & & & & 657 & \\
\hline & \multirow{2}{*}{2} & \multirow{2}{*}{-} & \multirow{2}{*}{ - } & 520 & \multirow{2}{*}{490} \\
\hline & & & & 461 & \\
\hline
\end{tabular}




\section{Elastic Modulus Test Results}

Table 11.12 Elastic modulus and Poisson's ratio.

\begin{tabular}{|c|c|c|}
\hline System & E-mod & P/R \\
\hline \multirow{4}{*}{ ECC } & 1.77 & 0.21 \\
\cline { 2 - 3 } & 2.61 & 0.25 \\
\cline { 2 - 3 } & 2.67 & 0.24 \\
\cline { 2 - 3 } & 2.08 & 0.22 \\
\cline { 2 - 3 } & 2.66 & 0.28 \\
\cline { 2 - 3 } & 2.72 & 0.24 \\
\hline \multirow{4}{*}{ HyFRC-A } & 3.38 & 0.13 \\
\cline { 2 - 3 } & 3.68 & 0.27 \\
\cline { 2 - 3 } & 3.95 & 0.17 \\
\cline { 2 - 3 } & 4.26 & 0.2 \\
\hline \multirow{5}{*}{ HyFRC-G } & 3.04 & 0.19 \\
\cline { 2 - 3 } & 2.64 & 0.23 \\
\cline { 2 - 3 } & 2.58 & 0.25 \\
\cline { 2 - 3 } & 2.82 & 0.28 \\
\cline { 2 - 3 } & 2.82 & 0.26 \\
\hline \multirow{4}{*}{ UHPC } & 8.18 & 0.22 \\
\cline { 2 - 3 } & 8.22 & 0.21 \\
\hline
\end{tabular}

